DIW BERLIN

Discussion

Papers

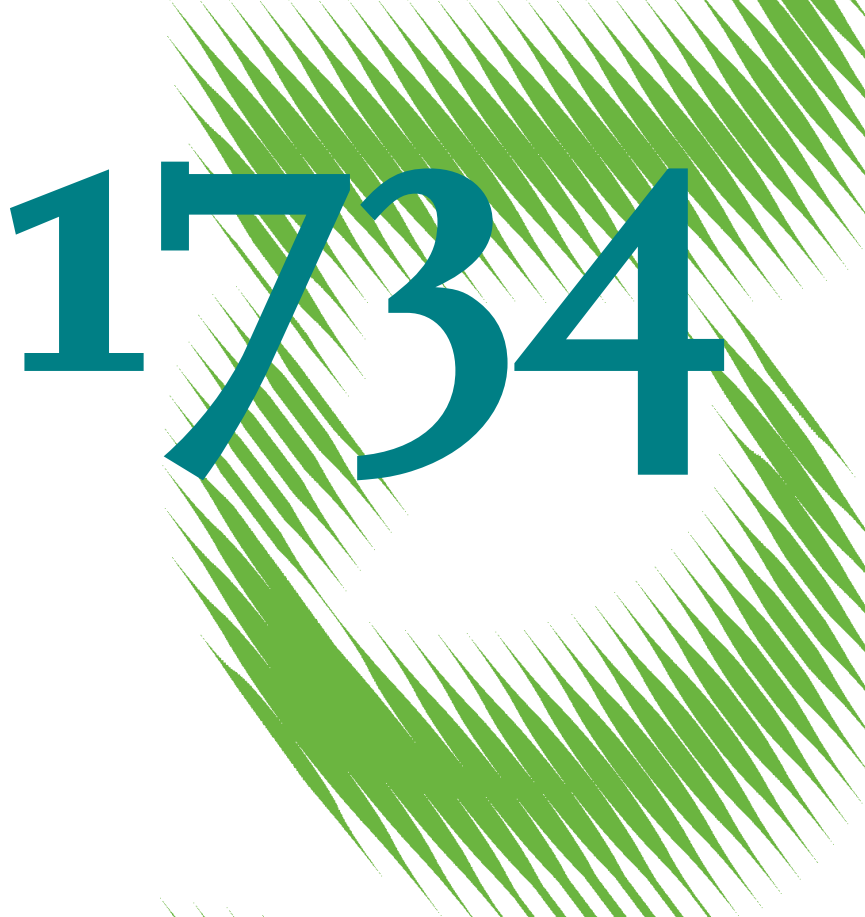

Price or Variety? An Evaluation of Mergers Effects in Grocery Retailing 
Opinions expressed in this paper are those of the author(s) and do not necessarily reflect views of the institute.

IMPRESSUM

(C) DIW Berlin, 2018

DIW Berlin

German Institute for Economic Research

Mohrenstr. 58

10117 Berlin

Tel. +49 (30) $89789-0$

Fax +49 (30) $89789-200$

http://www.diw.de

ISSN electronic edition 1619-4535

Papers can be downloaded free of charge from the DIW Berlin website:

http://www.diw.de/discussionpapers

Discussion Papers of DIW Berlin are indexed in RePEc and SSRN:

http://ideas.repec.org/s/diw/diwwpp.html

http://www.ssrn.com/link/DIW-Berlin-German-Inst-Econ-Res.html 


\title{
Price or Variety? An Evaluation of Mergers Effects in Grocery Retailing*
}

\author{
Elena Argentesi ${ }^{\dagger}$ Paolo Buccirossi $\$$ Roberto Cervone§ \\ Tomaso Duso, Alessia Marrazzo
}

April 2018

\begin{abstract}
Assortment decisions are key strategic instruments for firms responding to local market conditions. We assess this claim by studying the effect of a national merger between two large Dutch supermarket chains on prices and on the depth as well as composition of assortment. We adopt a difference-in-differences strategy that exploits local variation in the merger's effects, controlling for selection on observables when defining our control group through a matching procedure. We show that the local change in competitive conditions due to the merger did not affect individual products' prices but it led the merging parties to reposition their assortment and increase average category prices. While the low-variety and low-price target's stores reduced the depth of their assortment when in direct competition with the acquirer's stores, the latter increased their product variety. By analyzing the effect of the merger on category prices, we find that the target most likely dropped high priced products, while the acquirer added more of them. Thus, the merging firms reposition their product offerings in order to avoid cannibalization and lessen local competition. Further, we show that other dimensions of heterogeneity, such as market concentration, whether a divestiture was imposed by the Dutch competition authority, and the re-branding strategy of the target stores, are important for explaining the post-merger dynamics. A simple theoretical model of local-market variety competition explains most of our findings.
\end{abstract}

Keywords: Variety, Assortment, Mergers, Ex-post Evaluation, Retail sector, Supermarkets, Grocery. JEL Codes: L1, L41, L66, L81, D22, K21, C23

*This paper is partially based on a research project we undertook for the Dutch Competition Authority (ACM). We thank the ACM staff for their support throughout the course of that study, in particular Ron Kemp and Martijn Wolthoff. We also thank Luca Aguzzoni for his extremely valuable support during the early stages of the project, Lorenzo Migliaccio for his excellent research assistance, as well as Itai Ater, Pio Baake, Jan Bouckaert, Giacomo Calzolari, Federico Ciliberto, Alon Eizenberg, Luke Froeb, Alessandro Gavazza, Alessandro Iaria, Adam Lederer, Szabolcs Lorincz, Anna Lu, Franco Mariuzzo, Mattia Nardotto, Carlo Reggiani, Thomas Ross, Daniel Sokol, Hannes Ullrich, Christine Zulehner, as well as audiences at various conferences and seminars for helpful comments and suggestions. Tomaso Duso gratefully acknowledges support from the Berlin Centre for Consumer Policies (BCCP).

${ }^{\dagger}$ University of Bologna, Department of Economics, Piazza Scaravilli 2, 40126 Bologna, Italy. Email: elena.argentesi@unibo.it

${ }^{\ddagger}$ Lear, Via di Monserrato 48, 00186 Rome, Italy. E-mail: paolo.buccirossi@learlab.com.

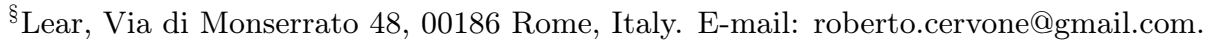

"Corresponding author: Deutsches Institut für Wirtschaftsforschung (DIW Berlin), DICE Düsseldorf, Berlin Centre for Consumer Policies (BCCP), and CESifo. Mohrenstr. 58, 10117 Berlin, Germany. E-mail: tduso@diw.de.

"Lear and University of Bologna. Email: alessia.marrazzo@learlab.com. 


\section{Introduction}

In retail markets, various dimensions of competition, in addition to prices, can be strategically used by firms to respond to local market conditions. Analyzing the reaction to a merger - a major change in market structure - can be a useful tool to assess the relative importance of such strategies, which might be relevant for consumers. The 2010 revision of the US Horizontal Merger Guidelines emphasize the importance of non-price dimensions of competition stating that

"enhanced market power can also be manifested in non-price terms and conditions that adversely affect customers, including reduced product quality, reduced product variety, reduced service, or diminished innovation. Such non-price effects may coexist with price effects, or can arise in their absence" (Horizontal Merger Guidelines, U.S. Department of Justice and the Federal Trade Commission, 2010, p. 2). However, not only is the evaluation of such effects and their interaction with price effects not straightforward, it remains one of the most controversial and still unresolved issues in merger control (OECD, 2013, p. 9). In particular, effects on variety are ambiguous, as mergers may "lead firms to spread similar products apart, to withdraw duplicative products, or to crowd products together to preempt entry" (Berry and Waldfogel, 2001, p. 1009).

To assess the importance of non-price strategies, we focus on a merger in grocery retail. This represents an ideal setting to study the competitive effects of assortment choices and product positioning as these strategies might play a key role for competition in these markets (Draganska, Mazzeo and Seim, 2009). Specifically, they can be a tool to respond to changes in local competitive conditions in the presence of uniform national pricing documented in several sectors including retailing (DellaVigna and Gentzkow, 2017). Moreover, non-price attributes are an important determinant of customer satisfaction (Matsa, 2011). Yet, the competitive effect of variety in grocery retailing is still largely unexplored. The study of this issue is the main contribution of our paper. Moreover, while the growing literature on retrospective merger evaluation substantially helps to improve the understanding of the effect of realized mergers, most of these studies focus solely on price effects (Ashenfelter, Hosken and Weinberg, 2014). Thus, our paper also aims at contributing to this discussion by complementing more traditional approaches and providing new evidence of the effect of mergers not only on prices but also on non-price attributes such as variety.

We study the merger between two large Dutch supermarket chains (Jumbo and C1000) that was conditionally approved by the Dutch competition authority - Autoriteit Consument \& Markt 
$(\mathrm{ACM})$ - in 2012. We use a particularly rich database that entails quarterly information on average prices as well as variety for each of the 125 product categories sold in a sample of 171 stores of the merging parties and their main competitors located in different areas scattered across the Netherlands for the 2010-2013 period. These categories cover the entire space of grocery products offered in the country during the sample period. As commonly done in the literature on retail markets, we define variety as the depth of assortment, i.e. the number of stock keeping units (SKUs) sold in each product category (Ren et al., 2011). We enrich these category-level data-set with more fine-grained monthly information on a sample of 33 specific products that were sold throughout the whole sample period and chosen to represent a typical basket for Dutch households.

Our empirical strategy exploits the geographic variation in the intensity of local competition and market structure to causally identify the effect of the merger. This local variation is particularly appropriate for analyzing non-price dimensions of competitions such as assortment decisions, which are often made at the local level. It also helps verifying whether prices are indeed set nationally. We estimate the effect of the merger by means of a Difference-in-Differences (DiD) strategy that relies on the comparison between areas where both merging parties were active before the merger and areas where only one of them was active. ${ }^{1}$ By defining our control group through a matching procedure based on observable characteristics, we account for differences in demand and supply conditions across treated and non-treated areas. The intuition behind our identification strategy is that the competitive effects of the merger (if any) are likely to be stronger in the former areas than in the latter ones, as, other things equal, only in overlap areas did the intensity of competition change.

We find that the merger did not have any significant effects on prices of individual products sold, neither in the merging parties' stores nor in competitors' stores. However, the merger led to a reduction in product variety and to an increase in average category prices, which would suggest a move toward a smaller and more expensive assortment. This effect is mainly driven by the merging parties' behavior, since competitors seem to react very little both in terms of variety and of average category prices. In particular, the average effect is the result of two opposing forces. On the one hand, the acquirer (Jumbo), the high-variety chain, raised its assortment as well as its average category prices. This suggests that Jumbo added high-priced products

\footnotetext{
${ }^{1}$ Aguzzoni et al. (2016) and Allain et al. (2017) are two examples of papers that use the same identification strategy to assess the effect of mergers in retailing.
} 
to its product line. On the other hand, C1000 (the target) decreased both its assortment and its average category prices, which implies a move toward a smaller and cheaper assortment. Thus, looking behind average effects allows understanding that the merged entity repositioned its product offerings in terms of depth and composition of assortment to reduce the business stealing effect between the two merged chains.

We build a simple theoretical model where variety can be both a vertical and horizontal attribute of a store and show that, after a merger between two close competitors like the one that we consider, the new entity optimally reduces assortment in the low-variety store because this entails an increase in the other store's demand. This is consistent with previous theoretical and empirical findings. For instance, Gandhi et al. (2008) show in a theoretical setting that merging parties move away from each other in the product space to avoid cannibalization. Similarly in an empirical study, Sweeting (2010) finds that firms buying competing radio stations tend to differentiate them, thereby avoiding audience cannibalization. However, in our model the new entity may lower or raise variety in the high variety store depending on the relative importance of consumers for which variety is a vertical attribute. Hence a finding that variety increased in the high-variety chain suggests that in the relevant market a significant number consumes considered variety a horizontal characteristic.

Because of the richness of our data, we assess the effects of the merger on prices and variety not only for the merging parties but also for their main competitors. Being able to estimate the rivals' reaction to the merger is particularly relevant for two reasons. First, while the effects of mergers on rivals' prices is studied in the literature, the effects on rivals' price and variety is not yet analyzed. Methodologically, this is important as the study of rivals' reactions to a merger might help to identify its competitive effect (Deneckere and Davidson, 1985). Second, from a policy perspective, the joint assessment of the merger's price and variety effects for both the merging parties and competitors allows us to draw richer conclusions on the merger's implications in terms of consumer surplus, as we can better approximate its effect at the market level. We find a limited response by competitors in terms of assortment (slight increase) and no response in terms of average category prices. This implies that rivals' reaction is unlikely to compensate for the changes in the merging parties' strategies.

Our study contributes to the intense discussion on competition in the retail sectors, especially in grocery markets, which is at the center of public discussion for several reasons. First, grocery retail plays a central role in consumers' everyday life, with supermarkets being the key point 
of sales for buying food and household products in most countries. ${ }^{2}$ Second, the sector has drastically been transformed by the interplay of several forces on both the supply and demand sides. On the demand side, consumers' habits have changed, such that they tend to do most of their shopping in a single stop, typically a large supermarket. On the supply side, the creation of large supermarket chains coupled with innovations in logistics and distribution allowed the internalization of economies of scale and scope. These developments brought significant benefits to consumers with lower prices and larger variety. Yet, competition authorities are still concerned that effective competition in increasingly concentrated grocery markets may not be sustainable, as underlined by the sector inquiries performed in Germany and the U.K. ${ }^{3}$

For these reasons, mergers in grocery markets tend to be closely scrutinized by antitrust authorities. While they might constitute a natural and legitimate mean to react to a rapidly changing competitive environment, at the same time they might be the main vehicle for food retailers to increase market power in already highly concentrated regional markets. Therefore, from a policy perspective, it is crucial to understand the effects of mergers between supermarket chains and whether intervention by antitrust authorities is needed, correct, and effective. To this aim, our paper provides a novel contribution to the ex-post evaluation of merger policy enforcement. Indeed, the large geographical variation entailed in our data allows us to analyze other dimensions along which a merger can display its effects. In particular, we find that the negative effect on variety is stronger in very concentrated areas (i.e. areas with pre-merger HHI larger than 4000). Moreover, we analyze whether and how structural remedies - specifically, divestitures - imposed by the Dutch antitrust authority in 18 local markets were effective in alleviating the potentially anticompetitive effect of the merger. Our empirical findings suggest that divestitures did not outweigh the reduction in variety caused by the mergers, although they led to a reduction in average category prices. Finally, we investigate the effect of rebranding strategies and find that the negative effect on variety is even stronger in C1000 stores that were not rebranded as Jumbo (33 out of 49 C1000 stores in our sample).

The paper is structured as follows. In Section 2, we summarize the relevant literature. In

\footnotetext{
${ }^{2}$ The grocery distribution sector as a whole accounts for about $20 \%$ of global GDP (Bronnenberg and Ellickson, 2015). On average, spending on food represents around $15 \%$ of household budgets in the European Union. In 2011, the total turnover of the food supply chain exceeded 3,500 EUR billion in the European Union and generated around $6 \%$ of the EU gross value added for a total of 650 EUR billion. See http://bit.ly/1tNbFQu.

3 An overview of the work of the Bundeskartellamt on grocery markets in Germany is found here: http://bit.ly/1SlXG3e. A similar analysis of U.K. grocery markets is available at: http://bit.ly/1YB39D5.
} 
Section 3, we provide some background information on the Dutch grocery market and on the merger under consideration. Section 4 describes the data. We present our econometric model in Section 5 and the empirical results in Section 6. Section 7 presents a simple theoretical model of competition in variety. Section 8 concludes.

\section{Related Literature}

Our paper relates to several strands of literature. First, it contributes to the literature studying the link between market concentration and product variety. In particular, both Gandhi et al. (2008) and Mazzeo, Seim and Varela (2014) theoretically study the issue of product repositioning after mergers and highlight the importance of considering effects on variety together with price effects. Yet, their predictions are not unambiguous, depending on the specific form of competition as well as the assumed consumer preferences. Lommerud and Sørgard (1997) show that merged firms might have a strategic incentive to narrow product ranges and that this is generally welfare detrimental. The empirical evidence on this issue is also mixed. Most existing studies focus on very different industries from grocery retail and do not focus on the effect of a specific merger but rather consider several mergers or changes in concentration due to other factors such as entry or exit. A number of papers analyze the effects of the merger wave that took place in the US radio industry at the end of the 1990s. Berry and Waldfogel (2001) find that these mergers increase variety and Jeziorski (2014) quantifies the effect of this increased variety on both sides of the market (listeners and advertisers). Sweeting (2010) finds that these mergers do not affect aggregate variety, because changes affecting the merging parties and competitors offset. The evidence on other markets is mixed. George (2007) finds that content variety increases with ownership concentration in the US daily newspaper market on prices and product characteristics. Based on the estimation of a structural demand model, Fan (2013) simulates the effect of a hypothetical merger between two local newspapers in the United States. She finds that, following the merger, newspaper publishers have an incentive to reposition their product and decrease the content quality, the ratio of local news, as well as their variety, while prices increase. This leads to welfare losses for readers. She also shows that the effects of mergers would be underestimated if one ignored the adjustments of product characteristics. Similarly, Chu (2010) builds a structural model to analyze the cable TVs' response to satellite entry in terms of prices and quality (measures as number of channels), showing through a counterfactual scenario that eliminating 
quality competition implies softer price competition and reduced consumer welfare. Götz and Gugler (2006) find evidence of a reduction of variety after mergers in retail gasoline markets. Watson (2009) finds mixed evidence on the effect of geographic differentiation on competition and variety in retail eyeglasses. Specifically, he empirically finds a non-monotonic relationship between the intensity of local competition, i.e., the closeness of the rival firms, and the firm's product range. Finally in an extension of their main price-analysis, Ashenfelter, Hosken and Weinberg (2013) analyze the effects of a merger between home appliance manufacturers on the length of their product line. They find a substantial reduction in variety by the merging parties.

Our contribution to this literature is not just confined to adding evidence for another important sector, rather it also extends the literature on the interaction between competition in price and non-price dimensions. To this extent, the understanding of decisions about variety by retailers as a consequence of a merger is particularly useful. Indeed, in grocery markets, retail chains often choose nearly-uniform national pricing to limit price discrimination across geographic markets, and this might be a costly strategy for firms (DellaVigna and Gentzkow, 2017). Therefore, assortment repositioning can be a viable strategy to absorb local shocks and dampen profitreductions of national pricing. Our analysis sheds light on this issue. Moreover, our paper further looks at how several other dimensions of local competition, such as local market concentration and the strength of discounters, as well as characteristics of the merging firms, interact with the effect of the merger on price and variety. Thus, it helps us better understand which mechanisms best explain the effect of mergers in a particularly important industry like grocery retailing.

Our paper is also related to the growing literature on ex-post merger evaluation and, in particular, to the relatively small number of papers analyzing the effect of mergers in retailing sectors. ${ }^{4}$ Hosken, Olson and Smith (2018) highlight the importance of looking at local competition in retail markets, as they find that price effects of mergers in the U.S. grocery retailing industry significantly depend on the degree of local concentration. Barros, Brito and de Lucena (2006) estimate the effect of additional concentration on prices in the Portuguese food retailing market, and find that they generally increased. Similarly, Allain et al. (2017) find that grocery mergers in France significantly raised prices, especially in local markets experiencing larger increases in concentration. Rickert, Schain and Stiebale (2018) find a similar result on the effect of a merger between German supermarkets. On the contrary, Chakraborty et al. (2014) show that the 2004 Safeway/Morrison merger in the U.K. lowered prices and led to a change in the form of price

${ }^{4}$ See Hosken and Tenn (2016) for a survey of retail mergers. 
competition. Hanner et al. (2015) assess the effect of retail mergers on entry in the U.S. and show that the relative position of brands change over time but these changes are rarely determined by entry or exit of new, large, firms. Market share dynamics among the incumbents are the driving force and small entrants only gain market shares in small markets. Despite the potentially relevant welfare implications of non-price effects of retail mergers, we are only aware of a discussion paper analyzing mergers' variety effects within this literature on mergers retrospectives. Pires and Trindade (2015) study a series of 14 different supermarket merger events, which affected 61 different US cities. They show that these mergers did not have any effect on prices but increased variety on average by $1 \%$. Their implementation differs from ours in several dimension. First, they do not account from selection on observables when constructing the control group. Second, they only study the effect on overall number of products in a store, without differentiating across different categories. Finally, their estimates mix the effect of several mergers that are potentially different one from the other. Therefore the average treatment effect that they measure must be taken very cautiously. Hence, the analysis of the causal effect of a national merger on variety at the category level in local sub-markets is the main novel contribution we offer in this paper.

Our study is also related to the literature that analyzes variety and, more generally, non-price attributes in retail markets. Matsa (2011) analyzes the effect of competition on a particular dimension of quality, i.e. inventory shortfalls, which is related to variety of assortment. ${ }^{5}$ Bronnenberg (2015) builds a general equilibrium model that explains the optimal provision of variety in the market. Brynjolfsson, Hu and Smith (2003) estimate the effect of increased variety offered by online bookstores on consumer welfare. Hwang, Bronnenberg and Thomadsen (2010) explain the drivers of local variation in assortment choices by US supermarket chains. Ren et al. (2011) analyze instead the role of product variety as a tool of differentiation in consumer electronic retailing. Finally, Richards and Hamilton (2006) studies price and variety competition among grocery retailers in the U.S. These contributions highlight the importance of variety as a strategic variable in retail markets, although they do not focus on the impact of mergers specifically, which is the focus of our paper.

\footnotetext{
${ }^{5}$ See Matsa (2011), p. 1569, for a discussion about the relationship between shortfalls and variety.
} 


\section{The Dutch Grocery Sector and the Merger}

Between 2009 and 2012, several mergers took place in the Dutch grocery sector. The Dutch competition authority (ACM) cleared all of them, mostly subject to remedies. In this paper we focus on the last of these mergers, Jumbo's acquisition of $\mathrm{C} 1000 .{ }^{6}$ In the following subsections, we first describe the functioning of the market as well as the issues related with the last merger.

\subsection{The Dutch Grocery Market}

The main market players at the time of the mergers included the merging parties - Jumbo and C1000 - and several other supermarket chains. Jumbo is a full-service supermarket formula operating across the country. It had a regionally strong position in the southern regions of the Netherlands, which had already expanded thanks to the previous acquisition of Super de Boer (SdB) and Schuitema. The most important characteristic of the Jumbo core marketing proposition is the "every day low price" guarantee. Jumbo stores used to run few promotions. C1000 was also a full-service supermarket formula, which operated across the country. Its core strategy was on deep, short-lived, promotions. Its assortment was reportedly smaller than the other major national players.

Among competitors with a national footprint, Albert Heijn (AH) is the largest full-service supermarket chain and is perceived as the market leader. It operates across the country adopting various store formats. Its commercial offering is similar to Jumbo's offering, especially in terms of product variety. Moreover, it is the only other major chain of supermarkets operating across the whole of Dutch territory. Two large hard discounters have an important presence in the Dutch market: Aldi and Lidl. During the first half of the 2010s, hard discounters progressively increased their assortment and started selling a (limited) list of branded goods. However, significant differences with traditional supermarket formulas still exist. Finally, the market is characterized by a series of other, smaller, regional players, including Coop, Detail Group, Spar (part of an international group with a stronger position in other countries), Hoogvliet, and Jan Linders.

\section{[insert Figure 1 here]}

\footnotetext{
${ }^{6}$ In a study we completed for the ACM (Argentesi et al. (2015)), we assess the price effects of all these mergers. In this paper, we only focus on the last merger because it was the most relevant one concluding the acquisition process that started in 2009 and because the data on product assortment are only available for a limited period.
} 
Figure 1 represents the time evolution of the market shares of all supermarket chains and discounters (at the national level) both in terms of net sales floor area (left panel) and in terms of the number of stores (right panel). AH is clearly the largest chain. The combination of SdB, C1000, and Jumbo has a net sales area similar to AH. A considerable number of stores belong to chains other than the ones listed. Overall, the total number of supermarkets has essentially remained constant from the beginning of 2009 through the end of 2011.

\subsection{The Merger between Jumbo and C1000}

In our analysis, we study Jumbo's acquisition of over 400 locations (the entire C1000 supermarket chain) that took place in February 2012. C1000 stores initially continued to operate under the C1000 sign and were expected to be re-branded under Jumbo brand during the years following the merger. At the end of our sample period, the re-branding from C1000 to Jumbo was not yet fully completed. The Jumbo/C1000 merger approval was conditional on the divestiture of eighteen stores. Jumbo complied in July 2012 to this set of remedies by selling the eighteen locations - along with additional stores - to Coop and Ahold (owner of the Albert Heijn chain).

The geographic market definition adopted by the ACM was a 15-minute isochrone around the analyzed stores. However, the ACM noted that Dutch consumers are not inclined to shop outside their neighborhood. Hence, in practice, the geographic market definition coincides with the administrative borders of each town. In our analyses, we adopt the definition put forward by the ACM and control for a number of explanatory variables measured at the municipal level to account for local demand and supply drivers as well as levels of competition. ${ }^{7}$

With respect to the product dimension, the relevant markets defined by the ACM include both supermarket chains and hard discounters. In our study, we embrace the product market definition adopted by the ACM. However, we restrict our analysis to a particular format (i.e., regular supermarket), in order to maximize the similarity between the different stores analyzed and make our final sample more homogeneous. Moreover, given the increasing role covered by hard discounters (e.g., Lidl and Aldi) in the Dutch market in recent years, we explicitly control for their presence and strength in each relevant geographic market.

\footnotetext{
${ }^{7}$ We drop all large cities from our sample since the geographic market definition is more complex in this case as there are clearly several geographical markets within a city.
} 


\section{Data and Sample}

For our empirical analysis, we collected store-level data for an appropriately selected sample of stores from Information Resources Incorporated (IRI), a firm specialized in collecting and analyzing data on retailing. ${ }^{8}$ The period under analysis is January 2009 to December 2013 and the date of the merger is defined by the date of the ACM decision in February 2012.

The supermarkets included in our sample are selected from areas where the merging parties overlap and from comparable areas where they do not overlap. ${ }^{9}$ To define comparable areas, we pairwise match cities where the merging parties overlap with non-overlap cities by applying a propensity score matching approach, a technique that allows collapsing a set of different characteristics into a single dimension.

We assess the level of similarity taking into account a full range of observable factors that could vary across overlap and non-overlap areas, such as demand and supply characteristics (for a similar approach see Aguzzoni et al. (2016)). Specifically, we use the average density population, average store size, HHI, number of stores, average income, stores' rental cost, and the presence of hard discounters. Our selection ensures a widespread geographic coverage of the Dutch territory and a balanced representation of all merging parties and of the selected subset of competitors. ${ }^{10}$

Within areas of overlap and areas of non-overlap, we select a suitable number of stores both from the merging parties and from competing chains. Our final selection includes over 171 different stores representing the merging parties' chains and two competitors (Albert Heijn and Coop). ${ }^{11}$

For this list of stores, we obtained data both at the product level and at the category level. In particular, we have information on turnover, volumes, and number of products (SKUs) for each of the 125 product categories collected in the IRI database. Moreover, we have information on turnover and volumes on a selection of specific products within several categories. Hence, we

\footnotetext{
${ }^{8}$ See http://www.iriworldwide.nl/.

${ }^{9}$ Two further mergers affected the Dutch market in the previous four years (2009-2012). In order to isolate the effect of the merger under analysis, we restrict the choice of the areas and, consequently, of the stores in such a way that the average behavior of the treated and control group could not be biased by the occurrence of the other events. For a further discussion of this issue we refer to Argentesi et al. (2015).

${ }^{10}$ Further details on the propensity score matching procedure used in the analysis are reported in Appendix A.

${ }^{11} \mathrm{~A}$ description of the criteria for choosing the stores in our sample is in Appendix A.0.1.
} 
have two separate databases to study the merger's effect on price and variety, which we discuss in the subsequent subsections.

\subsection{Product-level Data}

In order to quantify the effect of the merger on prices, we collected information on a balanced sample of products that were sold throughout the entire sample period. This allows us to use SKU-specific fixed effects that significantly enhance the quality of our specification. Due to several constraints, we could not collect product-level price data on all products sold in each store. Hence, we based our selection of categories and products on best practices from the academic literature and ideas originating from the 2014 inquiry in the food retail sector carried out by the German Cartel Office (Bundeskartellamt (2015)). The final list of categories includes coffee, cola, cleaners, diapers, fresh milk, traditional Dutch sausage (frikandel), mayonnaise, olive oil, sanitary napkins, shampoo, and toilet paper.

Our selection of these categories is based on the following criteria: i) the inclusion of both 'food' and 'non-food' items; ii) the inclusion of traditional items for which comparisons across geographic markets are easier; iii) the inclusion of items belonging to the basket of goods typically consumed in the Netherlands; and iv) the inclusion of items whose characteristics set them apart from other items, either because we expect lower price sensitivity or due to higher level of differentiation and innovation (e.g., diapers).

To measure price changes, it is important that the selected products are comparable both over time and across stores. Dutch supermarket assortments usually include at least one A-brand item, such as 'Coca-Cola', one private label, and one first-price (i.e., cheapest) item for each product. We exclude first-price items from our sample, as the data provider indicates that these may differ significantly in quality. Similar problems hold for fresh articles, which we also exclude. For each product defined at SKU level, we have three time series: two SKUs for 'A-brands' and one SKU for private labels. We try to ensure comparability across stores using the same quality and format (e.g., 'fresh whole milk, 1 liter bottle') as well as comparability over time (e.g., not mixing different SKU over time unless necessary to ensure a sufficient coverage of the period under scrutiny). ${ }^{12}$

Panel A of table 1 reports descriptive statistics on prices for our sample of products. Because we have very different products in our sample, the price variation is large, ranging between few

\footnotetext{
${ }^{12}$ The list of selected SKUs for the price analysis is reported in Appendix B.
} 
cents and 20 EUR: some products are quite cheap, while other very expensive. As expected, private label products are, on average, much (33\%) cheaper than A-brand products.

\subsection{Category-level Data}

To analyze the effect of the merger on product variety, we collected quarterly data on the number of SKUs for each of the 125 product categories sold in each of the 171 stores in our sample. This variable represents the depth of assortment and measures the product offerings available to consumers in each store. In addition, we compute an average price per category using quarterly data on turnover and sales volumes for each product category. Our database includes total turnover (in EUR), volume (sales), promotional turnover (in EUR), and promotional share (as a percentage of total sales) measured at store level for the 2009-2013 period. Measurements are weekly but are provided with a four-week periodicity starting with week 4 of 2009 . Hence, our monthly price data is determined as total turnover over volumes, and is net of promotional measures.

Panel B of table 1 reports descriptive statistics on the average category prices and variety. The average category price lays between the average brand price and the average price for private labels. The average number of SKUs per category is very large (95.2) as it is the variation across categories, stores, and time. Some categories are not offered at all in some stores in a given quarter, while other categories have up to 1,689 different SKUs (for instance sauces).

\section{[insert Table 1 here]}

\subsection{Control Variables}

To identify the appropriate control areas as well as to cleanly disentangle the effect of the merger on prices and variety from the effect of market conditions, we collect data on demand and supply shifters in order to control for them in our analysis. We use two main sources: the Central Bureau of Statistics - Statistics Netherlands (http://www.cbs.nl/en-GB/menu/home/default.htm) and the Department of Spatial Economics \& Spatial Information laboratory of VU University Amsterdam. Local demand and market conditions are summarized in Table 2, which also reports preliminary statistics for each variable. As shown, data have different time references.

\section{[insert Table 2 here]}




\section{Empirical Model}

The aim of the study is to analyze the impact of the merger on prices and variety. We implement a Difference-in-Differences (DiD) approach, in which we exploit both time and cross-sectional variation of prices and product variety in order to identify the effect of the merger. The DiD approach entails a comparison of two properly identified groups: the treated group - which is affected by the 'treatment', i.e., the merger - and the control group - which is not affected by the 'treatment'- before and after the merger decision. The strength of this method is that it isolates the effect of the merger from any other factors that (i) may affect the trend in price (variety); and (ii) may be related to the differences between the treated and the control group.

The matching procedure that we adopted to define the control group controls for selection into the treatment due to observable characteristics, while the double differencing entailed in the DiD approach removes the time-invariant group-specific unobserved heterogeneity as well as the common time effects that might be otherwise confounded with the effect of the merger.

The basic idea of our empirical strategy is that competition in grocery markets works at the local level. This is in line with the geographic market definition commonly adopted by competition authorities and by the ACM in this specific case. The competitive effects of a merger are expected to be potentially stronger in areas characterized by an overlap between the merging parties - i.e., areas where stores of both chains were present at the time of the merger - than in areas where the parties did not compete with each other door to door. The former areas, in fact, would be the ones experiencing stronger changes in competitive conditions as a decrease in the number of competitors occurs. Therefore, we can identify the potential effect of mergers by comparing prices and variety of the merging parties in areas of overlap (treated group) vis-à-vis areas of no overlap (control group). ${ }^{13}$

\subsection{Econometric Specification}

We run our analysis for the full sample, including the merging firms and competitors, as well as separately for each of the two merging parties and their competitors. The estimation on the full sample aims at measuring the overall effect of the merger at the market level, which is

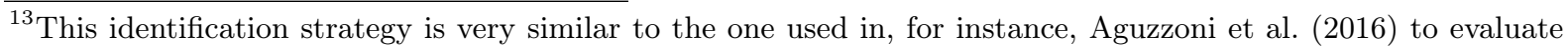
the price effect of a merger between U.K. book retailers, Hosken, Olson and Smith (2018) to study the effect of U.S. grocery mergers on prices, as well as Allain et al. (2017) to study the price effect of mergers across French supermarkets.
} 
possibly the most relevant for consumers. The estimations on the sub-samples aim to identify the strategic reactions of the different players in the market, which helps us study the mechanism driving the average effects and better explain the post-merger competitive dynamics.

We compare the change in an outcome variable in a selection of stores that were located in overlap areas with the change in the same outcome variable in other stores picked from the bestmatched non-overlap areas before and after the merger. ${ }^{14}$ We estimate the following equation: ${ }^{15}$

$$
\text { Out }_{i s t}=\alpha+\text { Boverlap }_{s}+\gamma \text { post }_{t}+\text { Spost }_{t} \times \text { overlap }_{s}+\lambda Z_{\text {st }}+\mu_{i s}+\tau_{t}+\varepsilon_{i s t},
$$

where Out $t_{i s t}$ is the price (variety, category price) level for product (products' category) $i$ at store $s$ during month (quarter) $t$; overlap $_{s}$ is a dummy variable that takes on the value of one if the store is located in an overlap area; post $_{t}$ is a dummy variable that takes on the value of one if the products' price (variety, category price) is observed in the post-merger period (i.e. after February 2012 for the price regression and after the first quarter of 2012 for the variety and category price regressions); $Z_{s t}$ is a set of variables that control for local market features (on the demand and supply side) that change over time.

We control for the average difference in the price (variety, category price) across different products (product categories) and supermarket chains by including fixed effects $\mu_{i s}$ for all combinations of products (product categories) and supermarket insignias. By following this approach, we are able to control for the effect on price and variety determined by the change in insignia. Moreover a time trend together with a set of quarterly dummies $\tau_{t}$ is used to capture aggregate shocks affecting all stores. ${ }^{16}$ The error term $\varepsilon_{i s t}$ is assumed to be heteroskedastic and correlated at the product-insignia level in the price analysis and products' category-insignia level in the analyses based on category data (i.e. the average category prices and variety). ${ }^{17}$

The main variable of interest is post $_{t} \times$ overlap $_{s}$, whose coefficient measures the average treat-

\footnotetext{
${ }^{14}$ In order to account for the possibility that stores adopt a national pricing policy, we perform an additional analysis on the price effects of the merger where we use the competitors to the merging parties as a control group (see Ashenfelter, Hosken and Weinberg (2013) and Aguzzoni et al. (2016)). The underlying assumption, based on economic theory (e.g., Deneckere and Davidson (1985)), is that if the merging parties increase their prices after the merger, competitors will also increase their prices, but less than the merging parties. The results of this exercise are consistent with those obtained with our main identification strategy and are available in Argentesi et al. (2015).

${ }^{15}$ Estimating this equation in logarithms leads to qualitative and quantitative similar results.

${ }^{16} \mathrm{We}$ also tried a specification with time fixed effects and obtained similar results.

${ }^{17}$ We experimented with different correlation structures but our results were not significantly affected.
} 
ment effect on the treated of the merger by identifying the additional variation in price, variety, and category prices experienced by the treated stores compared to the control stores moving from the pre-merger to the post-merger period.

\subsection{Identification}

The first key ingredient of our identification strategy is to assess whether competition in grocery retail works at the local level, as we compare the different evolution of treated and not-treated local markets. Thus, in section 5.2.1, we discuss the descriptive empirical evidence supporting this claim in detail.

Second, to causally identify the effect of the merger on the outcomes of interest, we need to ensure that the difference in the average behavior in the control group adequately represents the counterfactual difference in the average behavior that would have occurred absent the merger. Thus, we need to make sure that the control group is comparable to the treatment group in terms of observables characteristics before treatment. Our matching approach for the selection of the relevant areas and stores should help ensure this condition is met. ${ }^{18}$ In Appendix A we show that observables are balanced between overlap and non-overlap areas. In Section 5.2.2 we show that the evolution of the dependent variables in treated and control areas was similar before the merger, i.e. test the common trend assumption.

\subsubsection{Local or National Competition?}

The choice of the most appropriate counterfactual to evaluate the effects of a merger strictly depends on the geographic extent of competition. A comparison between the price - or other variables of interest - in areas where the merging parties overlap (i.e. areas affected by the merger) vis-à-vis areas of no overlap (i.e. not affected by the merger) identifies the effect of the merger only if competition is, at least to some extent, local.

In general, retail chains may have national or local pricing strategies and retail offerings. ${ }^{19}$ For

\footnotetext{
${ }^{18}$ Note that the matching procedure is made store by store and separately for each of the two merging parties and for the competitors. For instance, for each merging party store in overlap areas, we find the store that best matches among those in non-overlap areas.

${ }^{19}$ Dobson and Waterson (2005) analyze in a theoretical setting the relative profitability of uniform and local pricing if compared to a national pricing strategy. A joint report by the UK Competition Commission and the Office of Fair Trading (Competition Commission and Office of Fair Trading (2011)) stresses the relevance of this issue in retail mergers.
} 
instance, DellaVigna and Gentzkow (2017) document uniform pricing policies in US retailing, while Ater and Rigbi (2017) and Eizenberg, Lach and Yiftach (2018) show significant local price dispersion in grocery prices in Israel, and Rickert, Schain and Stiebale (2018) documents local pricing in Germany. Since this issue was not fully explored during the review of the Jumbo/C1000 merger, in the study we conducted for the ACM (Argentesi et al. (2015)), we carry out a more in depth assessment, examining both qualitative evidence - such as questionnaires to market participants and evidence collected during phone interviews - and quantitative evidence on the variation of retail offers across stores.

With respect to pricing strategies, both the questionnaires and the interviews support the view that prices are generally set at the national level. In addition, the majority of respondents reported that promotional measures, which affect final prices to consumers, are typically set centrally, although these are occasionally set at store level. The interviews also indicated a consensus that Jumbo allows for greater degree of autonomy in price setting at store level than other chains. Therefore, we complement the qualitative evidence with an analysis of the geographic extent of price variability.

First, we graphically analyze the price distribution for different supermarket chains of each SKU at different points in time by means of boxplots. Second, we compute, for each SKU and each month, the standard deviation of price from SKU's average price of that month. We then divide the standard deviation of each SKU's price by the average price of that SKU in order to obtain a measure of the price dispersion (the coefficient of variation) that is independent of the price level. These analyses for several products in our sample are shown in Appendix C. Although price variation appears to be limited (both by looking at boxplots and by a close examination of the cumulative distribution function of the coefficient of variation), figures show that some variability exists. Therefore, given the existence of some variation, local competition cannot be ruled out. Studying the reaction to the local shock due to a merger that differently affected different regional market, can be a way to shed further light on this issue.

As for variety, most of the questionnaires report that, although the overall range of assortment is generally set at central level, individual stores are allowed a substantial degree of autonomy in their individual assortment decisions. Stores belonging to each chain may adapt their own assortment to the local conditions of supply (e.g., competitive pressure coming from the other local players), demand (e.g., distribution of consumer preferences), and individual constraints (e.g., size of the stores, shelf space, etc.). For this reason, it is quite safe to assume that decisions 
on product assortment are set locally. To provide more formal evidence on this assumption, we perform a similar analysis as we did it for prices in Appendix C. By means of box-plots and the analysis of the coefficient of variation we show the existence of substantial local variation in assortment decisions for several exemplifying categories.

\subsubsection{Common trends}

To support our identification strategy based on selection on observables and check whether our empirical approach is appropriate, we analyze whether the pre-merger common trend assumption is empirically verified in our data. If this assumption is met, with the treatment and control groups behaving similarly pre-merger, we can be more confident that the control group is a good counterfactual for the treatment group after the merger. For each of our variables (individual prices, variety, and average category prices), we first provide a descriptive visual inspection of the trends and, then, perform a formal test of the common trend assumption.

Figure 2 shows the average trend of product-level prices for stores in the overlap and nonoverlap areas for a subset of products in the analyzed categories. We do not differentiate between the merging parties and the competitors. The average price evolution faced by consumers in the treatment and control areas are almost identical, i.e. are subject to the same common trend during the pre-treatment period.

\section{[insert Figure 2 here]}

As for variety, Figure 3 compares the evolution of the total number of SKUs per store - our measure of variety - in the overlap areas to the average level of product variety in non-overlap areas, for some selected product categories. ${ }^{20}$ Again, we do not differentiate among stores from the merging parties and competitors to obtain the aggregate picture at the market level, which is possibly the one most relevant for consumers. Although trends seem to differ across categories, in this case the figures also show quite similar trends before the merger within each category. However, almost all series seem to diverge post-merger.

\section{[insert Figure 3 here]}

\footnotetext{
${ }^{20}$ Note that the sample for this analysis is not exactly the same as the one used for the price analysis due to data quality issues that forced us to drop a number of observations. Hence, we undertook a separate matching procedure to identify overlap and non-overlap areas for the analysis on variety, since the relevant variable for this analysis is different from the one relevant for the price analysis.
} 
Finally, Figure 4 plots the series of average prices per category in overlap and non overlap areas for the full sample that includes both the merging parties and their main competitors. The two series seem to follow the same trend in the pre-merger period, meeting the key assumption for the identification of the average treatment effect through the DiD approach. They start to diverge some time after the merger, when prices in overlap areas become higher than prices in non-overlap areas.

\section{[insert Figure 4 here]}

In addition to this graphical evaluation, we also perform a formal test of the common trend hypothesis. Similarly to Ashenfelter, Hosken and Weinberg (2014), we first estimate the deviation of the treated areas prices (variety, category price) from the average price (variety, category price) of the control areas in each quarter. Then, we compute the slope of a linear trend of these deviations in the pre-merger period and test whether the estimated slope is statistically different from zero. The test confirms that individual prices show a common trend in treated and control areas. For variety, only one category out of 125 does not show a common trend. For average prices, 10 categories out of 125 does not show a common trend. If we exclude categories without common trend form our sample the estimated treatment effect is not affected. ${ }^{21}$

\section{Empirical Results}

\subsection{The Average Merger Effects by Insignia}

In this Section, we discuss the results of our analysis of the average effect of the merger both on the entire sample and by insignia. In particular, for our three outcome variables (individual SKUs' prices, variety, and category-level prices) we disentangle the effect for each of the two merging parties and for their main competitors (Albert Heijn and Coop). This additional analysis is particularly relevant as it allows a heterogenous response to the merger of the different market players that help us better identifying the mechanism at play.

\subsubsection{The Merger Effects on Prices}

We start by looking at the evolution of prices on the selected sample of products across a subset of categories discussed in Section 4.1. This exercise is meant to assess whether the merger led to

\footnotetext{
${ }^{21}$ The results of this test are available upon request.
} 
an increase in the price of a set of SKUs that is chosen to be representative of the consumption bundle of Dutch consumers.

The graphs shown in Figure 2 already offered a preliminary glimpse of the result of the following econometric analysis: prices in the treated and control stores seem to mostly maintain the same trend and level throughout the period of the analysis. If prices were set locally and the merger had any negative impact on prices, we would expect the distance between the two price trends to increase in the post-merger period.

To confirm the result of this graphical analysis, we perform several regressions using the aforementioned DiD methodology. Results are reported in Table 3. Overall, product-level prices seem to have significantly decreased in the post-merger period for both treated and control stores. However, our regressions show that the price change post-merger is not different between overlap and non-overlap stores. The average result estimated in the full sample (column 1) holds both for both merging parties' (columns 2 and 3 for C1000 and Jumbo respectively) and for the competitors' prices (column 4), suggesting that the merger did not have any significant effect on prices at the individual product level.

\section{[insert Table 3 here]}

These results might have two main explanation. First, it might be that the merger did not have any competitive effect. Second, the findings are consistent with nearly-uniform pricing strategies at the national level. Because prices seems not to respond to any other local conditions, as all control variables other than seasonality dummies are not significant determinants of prices, it seems that the second explanation might be more reasonable in this setting. While there is some local component in pricing, this does not seems to be the first-order strategy for local managers to respond to local conditions.

\subsubsection{The Merger Effects on Variety}

We then turn to the analysis of the effects of the merger on decisions about product assortments and variety. This analysis might be particularly informative, as this seems to be one of the key strategic variables for supermarkets at the local level.

As before, the graphical analysis presented in Figure 3 indicates a common trend before the merger within each category, which seemed to diverge post-merger for almost all series. Specifically, we observe a decrease in variety for most categories. To gain a precise estimate of 
these effects and to understand where the post-merger decrease in product variety originates, we perform a formal econometric analysis. According to our results presented in Table 4, the merger negatively affected the average level of the product variety at the market level (column 1). Considering that the average variety level in the control stores in the post-merger period (counterfactual level) is equal to 97.2 SKUs per category and the coefficient estimate for the treatment effect is -3.065 , the merger caused an average reduction in variety by $3.2 \%$.

If we separately look at the effect on the two merging parties and on their competitors (columns 2,3 , and 4), we see however that this average effect is the result of opposing trends. In particular, C1000, the low-assortment chain, sharply reduced variety after the merger, by $15 \%$, whereas Jumbo increased its assortment by $8 \%{ }^{22}$ This is compatible with a repositioning in terms of the depth of assortment whereby the two chains tend to differentiate themselves after the merger when they compete in the same local market.

The estimated effect of the merger on competitors' variety (column 4) is weakly significant and indicates that competitors slightly increase their assortment in overlap areas, where the merger is supposed to have produced a stronger effect. Note, however, that the magnitude of the effect on competitors is tiny and much smaller than the first-order effect on the merging parties, therefore has a limited impact on the market-level effect.

\section{[insert Table 4 here]}

The fact that stores strategically reposition their assortment as a reaction to changes in local conditions, while they do not adjust prices, strongly suggests that this competitive dimension might be the main instrument for local managers to maximize their profits.

\subsubsection{The Merger Effect on Category-level Prices}

In order to get an indication on the variation in the composition of assortment after the merger, we analyze the post-merger dynamics in average category prices, both for each of the two merging parties and for their competitors. Since the merger does not seem to lead to a change in the price of individual products while the length of assortment did change, looking at average category prices may give us an indication on whether retail chains modify the composition of their assortment within each category.

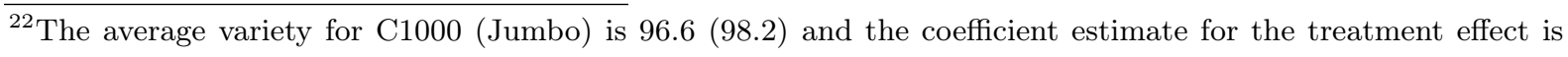
$-14.70(8.66)$.
} 
As shown in Figure 4, the series of average prices per category in overlap and non-overlap areas start to diverge some time after the merger, when prices in overlap areas become higher than prices in non-overlap areas. This graphical evidence is confirmed by our regression results, which are reported in Table 5. First, average category prices in the full sample significantly decreased in the post-merger period for both treated and control stores - the coefficients' estimate for the variable 'post' are negative and significant in all specifications. This mimics the results observed for the individual prices, which could be the driver of category price dynamics as well. However, and more interestingly for this study, our regressions show that, on the full sample, post-merger prices are higher in stores located in the overlap areas compared to stores located in the nonoverlap areas ('Overlap $\times$ Post'). This means that the merger led to an increase in the average category prices. This effect appears to be driven by the merging parties' stores, whereas the effect on the main competitor's prices is insignificant. Specifically, C1000 decreased category prices on average by almost 4 cents (a decrease of $2 \%$ ), while Jumbo increased prices by almost 15 cents (an increase by $8 \%$ ). ${ }^{23}$

\section{[insert Table 5 here]}

The evidence so far is suggestive of the fact that the effect on average category prices might not be due to a price effect, but instead to a composition effect. Consider C1000. Since SKU prices did not change and variety was substantially reduced in overlap area compared to control areas, the decrease in the average category price can be rationalized by the fact that this chain dropped high-priced products after the merger in overlap areas. Jumbo instead increased its assortment as well as category prices, which suggests that it added high-priced products to its assortment. In other words, the high-variety and high-price chain Jumbo became even more high-variety and high-price, whereas the low variety and low-price chain C1000 became even more low-variety and low-price. ${ }^{24}$

Our interpretation of this evidence is that the merging chains repositioned their products in terms of depth as well as composition of assortment in order to avoid cannibalization and soften competition. This explanation is consistent with a theoretical literature on the effect of mergers on product positioning (Gandhi et al., JIE 2008; Mazzeo et al., 2014). In Section 7, we present

\footnotetext{
${ }^{23}$ The average category price for C1000 was 1.86 EUR, while it was 1.75 EUR for Jumbo.

${ }^{24}$ It should be noted that, for category prices, the former effect is stronger than the latter, i.e. the coefficient of the 'Overlap $\times$ Post' dummy for C1000 is smaller and less significant than the corresponding coefficient for Jumbo.
} 
a simple model of competition in variety that rationalizes this evidence. The model shows that the merging parties' decision to change variety after the merger is due to the fact that they internalize the effect of their positioning on the other chain.

\subsection{Additional Heterogeneous Effects}

In order to explore further the drivers of the previous results, we estimate a set of heterogeneous treatment effects. We show the results of such additional regressions for the full sample, as well as for each of the merging parties and their competitors.

\subsubsection{Market Concentration}

First, we investigate whether the effect of the merger varies across areas depending on the level of post-merger concentration (Tables 6, 7, and 8). While we do not find any effect on individual prices, we find that the effect on variety is particularly severe in areas where concentration is high (Herfindal-Hirschmann-Index - HHI - higher than 4,000). Interestingly, this is especially true for competitors. This result suggests that in highly problematic areas, consumers were strongly and negatively affected by the merger: average assortment is reduced by $50 \%$ more than in less problematic areas as a consequence of the merger. It is also interesting to notice that the differentiation effect between the merging parties is smaller in highly concentrated areas. Indeed, the reduction in variety in C1000 stores and the increase in variety in Jumbo stores is less pronounced in these areas. This is consistent with the predictions of the theoretical model described in Section 7, because in highly concentrated areas the incentive to horizontally differentiate is weaker than in other areas.

The effect on average category prices is not significantly different in highly concentrated areas as compared to less concentrated ones, suggesting that overall the composition of assortment is not differentially affected. Consistent with the results on variety, both the reduction in average prices for $\mathrm{C} 1000$ and the increase in average prices for Jumbo are weaker in areas where the market is highly concentrated.

\section{[insert Tables 6, 7, and 8 here]}




\subsubsection{Divestitures}

We further explore whether the effect of the merger was different in areas affected by structural remedies. In particular, the ACM reqired the merged entity to divest 18 stores, which were sold to Coop and to the Albert Heijn chain. We therefore define a variable that takes value of 1 from the moment in which the merging parties realized the divestitures (July 2012) and in the city where they occurred. We then interact this variable with the 'Overlap $\times$ Post' dummy. Thus, the coefficient of this double interaction measures the difference between the treatment effect measured in overlap areas without a divestiture if compared to areas where one of the C1000 stores were divested.

As for our baseline regression, we find no differential effect on individual prices for areas without divestitures if compared to control areas post-merger (Table 9). Concerning variety, we still estimate a significant negative effect of the merger in the full sample (Table 10). However, this effect is not different in areas where a divestiture took place compared to overlap areas without divestitures. Hence, the overall effect of the merger in areas affected by the remedies is not significantly different than in other treated areas where no divestiture was required. Yet if we look at the effect by insignia, we observe that remedies did have an effect. Both C1000 and Jumbo reduced variety, which also implies that the differentiation effect between the merging parties is much weaker in areas with divestitures.

Finally, and perhaps more interestingly, average category prices seem to have decreased in overlap areas where divestitures were imposed (Table 11). This is exactly the opposite effect that we observe in overlap areas where no divestiture was imposed. Moreover, in this case, differently from our baseline model, we observe that both C1000 and Jumbo decrease category prices.

These results all together indicate that, in areas where remedies were imposed, variety and category prices decreased and the strategic repositioning effect both in terms of depth and composition of the assortment was reduced. In essence, this also means that, on average and in both merging parties' stores, relatively more expensive products were dropped from the assortment.

[insert Tables 9, 10, and 11 here] 


\subsubsection{Rebranding}

Finally, we assess whether the effect on variety is related to the rebranding of C1000 stores to Jumbo. During the sample period, over $70 \%$ of the C1000 stores continued to operate without being rebranded to Jumbo. Yet, in principle, rebranded and non-rebranded stores may react differently to the merger in terms of assortment. On the one hand, rebranded C1000 stores need to adapt their assortment to Jumbo's. Given that Jumbo had a higher pre-merger assortment, we might expect an increase of assortment in C1000 rebranded stores. On the other hand, the incentive to differentiate from Jumbo stores in overlap areas may lead to a strategic repositioning that leads to a reduction in assortment independently on whether the store was rebranded or not. In non-rebranded stores, we should only observe the latter effect. In order to understand whether this is the case, we restrict our sample to C1000 stores and interact the treatment variable with a dummy that is equal to 1 for stores that were not rebranded during our sample period.

As for all other regressions, we do not see any differential effect on SKU prices (Table 12, column 1). The estimation results confirm instead that the reduction in variety is much larger for stores that are not rebranded, because for them only the strategic repositioning effect is at play (Table 12, column 2). The coefficient of the 'Overlap $\times$ Post' dummy -which represents the effect on the rebranded C1000 stores- also indicates that variety dropped after the merger, suggesting that the strategic repositioning effect prevails over the effect of adaptation of assortment toward Jumbo.

As for category prices, we find that C1000 rebranded stores in overlap areas slightly decrease category prices compared to stores in non-overlap areas. However, we do not see that rebranded stores change the composition of their assortment if compared to non-rebranded stores (Table 12, column 3). This implies that rebranded stores do not take the more expensive products within Jumbo's assortment, which appears reasonable. Even after being rebranded to Jumbo, C1000 stores tend to be the 'low-quality' variant of the Jumbo stores.

\section{[insert Table 12 here]}

To understand whether this is just a transitory effect, we also estimated this effect considering different lengths of the post-merger period ${ }^{25}$. Our findings suggest that C1000's variety decreases over time as a consequence of the merger, in line with the idea that this product repositioning takes some time to be fully realized.

\footnotetext{
${ }^{25}$ These results can be obtained upon request
} 
These results do not necessarily imply that operating stores under two different insignias is a long-run decision of the merged entity. Our evidence just suggests that, for the stores that were not rebranded (33 out of $49 \mathrm{C} 1000$ stores in our sample), the depth of assortment decreased even more than in rebranded stores as a result of the merger.

\subsection{Robustness Checks}

The results shown in the previous sections are robust to several checks (see Tables 17, 18, and 19 in Appendix D). First, since we do not know exactly when the two merging parties became one single entity and because the competitive conditions could have started changing with the notification of the acquisition, we also run specifications where we exclude windows of 3 and 6 months around the merger date from our dataset. Results do not change, regardless of whether we look at the full sample, merging parties, or competitors. In particular, for the analysis on variety (Table 18 in the Appendix D), when we drop three and six months of data from around the merger date, the effects are even stronger than in our baseline regressions. Results for average category prices (see Table 19 in Appendix D) also show that the effect is larger when we drop 3 or 6 months around the merger decision. This is in line with the qualitative evidence of Figure 4, showing that there is a delay in the realization of the effect of the merger.

Second, for the analysis on variety, we exclude from the dataset the products that show a seasonality in their assortment trend (namely sun protection products, insecticides, and greeting cards). Even in this case, our qualitative and quantitative results do not change: the effect of the merger on variety is still significant and negative. Finally, we re-balanced the sample dropping categories without common trend, as explained in Section 5.2.2 and results are not affected.

The results presented so far, even the heterogeneous treatment effects, represent average effects across all 125 categories in our sample. While we think that this is the right approach, as we want to measure the average effect for a consumer who buys a basket of goods potentially including products from all categories, it is interesting to understand which categories drive this average result. In an additional robustness check, we therefore re-run our previous regression at the category level for the merging parties. ${ }^{26}$ Reassuringly, 112 out of 125 coefficients' estimate of the average treatment effect on variety are negative. ${ }^{27}$ Among these estimates, 37 are significant. ${ }^{28}$

\footnotetext{
${ }^{26}$ For the sake of space, we do not report the results of these 125 regressions but they are available upon request.

${ }^{27}$ Only for one category - chilled rice and pasta- we estimate a positive but tiny (0.755) and significant effect of the merger.

${ }^{28}$ Note that by running our model at the category level, we essentially compare the evolution of one time series
} 
Among the categories for which we find significant negative effects, we have both food and nonfood products. This means that the average effect discussed in the previous sections captures the main tendency of the merger on merging firms' overall assortment decisions. As for average price, the effect of the merger is positive for 114 out of 125 categories, but only 2 of them have significant coefficients. In this case, the lack of significance is most likely driven by the limited power of our regressions when we do it category per category.

\section{A Simple Model of Variety Competition}

We now present a simple model of variety competition that should help us to better understand the mechanisms behind the empirical results discussed so far. The purpose of this simple model is to study the impact of a merger on retail firms (stores) that compete on variety at local level.

We consider a local market where there are $n$ stores that belong to $n$ independent firms. We study a merger between two firms focusing on the stores' managers decision to adjust the depth of the assortment. We further assume that prices are unaffected. This assumption is consistent with our empirical findings and can be motivated by a national pricing strategy.

To model this situation we assume that each store $j(j=1, \ldots, n)$ sells a composite good and sets the value of a variable $v_{j} \in[0,1]$, where 0 represents the minimum level and 1 the maximum level of variety. The vector $v=\left(v_{1}, \ldots, v_{n}\right)$ identifies a strategy profile. A store offering a variety $v_{j}$ bears a cost equal to $c\left(v_{j}\right)$, with $c(0)=0, c^{\prime}\left(v_{j}\right)>0$, and $c^{\prime \prime}\left(v_{j}\right) \geq 0$. Marginal cost is assumed constant and normalized to zero. We order the stores according to their pre-merger level of variety so that:

$$
v_{j}<v_{j+1}, j=1, \ldots, n-1
$$

Moreover, we assume that stores that pre-merger offer a higher level of variety charge a higher price. ${ }^{29}$ This assumption has empirical validation: in our sample, chains with larger variety tend to have higher prices.

Consumers make their purchasing decisions taking into account both the price a store charges for the composite good and the store's variety. For some consumers, variety is a quality feature.

across the 50 overlap areas to the 37 non-overlap areas for which we have data on the merging parties' assortment (see table 15 in appendix A). Hence, the fact that several coefficients are not significant is most likely due to the limited power of our regression.

${ }^{29}$ Note that this condition will hold in the equilibrium of a game in which stores have to decide both the level of variety and the price. 
They prefer shopping at the store with the highest variety if all stores charge the same price. These consumers will be referred to as "vertical consumers" (v-consumers, hereafter) because for them variety is a feature that vertically differentiates stores. Other consumers incur decision costs that increase in the level of variety offered by the store at which they shop. These consumers have a preferred level of variety. They are named "horizontal consumers" (h-consumers, hereafter), because they consider variety a feature that horizontally differentiates stores.

To model this demand heterogeneity, we assume that there is a unit mass of consumers with a unitary demand for the composite good offered by the $n$ stores and that this mass of consumers can be split in two disjoint subsets; the first subset, of size $\alpha$, with $0 \leq \alpha \leq 1$, includes vconsumers; the second subset, with size $1-\alpha$, includes h-consumers.

V-consumers, indexed by $i$, vary according to the intensity of their preference for variety. Thus the level of gross utility (in monetary terms) v-consumer $i$ obtains when she buys from store $j$ is described by the following $C^{2}$ function:

$$
u\left(v_{j}, w_{i}\right),
$$

with $u_{v_{j}}>0, u_{v_{j} v_{j}} \leq 0$ and where $w_{i}$ is an idiosyncratic v-consumer's characteristic such that $u_{v_{j} w_{i}}>0 ; w_{i}$ represents how much consumer $i$ cares about variety (i.e. consumers with a higher $w$ obtain a higher marginal utility from variety). This idiosyncratic characteristic is distributed according to the cumulative $G\left(w_{i}\right)$ over a compact set that can be normalized to $[0,1]$, without any loss of generality. We assume that $G^{\prime \prime}\left(w_{i}\right) \leq 0$.

$\mathrm{H}$-consumers have a preferred level of variety. If a h-consumer, indexed by $h$, buys from store $j$, his level of gross utility (in monetary terms) is described by the following $C^{2}$ function:

$$
b\left(v_{h}\right)-t\left(d\left(v_{h}, v_{j}\right)\right)
$$

where $v_{h}$ is the preferred level of variety for h-consumer $h, b\left(v_{h}\right)>0$ is the gross benefit of buying at the (ideal) store that offers the preferred assortment, $d\left(v_{h}, v_{j}\right)$ is a measure of the distance between $v_{h}$ and the level of variety in store $j, v_{j}$, and $t(\cdot)$ is a "transportation cost" function that is increasing in $d(\cdot)$, with $t(0)=0$ and $t^{\prime \prime} \geq 0$. H-consumers are distributed over the variety space, $[0,1]$, according to the cumulative $H\left(v_{h}\right)$, with $H^{\prime \prime}\left(v_{h}\right) \leq 0$.

Let us define $w_{j}$ and $h_{j}$ as the v-consumer and the h-consumer respectively that are indifferent between buying from store $j$ and store $j+1$. We assume that the price differential between two adjacent stores is such that $h_{j}<v_{j+1}$, i.e. that the h-consumer that is indifferent between $j$ 
and $j+1$ has a preferred level of variety that is below that offered by store $j+1$. The overall demand for firm $j$ is $q_{j}(v)=q_{v j}(v)+q_{h j}(v)$ where: ${ }^{30}$

$$
q_{v j}(v)=\alpha\left[G\left(w_{j}\right)-G\left(w_{j-1}\right)\right]
$$

is the demand function for store $j=1, \ldots, n$ stemming from v-consumers, and

$$
q_{h j}(v)=(1-\alpha)\left[H\left(h_{j}\right)-H\left(h_{j-1}\right)\right]
$$

is the demand function for store $j=1, \ldots, n$ stemming from h-consumers.

We assume that before the merger the equilibrium profile $v^{*}=\left(v_{1}^{*}, \ldots, v_{n}^{*}\right)$ is such that the following FOCs are satisfied:

$$
\frac{\partial \pi_{j}}{\partial v_{j}}=\frac{\partial q_{j}}{\partial v_{j}} p_{j}-\frac{\partial c}{\partial v_{j}}=0 \text { for any } j=1, \ldots, n .
$$

Suppose that stores $j(j=1, \ldots, n-1)$ and $j+1$ merge. In this merger between "close competitors," we refer to store $j$ as the "low-variety store" and to $j+1$ as the "high-variety store." 31 The new entity resulting from the merger, denoted by $m$, will have to decide the level of variety in the two stores $(j$ and $j+1)$ it now controls. It will do so with the aim of maximizing the following profit function:

$$
\pi_{m}(v)=\pi_{j}(v)+\pi_{j+1}(v) .
$$

In Appendix E we prove the following proposition:

Proposition 7.1 After a merger between two close competitors, the new entity decreases variety in the low-variety store. The new entity decreases variety in the high-variety store only if there are "many" v-consumers.

If the two merging parties are close competitors, they have an incentive to change variety if this entails an increase in the demand of the other merging party. Let us consider v-consumers first. Both the low-variety store and the high-variety store have an incentive to decrease variety because the demand originating from v-consumers of the other merging party increases if they do so. On the contrary, the two merging parties increase the demand for the other party stemming from h-consumers if they increase the distance between them. This means that the low-variety

\footnotetext{
${ }^{30}$ We derive the stores' demand functions in appendix $\mathbf{E}$.

${ }^{31}$ In appendix E we also discuss the case of a merger between distant competitors, i.e. firms whose stores are not adjacent in terms of variety.
} 
store has an incentive to decrease variety and the high-variety store the opposite incentive. As a consequence, the prediction is not ambiguous for the low-variety store: they will decrease variety considering the effect of this choice both on v-consumers and on h-consumers. For the highvariety store, the incentive to decrease variety only exists if there are "many" v-consumers, as the former effect dominates the latter. Since the presence of many v-consumers make the stores' offer a vertically differentiated product and this tends to lead to more concentrated markets, we can argue that the negative impact on variety is likely to be larger in markets that show a higher level of concentration.

The above predictions are consistent with our empirical findings. Indeed, we find that C1000, the low-variety chain, reduces variety as a consequence of the merger. Jumbo increases variety, although to a lower extent, which in our model is possible only if there are not many v-consumers.

\section{Conclusions}

In industries where local competition plays an important role and prices are often nearlyuniformly set at the national level - such as the retail sector - firms might forgo profits for not being able to geographically price discriminate and, thus, respond to local market conditions. The empirical evidence presented in this paper shows that non-price terms and conditions are important strategic tools in such situations. Thus, the analysis of these additional dimensions, in particular assortment decisions, is crucial for shedding light on the extent of competition in the market and on its implications for consumer welfare. This is the major contribution of this paper.

To assess if and how local competitive conditions affect assortment and pricing decisions, we analyze a major merger between the Dutch grocery retailers Jumbo and C1000 that differently affected competition in various local markets. We find that the merger did not have significant price effects at the product level. This is consistent with the nearly-uniform pricing patterns across heterogenous local markets observed in the literature (DellaVigna and Gentzkow, 2017). When shaken by a change in market structure, local managers do not respond by changing prices. However, we show that the merger caused a significant decrease in the average depth of assortment at the market level. This effect is driven by two opposing forces: on the one hand, assortment in C1000 stores shrank and moved toward cheaper products; on the other hand, Jumbo increased the depth of its assortment and repositioned its offer toward high-price products. This finding can 
be explained with the strategic decision of the merging parties to adapt their assortment to the changes in local market conditions and avoid cannibalization. We rationalize this behavior in a simple theoretical model where stores compete on variety taking national prices as given. Finally, we also show that other local market conditions affect this strategic repositioning. Specifically, we find that the negative effect on assortment is particularly strong in areas where concentration is high, although the differentiation effect between the merging parties is smaller than in more competitive areas. Moreover, the strategic repositioning of the target C1000 stores is much more pronounced in markets where the stores were not re-branded to Jumbo.

Our findings show that assortment decisions are shaped by the intensity of competition and a crucial way to respond to local market conditions. Recognizing this is important to understand the working of retail markets. Furthermore, these results have important implications for policy and welfare analyses. The reduction in product assortment limits consumers' choice and may ultimately harm them. However, this effect is heterogenous if variety is a vertical differentiation attribute for some consumers and a horizontal one for others for which a deeper retail assortment might increase consumers' shopping costs (Klemperer and Padilla, 1997). While some consumers could benefit from having a larger set of more expensive products in some stores, other might be hurt by seeing some products disappear from their preferred stores or by the increased distance in terms of variety between the stores they can shop at. In such circumstances, merger policy might have redistributive effects across consumers which are difficult to evaluate. This consideration applies to any competitive dimension that may have an heterogeneous impact on consumer welfare. Indeed, while an increase in price (or a reduction in quality) has an obvious negative impact for all consumers, a modification of other characteristics that consumers value differently might benefit some of them and harm others. In these cases, the consumer welfare standard that is frequently adopted to assess the competitive consequences of a merger seems less appropriate than a total welfare standard.

Even if we do not have enough information to assess how a change in the assortment could have affected total welfare, our price analysis shows that the merger had no impact on individual products' prices charged by the merging stores in overlap areas. Therefore, even if the assortment adjustment promoted cost savings, these might not have been passed on to consumers. Hence, our comprehensive assessment of the effect of the merger reveals that it may have harmed most consumers through an average reduction in product variety that was not compensated by a change in prices. Our findings confirm therefore the importance of considering non-price effects 
besides price effects in ex-post evaluations of mergers in markets where non-price dimensions of competition are relevant for consumers. They however highlight that the welfare effects of strategic assortment repositioning are difficult to measure. This is an area that would deserve further research.

\section{References}

Aguzzoni, Luca, Elena Argentesi, Lorenzo Ciari, Tomaso Duso, and Massimo Tognoni. 2016. "Ex post Merger Evaluation in the U.K. Retail Market for Books." The Journal of Industrial Economics, 64(1): 170-200.

Allain, Marie-Laure, Claire Chambolle, Stephane Turolla, and Sofia B Villas-Boas. 2017. "The Impact of Retail Mergers on Food Prices: Evidence from France." The Journal of Industrial Economics, 65(3): 469-509.

Argentesi, Elena, Paolo Buccirossi, Roberto Cervone, Tomaso Duso, and Alessia Marrazzo. 2015. "Mergers in the Dutch Grocery Sector: An Ex-post Evaluation, A Report prepared for the Autoriteit Consument \& Markt (ACM)."

Ashenfelter, Orley C, Daniel Hosken, and Matthew C Weinberg. 2014. "Did Robert Bork Understate the Competitive Impact of Mergers? Evidence from Consummated Mergers." Journal of Law and Economics, 57(S3): S67-S100.

Ashenfelter, Orley C., Daniel S. Hosken, and Matthew C. Weinberg. 2013. "The Price Effects of a Large Merger of Manufacturers: A Case Study of Maytag-Whirlpool." American Economic Journal: Economic Policy, 5(1): 239-61.

Ater, Itai, and Oren Rigbi. 2017. "The effects of mandatory disclosure of supermarket prices." mimeo.

Barros, Pedro Pita, Duarte Brito, and Diogo de Lucena. 2006. "Mergers in the food retailing sector: An empirical investigation." European Economic Review, 50(2): 447-468.

Berry, Steven T., and Joel Waldfogel. 2001. "Do Mergers Increase Product Variety? Evidence from Radio Broadcasting." The Quarterly Journal of Economics, 116(3): 1009-1025. 
Bronnenberg, Bart J. 2015. "The provision of convenience and variety by the market." The RAND Journal of Economics, 46(3): 480-498.

Bronnenberg, Bart J., and Paul B. Ellickson. 2015. "Adolescence and the Path to Maturity in Global Retail." Journal of Economic Perspectives, 29(4): 113-34.

Brynjolfsson, Erik, Yu (Jeffrey) Hu, and Michael D. Smith. 2003. "Consumer Surplus in the Digital Economy: Estimating the Value of Increased Product Variety at Online Booksellers." Management Science, 49(11): 1580-1596.

Bundeskartellamt. 2015. "Sektoruntersuchung Lebensmitteleinzelhandel. Darstellung und Analyse der Strukturen und des Beschaffungsverhaltens auf den MÃd’rkten des Lebensmitteleinzelhandels in Deutschland."

Chakraborty, Ratula, Paul W. Dobson, Jonathan S. Seaton, and Michael Waterson. 2014. "Market Consolidation and Pricing Developments in Grocery Retailing: A Case Study." In The Analysis of Competition Policy and Sectoral Regulation., ed. Yossi Spiegel and Martin Peitz, 3-29. Singapore:World Scientific.

Chu, Chenghuan Sean. 2010. "The effect of satellite entry on cable television prices and product quality." The RAND Journal of Economics, 41(4): 730-764.

Competition Commission, U.K., and U.K. Office of Fair Trading. 2011. "Commentary on retail mergers."

DellaVigna, Stefano, and Matthew Gentzkow. 2017. "Uniform Pricing in US Retail Chains." National Bureau of Economic Research Working Paper 23996.

Deneckere, Raymond, and Carl Davidson. 1985. "Incentives to Form Coalitions with Bertrand Competition." RAND Journal of Economics, 16(4): 473-486.

Dobson, Paul W., and Michael Waterson. 2005. "Chain-Store Pricing Across Local Markets." Journal of Economics \&5 Management Strategy, 14(1): 93-119.

Draganska, Michaela, Michael Mazzeo, and Katja Seim. 2009. "Beyond plain vanilla: Modeling joint product assortment and pricing decisions." Quantitative Marketing and Economics, $7(2):$ 105-146.

Eizenberg, Alon, Saul Lach, and Merav Yiftach. 2018. "Retail prices in a city." mimeo. 
Fan, Ying. 2013. "Ownership Consolidation and Product Characteristics: A Study of the US Daily Newspaper Market." American Economic Review, 103(5): 1598-1628.

Gandhi, Amit, Luke Froeb, Steven Tschantz, and Gregory J Werden. 2008. "PostMerger product repositioning." The Journal of Industrial Economics, 56(1): 49-67.

George, Lisa. 2007. "What's fit to print: The effect of ownership concentration on product variety in daily newspaper markets." Information Economics and Policy, 19(3-4): 285-303.

Götz, Georg, and Klaus Gugler. 2006. "Market concentration and product variety under spatial competition: Evidence from retail gasoline." Journal of Industry, Competition and Trade, 6(3-4): 225-234.

Hanner, Daniel, Daniel Hosken, Luke M. Olson, and Loren K. Smith. 2015. "Dynamics in a Mature Industry: Entry, Exit, and Growth of Big-Box Grocery Retailers." Journal of Economics \& Management Strategy, 24(1): 22-46.

Hosken, Daniel, and Steven Tenn. 2016. "Horizontal Merger Analysis in Retail Markets." In Handbook on the Economics of Retailing and Distribution. 250-286. Edward Elgar Publishing, Cheltenham UK.

Hosken, Daniel S., Luke M. Olson, and Loren K. Smith. 2018. "Do retail mergers affect competition? Evidence from grocery retailing." Journal of Economics $\&$ Management Strategy, 27(1): 3-22.

Hwang, Minha, Bart J. Bronnenberg, and Raphael Thomadsen. 2010. "An Empirical Analysis of Assortment Similarities Across U.S. Supermarkets." Marketing Science, 29(5): 858879 .

Jeziorski, PrzemysÅĄaw. 2014. "Effects of Mergers in Two-Sided Markets: The US Radio Industry." American Economic Journal: Microeconomics, 6(4): 35-73.

Lommerud, Kjell Erik, and Lars Sørgard. 1997. "Merger and product range rivalry." International Journal of Industrial Organization, 16(1): 21-42.

Matsa, David A. 2011. "Competition and product quality in the supermarket industry." The Quarterly Journal of Economics, 126(3): 1539-1591. 
Mazzeo, Michael, Katja Seim, and Mauricio Varela. 2014. "The Welfare Consequences of Mergers with Endogenous Product Choice." mimeo.

OECD. 2013. "The Role and Measurement of Quality in Competition Analysis."

Pires, Tiago, and Andre Trindade. 2015. "Ex-Post Evaluation of Mergers in the Supermarket Industry." http://bit.ly/2xauxju.

Ren, Charlotte R., Ye Hu, Yu (Jeffrey) Hu, and Jerry Hausman. 2011. "Managing Product Variety and Collocation in a Competitive Environment: An Empirical Investigation of Consumer Electronics Retailing." Management Science, 57(6): 1009-1024.

Richards, Timothy J., and Stephen F. Hamilton. 2006. "Rivalry in price and variety among supermarket retailers." American Journal of Agricultural Economics, 88(3): 710-726.

Rickert, Dennis, Jan Philip Schain, and Joel Stiebale. 2018. "Local Market Structure and Consumer Prices: Evidence from a Retail Merger." DICE Discussion Paper 280.

Sweeting, Andrew. 2010. "The effects of mergers on product positioning: evidence from the music radio industry." The RAND Journal of Economics, 41(2): 372-397.

Watson, Randal. 2009. "Product variety and competition in the retail market for eyeglasses." The Journal of Industrial Economics, 57(2): 217-251. 


\section{Figures and Tables}

Figure 1: Stores' market position (national level) over time: net sales floor area (left) and number of stores (right)
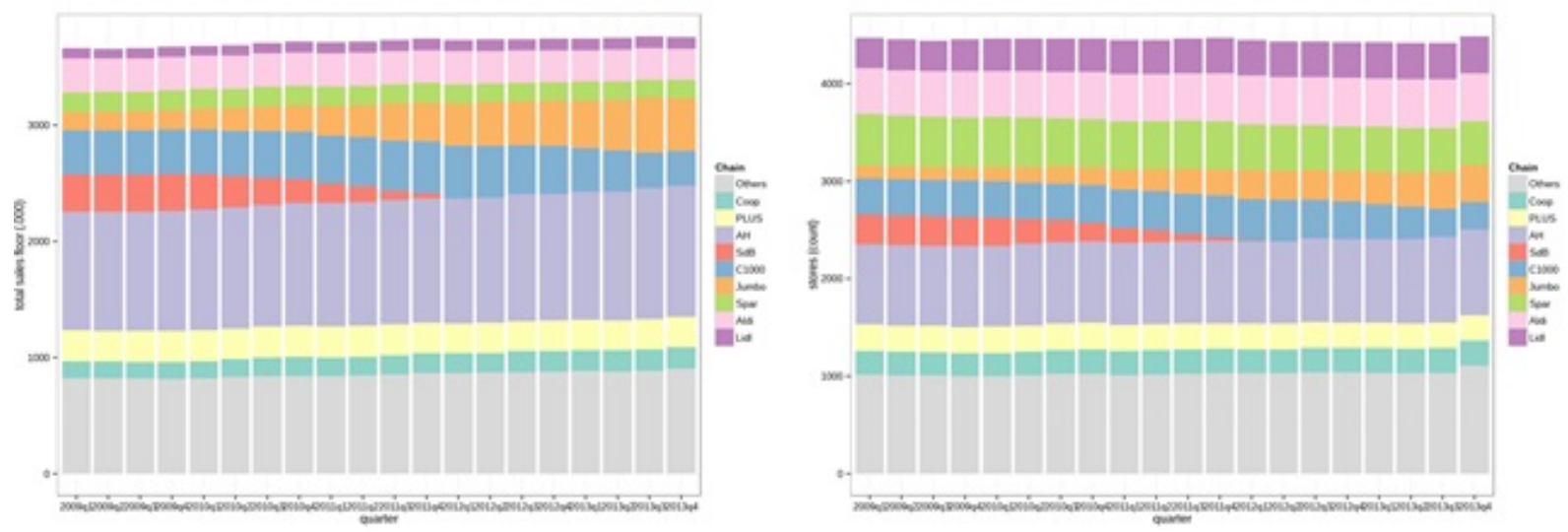

Source: Our elaboration on Supermarket Gids data. 
Figure 2: Trends for individual SKU prices in treated and control areas a) Across all categories

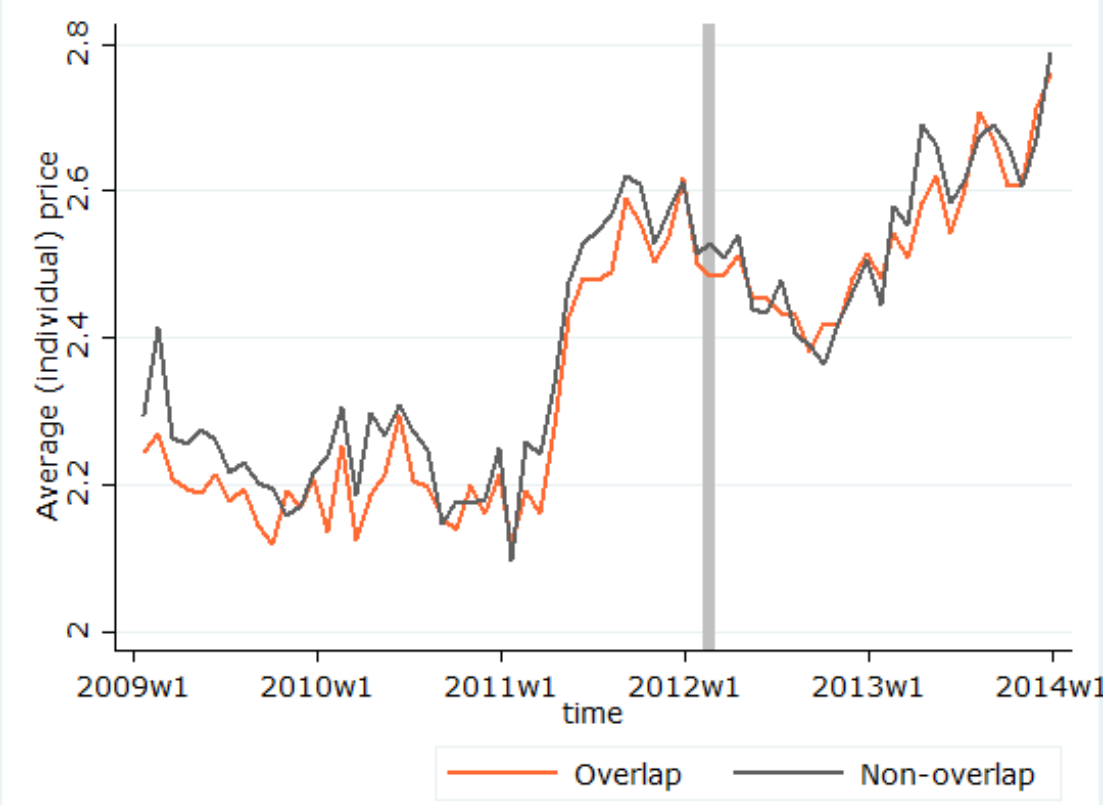

b) Per category

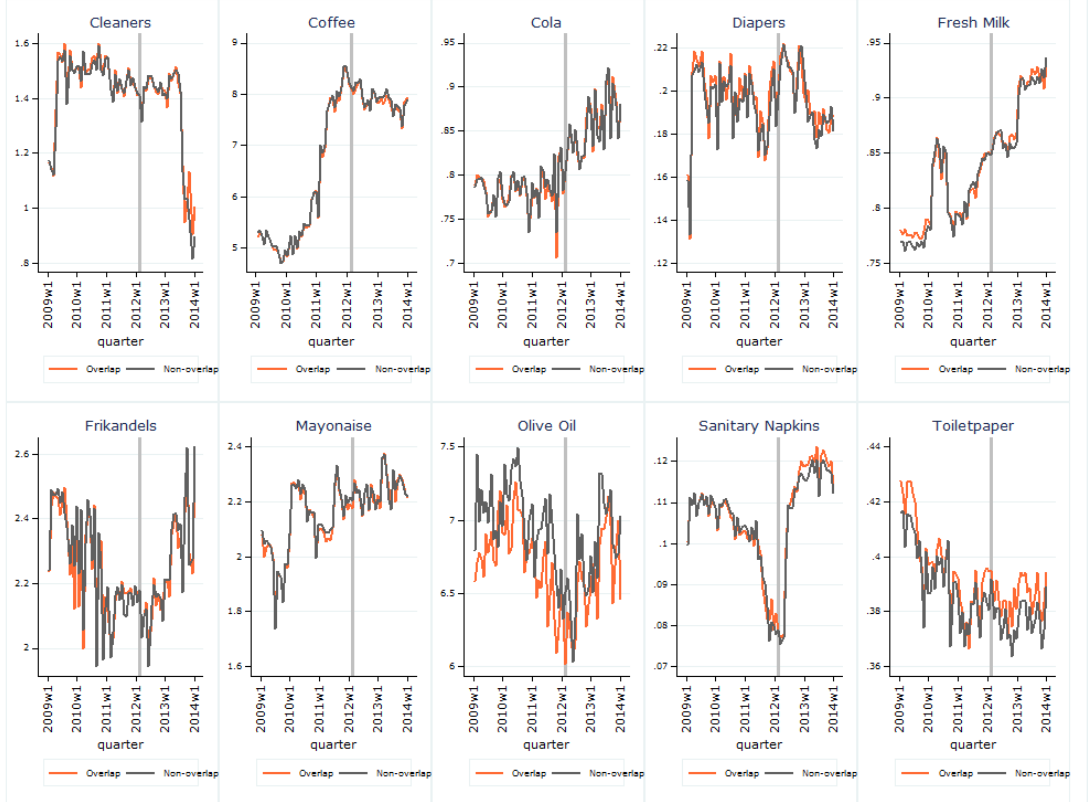

Source: Our elaboration on IRI data 
Figure 3: Trends for variety in treated and control areas

a) Across all categories

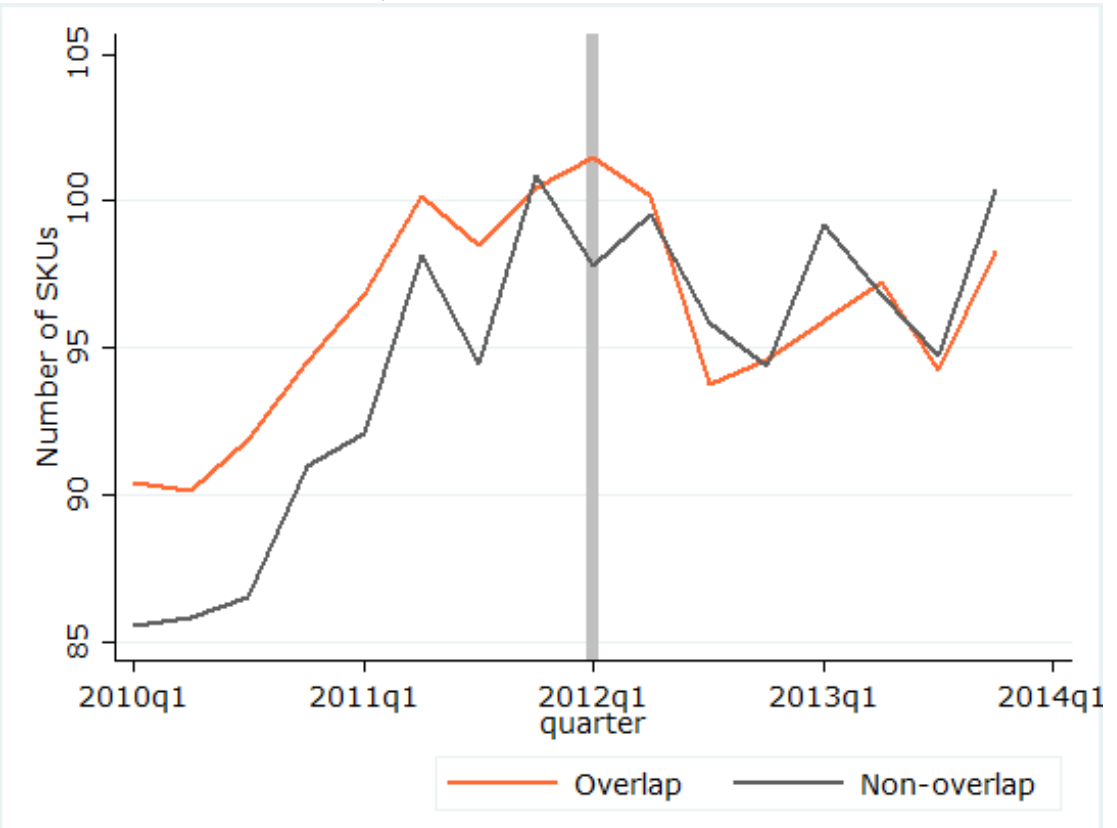

b) Per category
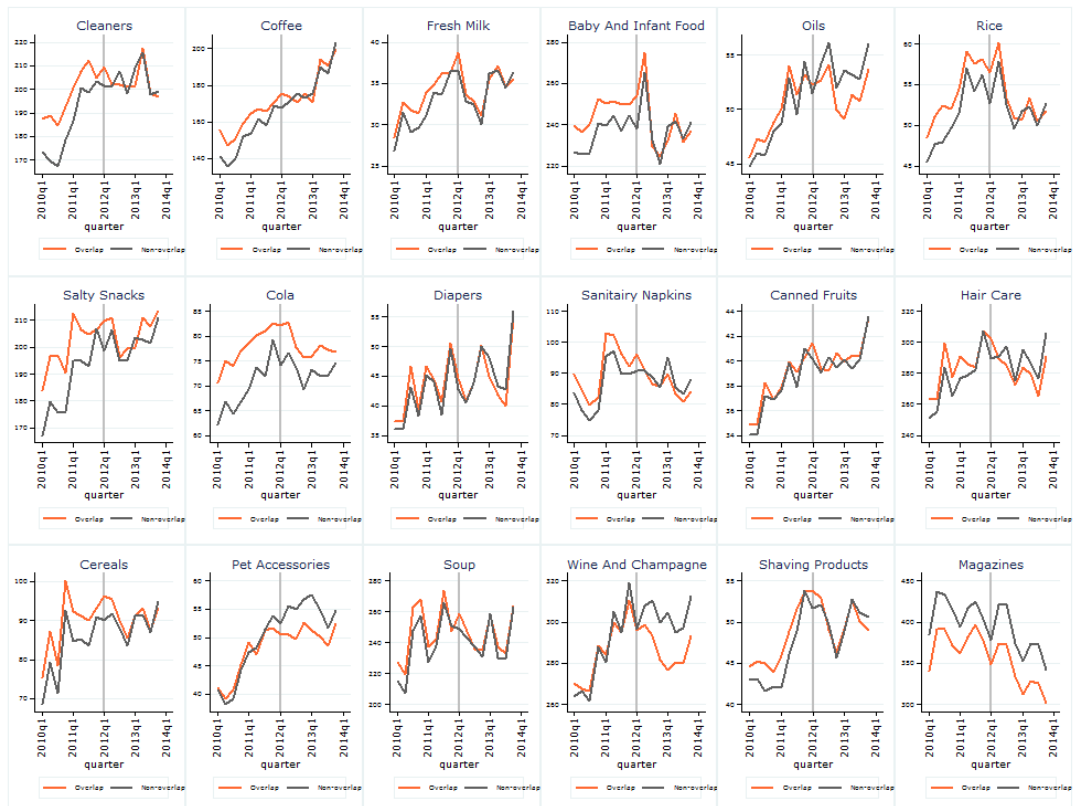

Source: Our elaboration on IRI data 
Figure 4: Trends for average category prices in treated and control areas

a) Across all categories

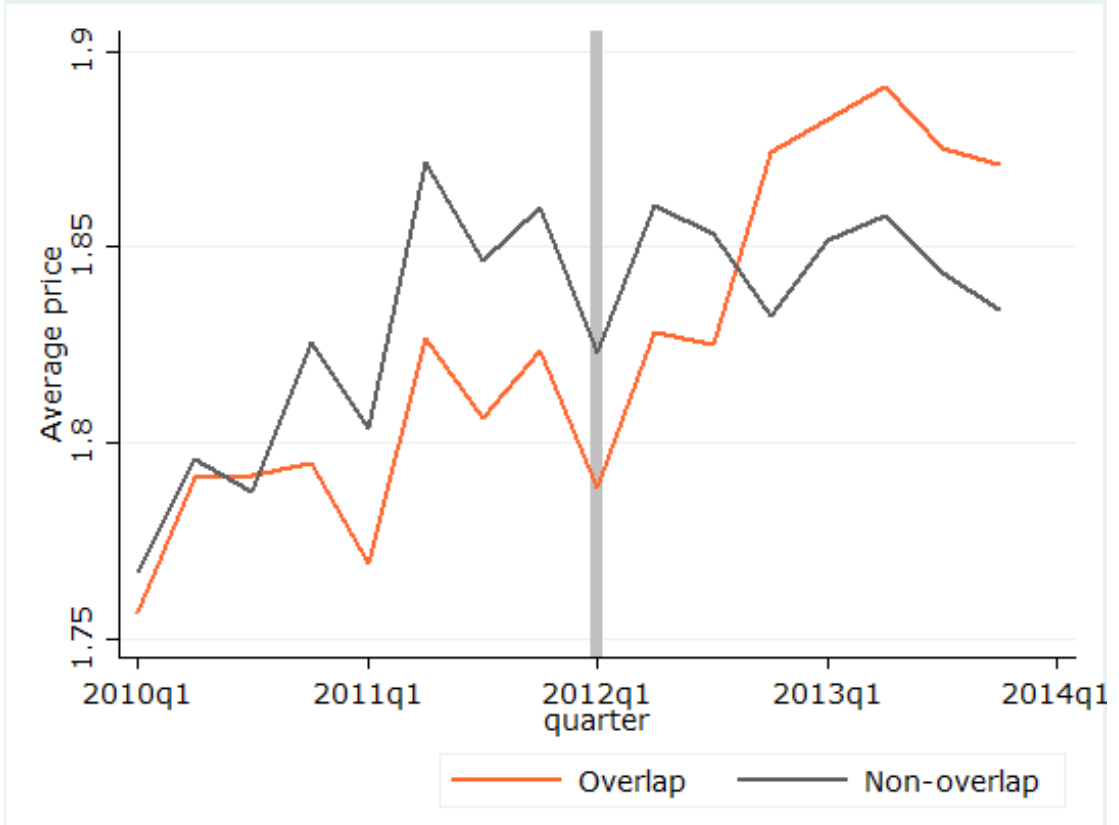

b) Per category
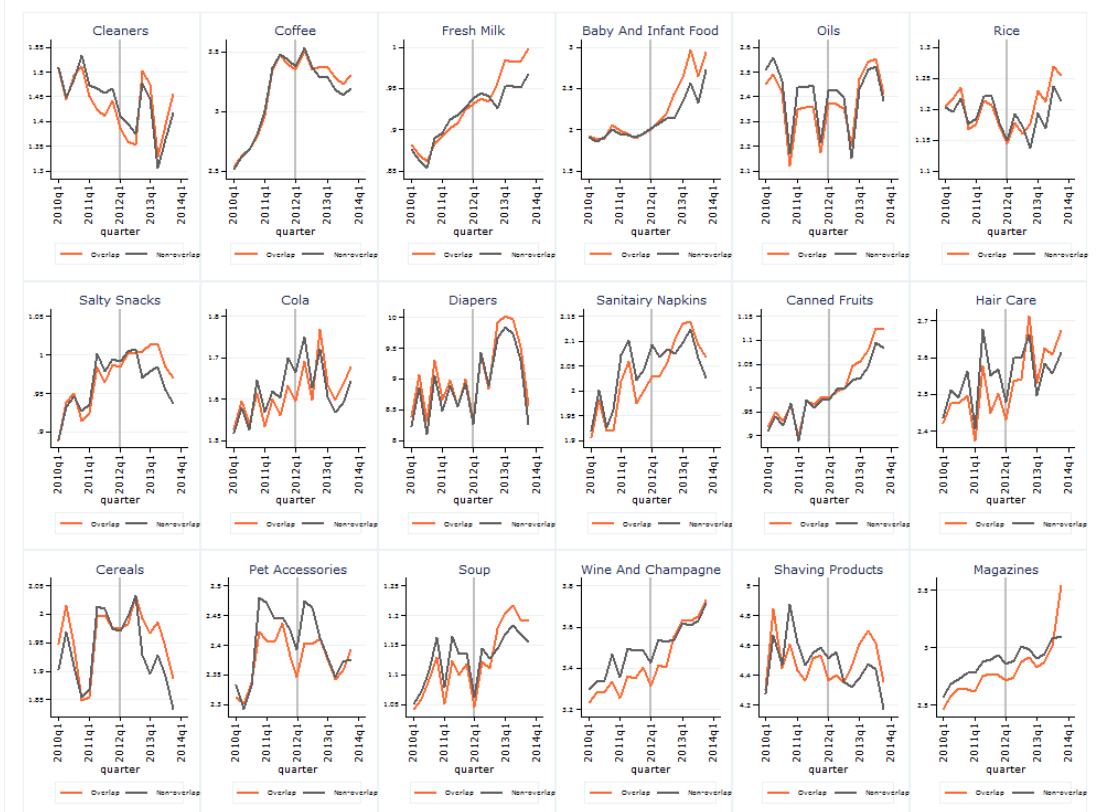

Source: Our elaboration on IRI data 
Table 1: Preliminary Statistics - Dependent variables Mean St. Dev. Min Max

\begin{tabular}{lcccc}
\hline \hline Panel A & & & & \\
Price A brand & 2.67 & 2.91 & 0.03 & 20 \\
Price Private Labels & 1.79 & 2.17 & 0.05 & 10.5 \\
\hline Panel B & & & & \\
Average Category Price & 1.82 & 1.25 & 0.18 & 36.5 \\
Variety & 95.2 & 110.42 & 0 & 1,689 \\
\hline
\end{tabular}




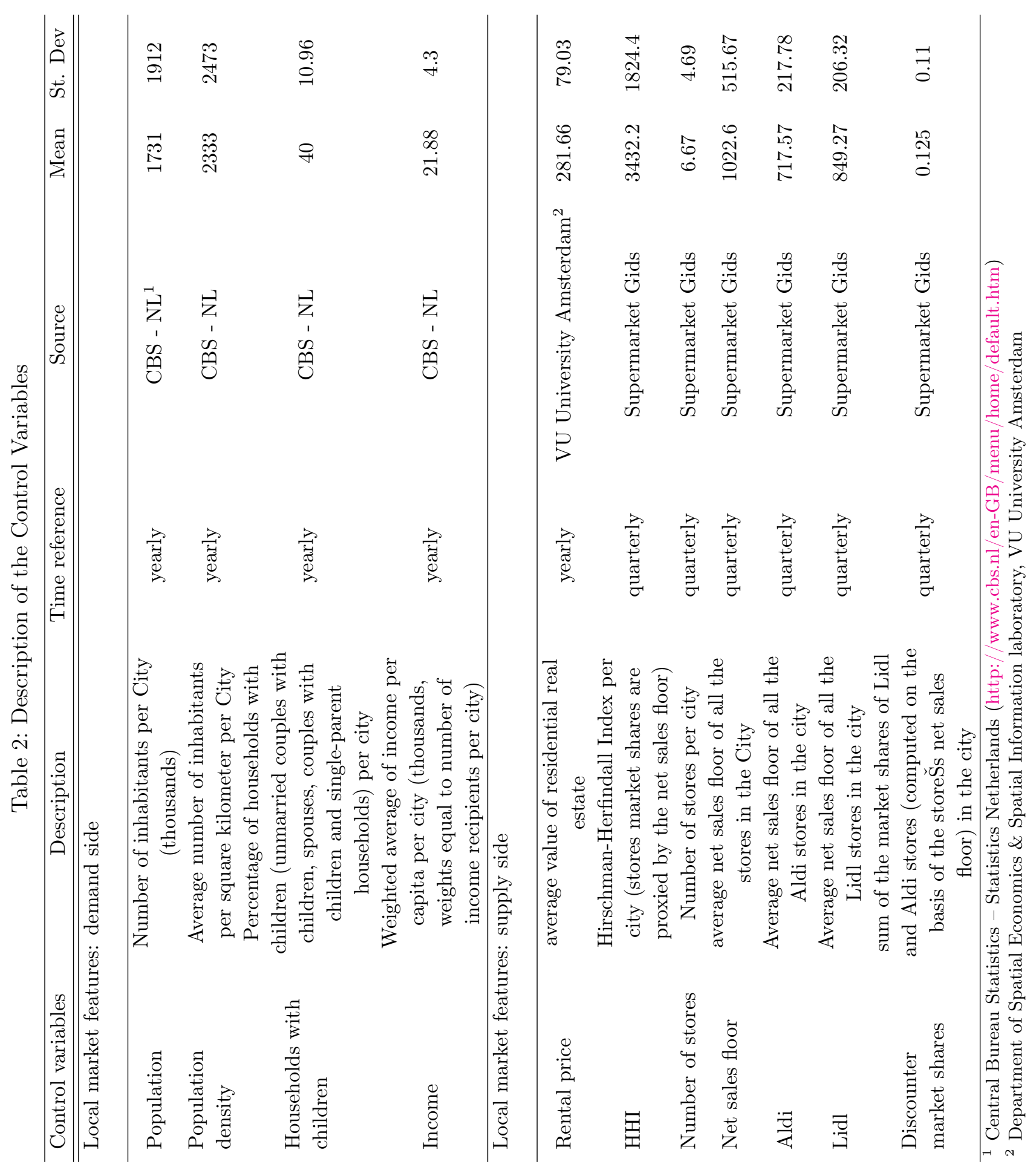


Table 3: Average Treatment Effect per Insigna: Price

\begin{tabular}{lcccc}
\hline & $(1)$ & $(2)$ & $(3)$ & $(4)$ \\
& Full sample & C1000 & Jumbo & Competitors \\
\hline \hline Post & $-0.105^{* * *}$ & $-0.0855^{* * *}$ & $-0.0979^{* *}$ & $-0.139^{* * *}$ \\
& $(0.016)$ & $(0.024)$ & $(0.030)$ & $(0.028)$ \\
Overlap & -0.00712 & -0.00704 & -0.00821 & -0.0126 \\
Overlap $\times$ Post & $(0.011)$ & $(0.017)$ & $(0.023)$ & $(0.020)$ \\
& 0.00133 & -0.00390 & 0.00733 & 0.0120 \\
Population & $(0.027)$ & $(0.046)$ & $(0.039)$ & $(0.048)$ \\
& -0.000140 & -0.000198 & -0.0000585 & -0.0000528 \\
Average Income & $(0.000)$ & $(0.000)$ & $(0.000)$ & $(0.000)$ \\
& 0.00210 & 0.000418 & 0.00189 & 0.00339 \\
Discounters Market Share & $(0.001)$ & $(0.003)$ & $(0.004)$ & $(0.002)$ \\
& $0.0459^{*}$ & 0.0135 & 0.0873 & $0.0823^{*}$ \\
HHI & $(0.020)$ & $(0.028)$ & $(0.067)$ & $(0.037)$ \\
& 0.0000745 & -0.000121 & 0.000314 & -0.000279 \\
Net Sales Floor & $(0.000)$ & $(0.000)$ & $(0.000)$ & $(0.001)$ \\
& 0.00000302 & 0.00000990 & -0.00000281 & -0.000000980 \\
House Value & $(0.000)$ & $(0.000)$ & $(0.000)$ & $(0.000)$ \\
& 0.0000173 & 0.0000548 & 0.0000173 & -0.0000110 \\
Quarter & $(0.000)$ & $(0.000)$ & $(0.000)$ & $(0.000)$ \\
Constant & $0.0388^{* * *}$ & $0.0351^{* * *}$ & $0.0347^{* * *}$ & $0.0453^{* * *}$ \\
& $(0.002)$ & $(0.003)$ & $(0.005)$ & $(0.004)$ \\
Observations & $-6.149^{* * *}$ & $-5.317^{* * *}$ & $-5.392^{* * *}$ & $-7.451^{* * *}$ \\
$R^{2}$ & $(0.465)$ & $(0.687)$ & $(0.933)$ & $(0.832)$ \\
\hline
\end{tabular}

Clustered-robust standard errors at the product-store level in parentheses. We control for fixed effect at the product-insignia level as well as a time trend and quarterly seasonal dummies. The symbols $* * *, * *, *$ denote significance level at the $1 \%, 5 \%$, and $10 \%$ significance level, respectively. 
Table 4: Average Treatment Effect per Insigna: Variety

\begin{tabular}{lcccc}
\hline & $(1)$ & $(2)$ & $(3)$ & $(4)$ \\
& Full sample & C1000 & Jumbo & Competitors \\
\hline \hline Post & $-2.402^{* * *}$ & 0.424 & $-6.504^{* * *}$ & -1.099 \\
& $(0.559)$ & $(0.656)$ & $(1.052)$ & $(0.727)$ \\
Overlap & $3.071^{* * *}$ & $11.41^{* * *}$ & -0.0837 & $-4.153^{* * *}$ \\
& $(0.537)$ & $(1.272)$ & $(0.377)$ & $(0.872)$ \\
Overlap $\times$ Post & $-3.065^{* * *}$ & $-14.70^{* * *}$ & $8.659^{* * *}$ & $0.722^{*}$ \\
& $(0.364)$ & $(1.458)$ & $(0.938)$ & $(0.290)$ \\
Population & $-0.0798^{* * *}$ & $-0.145^{* * *}$ & $0.0753^{* * *}$ & -0.00998 \\
Average Income & $(0.011)$ & $(0.021)$ & $(0.014)$ & $(0.017)$ \\
& $0.399^{* * *}$ & $-1.117^{* * *}$ & $-0.841^{* * *}$ & $2.114^{* * *}$ \\
Discounters Market Share & $(0.097)$ & $(0.182)$ & $(0.172)$ & $(0.253)$ \\
& 0.425 & $-21.50^{* * *}$ & $24.72^{* * *}$ & $15.90^{* * *}$ \\
HHI & $(1.243)$ & $(2.901)$ & $(2.799)$ & $(2.885)$ \\
& $-0.0874^{* * *}$ & $-0.238^{* * *}$ & $0.0820^{* * *}$ & $-0.157^{* * *}$ \\
Net Sales Floor & $(0.011)$ & $(0.028)$ & $(0.013)$ & $(0.039)$ \\
& $0.438^{* * *}$ & $0.869^{* * *}$ & 0.0165 & $0.184^{* * *}$ \\
House Value & $(0.047)$ & $(0.094)$ & $(0.019)$ & $(0.027)$ \\
& $0.0229^{* * *}$ & $0.0422^{* * *}$ & $0.0583^{* * *}$ & $-0.0163^{* * *}$ \\
Quarter & $(0.004)$ & $(0.006)$ & $(0.007)$ & $(0.004)$ \\
Constant & $0.532^{* * *}$ & $1.014^{* * *}$ & -0.204 & $0.294^{*}$ \\
& $(0.109)$ & $(0.153)$ & $(0.116)$ & $(0.117)$ \\
\hline Observations & $58.21^{*}$ & -35.44 & $216.9^{* * *}$ & $82.93^{* *}$ \\
$R^{2}$ & $(22.897)$ & $(31.216)$ & $(23.002)$ & $(26.022)$ \\
\hline
\end{tabular}

Clustered-robust standard errors at the category-store level in parentheses. We control for fixed effect at the category-insignia level as well as a time trend and quarterly seasonal dummies. The symbols $* * *, * *, *$ denote significance level at the $1 \%, 5 \%$, and $10 \%$ significance level, respectively. 
Table 5: Average Treatment Effect per Insigna: Average price

\begin{tabular}{lcccc}
\hline & $(1)$ & $(2)$ & $(3)$ & $(4)$ \\
& Full sample & C1000 & Jumbo & Competitors \\
\hline \hline Post & $-0.0361^{* * *}$ & -0.0185 & $-0.0836^{* * *}$ & $-0.0215^{* * *}$ \\
Overlap & $(0.005)$ & $(0.012)$ & $(0.007)$ & $(0.005)$ \\
& -0.00559 & $0.0219^{*}$ & -0.00801 & $-0.0201^{* *}$ \\
Overlap $\times$ Post & $(0.005)$ & $(0.011)$ & $(0.007)$ & $(0.007)$ \\
& $0.0254^{* * *}$ & $-0.0391^{* *}$ & $0.148^{* * *}$ & -0.00930 \\
Population & $(0.007)$ & $(0.014)$ & $(0.013)$ & $(0.008)$ \\
& -0.000178 & $-0.000467^{* *}$ & $0.00110^{* * *}$ & $-0.000392^{* *}$ \\
Average Income & $(0.000)$ & $(0.000)$ & $(0.000)$ & $(0.000)$ \\
& $0.00237^{*}$ & -0.00390 & $-0.0126^{* * *}$ & $0.0129^{* * *}$ \\
Discounters Market Share & $(0.001)$ & $(0.003)$ & $(0.002)$ & $(0.002)$ \\
& $0.0883^{* * *}$ & $0.0644^{*}$ & 0.0329 & $0.138^{* * *}$ \\
HHI & $(0.017)$ & $(0.032)$ & $(0.027)$ & $(0.035)$ \\
& $0.00119^{* * *}$ & 0.000451 & $0.00247^{* * *}$ & -0.0000795 \\
Net Sales Floor & $(0.000)$ & $(0.000)$ & $(0.000)$ & $(0.000)$ \\
& -0.00000197 & $0.0000142^{*}$ & $-0.0000165^{* * *}$ & -0.00000404 \\
House Value & $(0.000)$ & $(0.000)$ & $(0.000)$ & $(0.000)$ \\
& $0.000310^{* * *}$ & $0.000446^{* * *}$ & $0.000571^{* * *}$ & 0.000125 \\
Quarter & $(0.000)$ & $(0.000)$ & $(0.000)$ & $(0.000)$ \\
Constant & $0.0103^{* * *}$ & $0.0164^{* * *}$ & 0.00150 & $0.0102^{* * *}$ \\
& $(0.001)$ & $(0.001)$ & $(0.001)$ & $(0.001)$ \\
\hline Observations & $0.934^{* * *}$ & -0.425 & $2.975^{* * *}$ & $0.838^{* * *}$ \\
$R^{2}$ & $(0.107)$ & $(0.223)$ & $(0.228)$ & $(0.148)$ \\
\hline
\end{tabular}

Clustered-robust standard errors at the category-store level in parentheses. We control for fixed effect at the category-insignia level as well as a time trend and quarterly seasonal dummies. The symbols ***, $* *, *$ denote significance level at the $1 \%, 5 \%$, and $10 \%$ significance level, respectively. 
Table 6: Interaction with high concentration: Price

\begin{tabular}{lcccc}
\hline & $(1)$ & $(2)$ & $(3)$ & $(4)$ \\
& Full sample & C1000 & Jumbo & Competitors \\
\hline \hline Post & $-0.104^{* * *}$ & $-0.0835^{* *}$ & $-0.104^{* * *}$ & $-0.137^{* * *}$ \\
& $(0.016)$ & $(0.026)$ & $(0.030)$ & $(0.028)$ \\
Overlap & -0.00728 & -0.00599 & -0.00739 & -0.0124 \\
& $(0.011)$ & $(0.017)$ & $(0.022)$ & $(0.020)$ \\
Overlap $\times$ Post & 0.00482 & -0.000989 & 0.0186 & 0.00822 \\
& $(0.029)$ & $(0.050)$ & $(0.042)$ & $(0.050)$ \\
Overlap $\times$ Post $\times$ HHI $>4000$ & -0.0113 & -0.0112 & -0.0506 & 0.0203 \\
& $(0.038)$ & $(0.069)$ & $(0.055)$ & $(0.088)$ \\
Population & -0.000184 & -0.000193 & -0.000102 & -0.0000103 \\
Average Income & $(0.000)$ & $(0.000)$ & $(0.000)$ & $(0.000)$ \\
Discounters Market Share & 0.00187 & 0.000535 & 0.00194 & 0.00308 \\
Net Sales Floor & $(0.002)$ & $(0.003)$ & $(0.004)$ & $(0.002)$ \\
& 0.0391 & 0.0168 & 0.0751 & 0.0879 \\
House Value & $(0.022)$ & $(0.029)$ & $(0.082)$ & $(0.047)$ \\
HHI $>$ 4000 & 0.00000364 & 0.00000890 & -0.00000154 & -0.00000107 \\
Quarter & $(0.000)$ & $(0.000)$ & $(0.000)$ & $(0.000)$ \\
Constant & 0.0000178 & 0.0000486 & 0.0000218 & -0.0000102 \\
$R^{2}$ & $(0.000)$ & $(0.000)$ & $(0.000)$ & $(0.000)$ \\
\hline Observations & -0.00324 & -0.00868 & 0.0428 & -0.0184 \\
& $(0.031)$ & $(0.049)$ & $(0.050)$ & $(0.064)$ \\
& $0.0388^{* * *}$ & $0.0350^{* * *}$ & $0.0346^{* * *}$ & $0.0453^{* * *}$ \\
& $(0.002)$ & $(0.003)$ & $(0.004)$ & $(0.004)$ \\
& $-6.145^{* * *}$ & $-5.313^{* * *}$ & $-5.371^{* * *}$ & $-7.469^{* * *}$ \\
& $(0.465)$ & $(0.691)$ & $(0.927)$ & $(0.837)$ \\
\hline & 122,213 & 48,362 & 30,279 & 43,572 \\
& 0.9532 & 0.9510 & 0.9612 & 0.9514 \\
\hline
\end{tabular}

Clustered-robust standard errors at the product-store level in parentheses. We control for fixed effect at the product-insignia level as well as a time trend and quarterly seasonal dummies. The symbols ***, $* *, *$ denote significance level at the $1 \%, 5 \%$, and $10 \%$ significance level, respectively. 
Table 7: Interaction with high concentration: Variety

\begin{tabular}{|c|c|c|c|c|}
\hline & $\begin{array}{c}\text { (1) } \\
\text { Full sample }\end{array}$ & $\begin{array}{c}(2) \\
\text { C1000 }\end{array}$ & $\begin{array}{c}(3) \\
\text { Jumbo }\end{array}$ & $\begin{array}{c}\text { (4) } \\
\text { Competitors }\end{array}$ \\
\hline Post & $\begin{array}{c}-2.120^{* * *} \\
(0.536)\end{array}$ & $\begin{array}{c}2.720^{* * *} \\
(0.756)\end{array}$ & $\begin{array}{c}-6.962^{* * *} \\
(1.058)\end{array}$ & $\begin{array}{l}-1.339 \\
(0.769)\end{array}$ \\
\hline Overlap & $\begin{array}{c}3.359^{* * *} \\
(0.548)\end{array}$ & $\begin{array}{c}12.97^{* * *} \\
(1.399)\end{array}$ & $\begin{array}{c}0.337 \\
(0.381)\end{array}$ & $\begin{array}{c}-3.705^{* * *} \\
(0.862)\end{array}$ \\
\hline Overlap $\times$ Post & $\begin{array}{c}-2.299^{* * *} \\
(0.340)\end{array}$ & $\begin{array}{c}-15.82^{* * *} \\
(1.620)\end{array}$ & $\begin{array}{c}12.29^{* * *} \\
(1.298)\end{array}$ & $\begin{array}{c}1.152^{* * *} \\
(0.291)\end{array}$ \\
\hline Overlap $\times$ Post $\times$ HHI $>4000$ & $\begin{array}{c}-2.217^{* * *} \\
(0.657)\end{array}$ & $\begin{array}{l}2.836^{*} \\
(1.107)\end{array}$ & $\begin{array}{c}-10.76^{* * *} \\
(1.712)\end{array}$ & $\begin{array}{c}-6.580^{* * *} \\
(1.587)\end{array}$ \\
\hline Population & $\begin{array}{c}-0.0664^{* * *} \\
(0.010)\end{array}$ & $\begin{array}{c}-0.103^{* * *} \\
(0.016)\end{array}$ & $\begin{array}{c}0.0386^{* *} \\
(0.013)\end{array}$ & $\begin{array}{c}-0.00327 \\
(0.015)\end{array}$ \\
\hline Average Income & $\begin{array}{c}0.409^{* * *} \\
(0.095)\end{array}$ & $\begin{array}{c}-0.640^{* * *} \\
(0.141)\end{array}$ & $\begin{array}{c}-0.996^{* * *} \\
(0.183)\end{array}$ & $\begin{array}{c}2.039^{* * *} \\
(0.248)\end{array}$ \\
\hline Net Sales Floor & $\begin{array}{c}0.384^{* * *} \\
(0.041)\end{array}$ & $\begin{array}{c}0.689^{* * *} \\
(0.074)\end{array}$ & $\begin{array}{r}0.0400^{*} \\
(0.019)\end{array}$ & $\begin{array}{c}0.139^{* * *} \\
(0.025)\end{array}$ \\
\hline House Value & $\begin{array}{c}0.0213^{* * *} \\
(0.003)\end{array}$ & $\begin{array}{c}0.0366^{* * *} \\
(0.006)\end{array}$ & $\begin{array}{c}0.0601^{* * *} \\
(0.007)\end{array}$ & $\begin{array}{c}-0.0223^{* * *} \\
(0.005)\end{array}$ \\
\hline Discounters Market Share & $\begin{array}{c}1.864 \\
(1.272)\end{array}$ & $\begin{array}{c}-10.39^{* * *} \\
(2.066)\end{array}$ & $\begin{array}{c}14.67^{* * *} \\
(2.262)\end{array}$ & $\begin{array}{c}15.85^{* * *} \\
(2.984)\end{array}$ \\
\hline $\mathrm{HHI}>4000$ & $\begin{array}{c}-2.506^{* * *} \\
(0.613)\end{array}$ & $\begin{array}{c}-9.293^{* * *} \\
(1.264)\end{array}$ & $\begin{array}{c}4.104^{* * *} \\
(1.179)\end{array}$ & $\begin{array}{c}0.127 \\
(1.188)\end{array}$ \\
\hline Quarter & $\begin{array}{c}0.534^{* * *} \\
(0.110)\end{array}$ & $\begin{array}{c}0.985^{* * *} \\
(0.154)\end{array}$ & $\begin{array}{l}-0.159 \\
(0.116)\end{array}$ & $\begin{array}{l}0.317^{* *} \\
(0.116)\end{array}$ \\
\hline Constant & $\begin{array}{c}55.19^{*} \\
(23.009)\end{array}$ & $\begin{array}{c}-48.85 \\
(31.908)\end{array}$ & $\begin{array}{l}214.3^{* * *} \\
(23.060)\end{array}$ & $\begin{array}{c}77.22^{* *} \\
(26.036)\end{array}$ \\
\hline $\begin{array}{l}\text { Observations } \\
R^{2}\end{array}$ & $\begin{array}{l}225667 \\
.8805652\end{array}$ & $\begin{array}{c}90484 \\
.8333422\end{array}$ & $\begin{array}{c}72056 \\
.9048633\end{array}$ & $\begin{array}{c}63127 \\
.9417944\end{array}$ \\
\hline
\end{tabular}

Clustered-robust standard errors at the category-store level in parentheses. We control for fixed effect at the category-insignia level as well as a time trend and quarterly seasonal dummies. The symbols $* * *, * *, *$ denote significance level at the $1 \%, 5 \%$, and $10 \%$ significance level, respectively. 
Table 8: Interaction with high concentration: Average Price

\begin{tabular}{|c|c|c|c|c|}
\hline & $\begin{array}{c}(1) \\
\text { Full sample }\end{array}$ & $\begin{array}{c}(2) \\
\text { C1000 }\end{array}$ & $\begin{array}{c}(3) \\
\text { Jumbo }\end{array}$ & $\begin{array}{c}(4) \\
\text { Competitors }\end{array}$ \\
\hline Post & $\begin{array}{c}-0.0412^{* * *} \\
(0.005)\end{array}$ & $\begin{array}{r}-0.0137 \\
(0.013)\end{array}$ & $\begin{array}{c}-0.105^{* * *} \\
(0.008)\end{array}$ & $\begin{array}{c}-0.0182^{* *} \\
(0.006)\end{array}$ \\
\hline Overlap & $\begin{array}{c}-0.00967^{*} \\
(0.005)\end{array}$ & $\begin{array}{l}0.0174 \\
(0.011)\end{array}$ & $\begin{array}{c}-0.00132 \\
(0.007)\end{array}$ & $\begin{array}{c}-0.0197^{* *} \\
(0.007)\end{array}$ \\
\hline Overlap $\times$ Post & $\begin{array}{c}0.0307^{* * *} \\
(0.008)\end{array}$ & $\begin{array}{c}-0.0566^{* * *} \\
(0.017)\end{array}$ & $\begin{array}{c}0.198^{* * *} \\
(0.015)\end{array}$ & $\begin{array}{r}-0.0141 \\
(0.008)\end{array}$ \\
\hline Overlap $\times$ Post $\times$ HHI $>4000$ & $\begin{array}{r}-0.0241 \\
(0.013)\end{array}$ & $\begin{array}{c}0.0742^{* *} \\
(0.026)\end{array}$ & $\begin{array}{c}-0.219^{* * *} \\
(0.021)\end{array}$ & $\begin{array}{l}0.0344 \\
(0.020)\end{array}$ \\
\hline Population & $\begin{array}{c}-0.000423^{* * *} \\
(0.000)\end{array}$ & $\begin{array}{c}-0.000557^{* *} \\
(0.000)\end{array}$ & $\begin{array}{c}0.000457^{*} \\
(0.000)\end{array}$ & $\begin{array}{c}-0.000390^{* *} \\
(0.000)\end{array}$ \\
\hline Average Income & $\begin{array}{c}0.00159 \\
(0.001)\end{array}$ & $\begin{array}{c}-0.00368 \\
(0.003)\end{array}$ & $\begin{array}{c}-0.0133^{* * *} \\
(0.002)\end{array}$ & $\begin{array}{c}0.0124^{* * *} \\
(0.002)\end{array}$ \\
\hline Discounters Market Share & $\begin{array}{c}0.0496^{* *} \\
(0.018)\end{array}$ & $\begin{array}{l}0.0450 \\
(0.031)\end{array}$ & $\begin{array}{c}-0.0978^{* * *} \\
(0.029)\end{array}$ & $\begin{array}{c}0.147^{* * *} \\
(0.034)\end{array}$ \\
\hline Net Sales Floor & $\begin{array}{c}0.00000434 \\
(0.000)\end{array}$ & $\begin{array}{c}0.0000214^{* * *} \\
(0.000)\end{array}$ & $\begin{array}{c}-0.00000906^{* *} \\
(0.000)\end{array}$ & $\begin{array}{c}-0.00000274 \\
(0.000)\end{array}$ \\
\hline House Value & $\begin{array}{c}0.000333^{* * *} \\
\quad(0.000)\end{array}$ & $\begin{array}{c}0.000438^{* * *} \\
(0.000)\end{array}$ & $\begin{array}{c}0.000636^{* * *} \\
(0.000)\end{array}$ & $\begin{array}{c}0.000141^{*} \\
(0.000)\end{array}$ \\
\hline HHI > 4000 & $\begin{array}{c}0.0421^{* * *} \\
(0.011)\end{array}$ & $\begin{array}{r}-0.0240 \\
(0.018)\end{array}$ & $\begin{array}{c}0.173^{* * *} \\
(0.017)\end{array}$ & $\begin{array}{r}-0.0326 \\
(0.017)\end{array}$ \\
\hline Quarter & $\begin{array}{c}0.0102^{* * *} \\
(0.001)\end{array}$ & $\begin{array}{c}0.0167^{* * *} \\
(0.001)\end{array}$ & $\begin{array}{c}0.00229^{*} \\
(0.001)\end{array}$ & $\begin{array}{c}0.0103^{* * *} \\
(0.001)\end{array}$ \\
\hline Constant & $\begin{array}{c}0.996^{* * *} \\
(0.108)\end{array}$ & $\begin{array}{l}-0.467^{*} \\
(0.220) \\
\end{array}$ & $\begin{array}{c}2.904^{* * *} \\
(0.226) \\
\end{array}$ & $\begin{array}{c}0.812^{* * *} \\
(0.149) \\
\end{array}$ \\
\hline Observations & 216060 & 77605 & 71960 & 51881 \\
\hline$R^{2}$ & .8871619 & .8412363 & .8916562 & .9499007 \\
\hline
\end{tabular}

Clustered-robust standard errors at the category-store level in parentheses. We control for fixed effect at the category-insignia level as well as a time trend and quarterly seasonal dummies. The symbols ***, **, * denote significance level at the $1 \%, 5 \%$, and $10 \%$ significance level, respectively. 
Table 9: Interaction with high divestiture: Price

\begin{tabular}{|c|c|c|c|c|}
\hline & $\begin{array}{c}\text { (1) } \\
\text { Full sample }\end{array}$ & $\begin{array}{c}(2) \\
\text { C1000 }\end{array}$ & $\begin{array}{c}(3) \\
\text { Jumbo }\end{array}$ & $\begin{array}{c}(4) \\
\text { Competitors }\end{array}$ \\
\hline Post & $\begin{array}{c}-0.148^{* * *} \\
(0.019)\end{array}$ & $\begin{array}{c}-0.112^{* * *} \\
(0.029)\end{array}$ & $\begin{array}{c}-0.143^{* * *} \\
(0.038)\end{array}$ & $\begin{array}{c}-0.203^{* * *} \\
(0.035)\end{array}$ \\
\hline Overlap & $\begin{array}{c}-0.00678 \\
(0.009)\end{array}$ & $\begin{array}{c}-0.00723 \\
(0.014)\end{array}$ & $\begin{array}{c}-0.00463 \\
(0.020)\end{array}$ & $\begin{array}{r}-0.0127 \\
(0.016)\end{array}$ \\
\hline Overlap $\times$ Post & $\begin{array}{c}0.00329 \\
(0.026)\end{array}$ & $\begin{array}{c}0.00164 \\
(0.043)\end{array}$ & $\begin{array}{c}0.00641 \\
(0.039)\end{array}$ & $\begin{array}{l}0.0130 \\
(0.046)\end{array}$ \\
\hline Overlap $\times$ Post $\times$ Divestiture & $\begin{array}{c}0.00834 \\
(0.038)\end{array}$ & $\begin{array}{c}0.00551 \\
(0.054)\end{array}$ & $\begin{array}{l}0.0135 \\
(0.053)\end{array}$ & $\begin{array}{l}0.0345 \\
(0.100)\end{array}$ \\
\hline Population & $\begin{array}{c}-0.000164 \\
(0.000)\end{array}$ & $\begin{array}{c}-0.000213 \\
(0.000)\end{array}$ & $\begin{array}{c}-0.000195 \\
(0.000)\end{array}$ & $\begin{array}{c}-0.0000617 \\
(0.000)\end{array}$ \\
\hline Average Income & $\begin{array}{c}0.00192 \\
(0.001)\end{array}$ & $\begin{array}{c}0.000366 \\
(0.003)\end{array}$ & $\begin{array}{c}0.00120 \\
(0.004)\end{array}$ & $\begin{array}{c}0.00301 \\
(0.002)\end{array}$ \\
\hline Discounters Market Share & $\begin{array}{c}0.0464^{*} \\
(0.020)\end{array}$ & $\begin{array}{c}0.00933 \\
(0.029)\end{array}$ & $\begin{array}{l}0.0647 \\
(0.080)\end{array}$ & $\begin{array}{c}0.0979^{* *} \\
(0.037)\end{array}$ \\
\hline Net Sales Floor & $\begin{array}{c}0.00000351 \\
(0.000)\end{array}$ & $\begin{array}{c}0.00000815 \\
\quad(0.000)\end{array}$ & $\begin{array}{c}-0.00000215 \\
\quad(0.000)\end{array}$ & $\begin{array}{c}0.00000143 \\
\quad(0.000)\end{array}$ \\
\hline House value & $\begin{array}{c}0.0000127 \\
(0.000)\end{array}$ & $\begin{array}{c}0.0000481 \\
(0.000)\end{array}$ & $\begin{array}{c}0.00000716 \\
(0.000)\end{array}$ & $\begin{array}{c}-0.0000292 \\
(0.000)\end{array}$ \\
\hline HHI & $\begin{array}{c}0.0000576 \\
(0.000)\end{array}$ & $\begin{array}{c}-0.000110 \\
(0.000)\end{array}$ & $\begin{array}{c}0.000148 \\
(0.000)\end{array}$ & $\begin{array}{c}-0.000190 \\
(0.001)\end{array}$ \\
\hline Divestiture & $\begin{array}{c}-0.00209 \\
(0.014)\end{array}$ & $\begin{array}{c}0.00202 \\
(0.019)\end{array}$ & $\begin{array}{r}-0.0156 \\
(0.027)\end{array}$ & $\begin{array}{c}-0.00801 \\
(0.031)\end{array}$ \\
\hline Quarter & $\begin{array}{c}0.0408^{* * *} \\
(0.003)\end{array}$ & $\begin{array}{c}0.0361^{* * *} \\
(0.004)\end{array}$ & $\begin{array}{c}0.0372^{* * *} \\
(0.005)\end{array}$ & $\begin{array}{c}0.0482^{* * *} \\
(0.005)\end{array}$ \\
\hline Constant & $\begin{array}{c}-6.529^{* * *} \\
(0.517)\end{array}$ & $\begin{array}{c}-5.501^{* * *} \\
(0.761)\end{array}$ & $\begin{array}{c}-5.855^{* * *} \\
(1.048) \\
\end{array}$ & $\begin{array}{c}-8.021^{* * *} \\
(0.930)\end{array}$ \\
\hline Observations & 109,908 & 43,645 & 27,217 & 39,046 \\
\hline$R^{2}$ & 0.9528 & 0.9512 & 0.9600 & 0.9510 \\
\hline
\end{tabular}

Clustered-robust standard errors at the product-store level in parentheses. We control for fixed effect at the product-insignia level as well as a time trend and quarterly seasonal dummies. The symbols $* * *, * *, *$ denote significance level at the $1 \%, 5 \%$, and $10 \%$ significance level, respectively. 
Table 10: Interaction with divestiture: Variety

\begin{tabular}{|c|c|c|c|c|}
\hline & $\begin{array}{c}(1) \\
\text { Full sample }\end{array}$ & $\begin{array}{c}(2) \\
\mathrm{C} 1000\end{array}$ & $\begin{array}{c}(3) \\
\text { Jumbo }\end{array}$ & $\begin{array}{c}(4) \\
\text { Competitors }\end{array}$ \\
\hline Post & $\begin{array}{c}-11.24^{* * *} \\
(1.498)\end{array}$ & $\begin{array}{c}-17.28^{* * *} \\
(2.025)\end{array}$ & $\begin{array}{c}-10.17^{* * *} \\
(1.647)\end{array}$ & $\begin{array}{l}-2.002 \\
(1.288)\end{array}$ \\
\hline overlap & $\begin{array}{c}3.438^{* * *} \\
(0.554)\end{array}$ & $\begin{array}{c}11.53^{* * *} \\
(1.281)\end{array}$ & $\begin{array}{c}1.820^{* * *} \\
(0.431)\end{array}$ & $\begin{array}{c}-4.090^{* * *} \\
(0.869)\end{array}$ \\
\hline Overlap $\times$ Post & $\begin{array}{c}-3.834^{* * *} \\
(0.447)\end{array}$ & $\begin{array}{c}-19.58^{* * *} \\
(1.925)\end{array}$ & $\begin{array}{c}13.86^{* * *} \\
(1.407)\end{array}$ & $\begin{array}{c}0.671^{*} \\
(0.314)\end{array}$ \\
\hline Overlap $\times$ Post $\times$ Divestiture & $\begin{array}{c}0.578 \\
(0.297)\end{array}$ & $\begin{array}{c}10.15^{* * *} \\
(1.217)\end{array}$ & $\begin{array}{c}-16.39^{* * *} \\
(1.709)\end{array}$ & $\begin{array}{c}-3.013^{* * *} \\
(0.478)\end{array}$ \\
\hline Population & $\begin{array}{c}-0.107^{* * *} \\
(0.013)\end{array}$ & $\begin{array}{c}-0.167^{* * *} \\
(0.022)\end{array}$ & $\begin{array}{l}0.0192 \\
(0.015)\end{array}$ & $\begin{array}{c}-0.0490^{* *} \\
(0.015)\end{array}$ \\
\hline Average Income & $\begin{array}{l}0.0457 \\
(0.090)\end{array}$ & $\begin{array}{c}-1.804^{* * *} \\
(0.245)\end{array}$ & $\begin{array}{c}-1.466^{* * *} \\
(0.208)\end{array}$ & $\begin{array}{c}2.315^{* * *} \\
(0.266)\end{array}$ \\
\hline Net Sales Floor & $\begin{array}{c}0.415^{* * *} \\
(0.043)\end{array}$ & $\begin{array}{c}0.916^{* * *} \\
(0.095)\end{array}$ & $\begin{array}{c}-0.121^{* * *} \\
(0.024)\end{array}$ & $\begin{array}{c}0.110^{* * *} \\
(0.022)\end{array}$ \\
\hline House Value & $\begin{array}{c}0.0283^{* * *} \\
(0.004)\end{array}$ & $\begin{array}{c}0.0568^{* * *} \\
(0.008)\end{array}$ & $\begin{array}{c}0.0643^{* * *} \\
(0.007)\end{array}$ & $\begin{array}{c}-0.0236^{* * *} \\
(0.004)\end{array}$ \\
\hline Discounters Market Share & $\begin{array}{c}-6.851^{* * *} \\
(1.445)\end{array}$ & $\begin{array}{c}-25.91^{* * *} \\
(3.234)\end{array}$ & $\begin{array}{l}-1.795 \\
(1.970)\end{array}$ & $\begin{array}{c}12.44^{* * *} \\
(2.788)\end{array}$ \\
\hline HHI & $\begin{array}{c}-0.104^{* * *} \\
(0.013)\end{array}$ & $\begin{array}{c}-0.257^{* * *} \\
(0.030)\end{array}$ & $\begin{array}{c}0.00937 \\
(0.011)\end{array}$ & $\begin{array}{c}-0.192^{* * *} \\
(0.039)\end{array}$ \\
\hline Divestiture & $\begin{array}{c}-9.926^{* * *} \\
(0.965)\end{array}$ & $\begin{array}{c}-15.54^{* * *} \\
(1.721)\end{array}$ & $\begin{array}{c}-7.161^{* * *} \\
(0.874)\end{array}$ & $\begin{array}{c}-6.563^{* * *} \\
(1.111)\end{array}$ \\
\hline Quarter & $\begin{array}{c}1.337^{* * *} \\
(0.171)\end{array}$ & $\begin{array}{c}2.579^{* * *} \\
(0.289)\end{array}$ & $\begin{array}{c}0.244^{*} \\
(0.113)\end{array}$ & $\begin{array}{c}0.372^{*} \\
(0.145)\end{array}$ \\
\hline Constant & $\begin{array}{l}-100.3^{* *} \\
(35.841)\end{array}$ & $\begin{array}{c}-336.7^{* * *} \\
(56.505)\end{array}$ & $\begin{array}{l}146.9^{* * *} \\
(22.743)\end{array}$ & $\begin{array}{c}67.12^{*} \\
(31.699)\end{array}$ \\
\hline $\begin{array}{l}\text { Observations } \\
R^{2}\end{array}$ & $\begin{array}{c}182146 \\
.8770395\end{array}$ & $\begin{array}{c}73503 \\
.8333096\end{array}$ & $\begin{array}{c}58254 \\
.9005832\end{array}$ & $\begin{array}{c}50389 \\
.9420009\end{array}$ \\
\hline
\end{tabular}

Clustered-robust standard errors at the category-store level in parentheses. We control for fixed effect at the category-insignia level as well as a time trend and quarterly seasonal dummies. The symbols $* * *, * *, *$ denote significance level at the $1 \%, 5 \%$, and $10 \%$ significance level, respectively. 
Table 11: Interaction with divestiture: Average Price

\begin{tabular}{|c|c|c|c|c|}
\hline & $\begin{array}{c}\text { (1) } \\
\text { Full sample }\end{array}$ & $\begin{array}{c}(2) \\
\text { C1000 }\end{array}$ & $\begin{array}{c}(3) \\
\text { Jumbo }\end{array}$ & $\begin{array}{c}(4) \\
\text { Competitors }\end{array}$ \\
\hline Post & $\begin{array}{c}-0.0464^{* * *} \\
(0.008)\end{array}$ & $\begin{array}{l}0.00577 \\
(0.014)\end{array}$ & $\begin{array}{c}-0.166^{* * *} \\
(0.016)\end{array}$ & $\begin{array}{c}0.0273^{* * *} \\
(0.007)\end{array}$ \\
\hline Overlap & $\begin{array}{c}-0.00378 \\
(0.004)\end{array}$ & $\begin{array}{r}0.0257^{*} \\
(0.010)\end{array}$ & $\begin{array}{c}0.00567 \\
(0.008)\end{array}$ & $\begin{array}{c}-0.0233^{* * *} \\
(0.006)\end{array}$ \\
\hline Overlap $\times$ Post & $\begin{array}{c}0.0579^{* * *} \\
(0.009)\end{array}$ & $\begin{array}{c}-0.0391^{*} \\
(0.015)\end{array}$ & $\begin{array}{c}0.264^{* * *} \\
(0.020)\end{array}$ & $\begin{array}{l}-0.0127 \\
(0.009)\end{array}$ \\
\hline Overlap $\times$ Post $\times$ Divestiture & $\begin{array}{c}-0.133^{* * *} \\
(0.015)\end{array}$ & $\begin{array}{c}-0.0276 \\
(0.015)\end{array}$ & $\begin{array}{c}-0.319^{* * *} \\
(0.034)\end{array}$ & $\begin{array}{c}-0.0389^{*} \\
(0.018)\end{array}$ \\
\hline Population & $\begin{array}{c}-0.000220^{*} \\
(0.000)\end{array}$ & $\begin{array}{c}-0.000629^{* * *} \\
(0.000)\end{array}$ & $\begin{array}{c}0.000794^{* * *} \\
(0.000)\end{array}$ & $\begin{array}{c}-0.000580^{* * *} \\
(0.000)\end{array}$ \\
\hline Average Income & $\begin{array}{c}-0.000349 \\
(0.001)\end{array}$ & $\begin{array}{c}-0.00383 \\
(0.003)\end{array}$ & $\begin{array}{c}-0.0219^{* * *} \\
(0.003)\end{array}$ & $\begin{array}{c}0.0151^{* * *} \\
(0.002)\end{array}$ \\
\hline Discounters Market Share & $\begin{array}{c}0.0705^{* * *} \\
(0.018)\end{array}$ & $\begin{array}{c}0.0732^{*} \\
(0.031)\end{array}$ & $\begin{array}{c}-0.185^{* * *} \\
(0.040)\end{array}$ & $\begin{array}{c}0.119^{* * *} \\
(0.028)\end{array}$ \\
\hline Net Sales Floor & $\begin{array}{c}-0.00000218 \\
(0.000)\end{array}$ & $\begin{array}{c}0.0000157^{*} \\
(0.000)\end{array}$ & $\begin{array}{c}-0.0000207^{* * *} \\
(0.000)\end{array}$ & $\begin{array}{c}-0.00000465 \\
(0.000)\end{array}$ \\
\hline House Value & $\begin{array}{c}0.000369^{* * *} \\
(0.000)\end{array}$ & $\begin{array}{c}0.000445^{* * *} \\
(0.000)\end{array}$ & $\begin{array}{c}0.000676^{* * *} \\
(0.000)\end{array}$ & $\begin{array}{c}0.0000563 \\
(0.000)\end{array}$ \\
\hline HHI & $\begin{array}{c}0.00128^{* * *} \\
(0.000)\end{array}$ & $\begin{array}{c}0.000457 \\
(0.000)\end{array}$ & $\begin{array}{c}0.00208^{* * *} \\
(0.000)\end{array}$ & $\begin{array}{c}-0.000180 \\
(0.000)\end{array}$ \\
\hline Divestiture & $\begin{array}{c}0.0202^{* *} \\
(0.006)\end{array}$ & $\begin{array}{l}0.0204 \\
(0.011)\end{array}$ & $\begin{array}{c}-0.00271 \\
(0.011)\end{array}$ & $\begin{array}{c}-0.00121 \\
(0.013)\end{array}$ \\
\hline Quarter & $\begin{array}{c}0.0116^{* * *} \\
(0.001)\end{array}$ & $\begin{array}{c}0.0149^{* * *} \\
(0.001)\end{array}$ & $\begin{array}{c}0.00878^{* * *} \\
(0.001)\end{array}$ & $\begin{array}{c}0.00676^{* * *} \\
(0.001)\end{array}$ \\
\hline Constant & $\begin{array}{c}0.628^{* * *} \\
(0.127)\end{array}$ & $\begin{array}{l}-0.174 \\
(0.269)\end{array}$ & $\begin{array}{c}1.629^{* * *} \\
(0.201)\end{array}$ & $\begin{array}{c}1.414^{* * *} \\
(0.145)\end{array}$ \\
\hline Observations & 174,278 & 62,979 & 58,174 & 53,125 \\
\hline$R^{2}$ & 0.8828 & 0.8439 & 0.8825 & 0.9461 \\
\hline
\end{tabular}

Clustered-robust standard errors at the category-store level in parentheses. We control for fixed effect at the category-insignia level as well as a time trend and quarterly seasonal dummies. The symbols ***, **, * denote significance level at the $1 \%, 5 \%$, and $10 \%$ significance level, respectively. 
Table 12: Heterogenous Effects of Rebranding

\begin{tabular}{|c|c|c|c|}
\hline & $(1)$ & $(2)$ & $(1)$ \\
\hline & Price & Variety & Average Price \\
\hline \multirow[t]{2}{*}{ Post } & $-0.0857^{* * *}$ & 0.368 & -0.0183 \\
\hline & $(0.024)$ & $(0.657)$ & $(0.012)$ \\
\hline \multirow[t]{2}{*}{ Overlap } & -0.00750 & $10.27^{* * *}$ & $0.0218^{*}$ \\
\hline & $(0.018)$ & $(1.183)$ & $(0.011)$ \\
\hline \multirow[t]{2}{*}{ Overlap $\times$ Post } & 0.0103 & $-9.202^{* * *}$ & $-0.0535^{* *}$ \\
\hline & $(0.062)$ & $(0.959)$ & $(0.017)$ \\
\hline \multirow[t]{2}{*}{ Overlap $\times$ Post $\times$ No re-branding } & -0.0180 & $-7.584^{* * *}$ & 0.0248 \\
\hline & $(0.061)$ & $(0.848)$ & $(0.017)$ \\
\hline \multirow[t]{2}{*}{ Population } & -0.000197 & $-0.153^{* * *}$ & $-0.000422^{*}$ \\
\hline & $(0.000)$ & $(0.021)$ & $(0.000)$ \\
\hline \multirow[t]{2}{*}{ Average Income } & 0.000613 & $-0.718^{* * *}$ & -0.00435 \\
\hline & $(0.003)$ & $(0.151)$ & $(0.003)$ \\
\hline \multirow[t]{2}{*}{ Discounters Market Share } & 0.0162 & $-18.22^{* * *}$ & 0.0587 \\
\hline & $(0.033)$ & $(2.692)$ & $(0.032)$ \\
\hline \multirow[t]{2}{*}{ HHI } & -0.000119 & $-0.233^{* * *}$ & 0.000448 \\
\hline & $(0.000)$ & $(0.028)$ & $(0.000)$ \\
\hline \multirow[t]{2}{*}{ Net Sales Floor } & 0.00000957 & $0.804^{* * *}$ & $0.0000163^{* *}$ \\
\hline & $(0.000)$ & $(0.088)$ & $(0.000)$ \\
\hline \multirow[t]{2}{*}{ House Value } & 0.0000528 & $0.0346^{* * *}$ & $0.000449^{* * *}$ \\
\hline & $(0.000)$ & $(0.006)$ & $(0.000)$ \\
\hline \multirow[t]{2}{*}{ No-rebranded store } & 0.00230 & $6.543^{* * *}$ & -0.0134 \\
\hline & $(0.012)$ & $(0.809)$ & $(0.008)$ \\
\hline \multirow[t]{2}{*}{ Quarter } & $0.0351^{* * *}$ & $0.962^{* * *}$ & $0.0164^{* * *}$ \\
\hline & $(0.003)$ & $(0.153)$ & $(0.001)$ \\
\hline \multirow[t]{2}{*}{ Constant } & $-5.329^{* * *}$ & -34.58 & -0.400 \\
\hline & $(0.691)$ & $(31.451)$ & $(0.225)$ \\
\hline Observations & 48,362 & 90,484 & 77,605 \\
\hline$R^{2}$ & 0.9510 & 0.8347 & 0.8412 \\
\hline
\end{tabular}

We only present regressions for C1000. Clustered-robust standard errors at the product/category-store level in parentheses depending on the outcome variable. We control for fixed effect at the product/category-insignia level (depending on the outcomes) as well as a time trend and quarterly seasonal dummies. The symbols $* * *, * *, *$ denote significance level at the $1 \%, 5 \%$, and $10 \%$ significance level, respectively. 


\section{Appendices}

\section{Online appendix - Not for publication}

\section{A. Propensity Score Matching for Areas Selection and the Stores' choice}

This appendix describes the methodology used to select our units of observation: the stores. The ACM provided us with historical location data on all supermarkets in the Netherlands, the 'Supermarkt gids' database, which lists geographic data (including addresses, postal code, city, province) together with additional information (e.g., availability of parking or automatic counters). In 2013, the guide counts 6,641 stores. Our budget allowed selecting a total of 171 stores. As described in the paper, we compare the merging stores in the overlapping areas (treated stores) and the merging stores in the non-overlapping areas (control stores). To select appropriate stores for our analysis, we started by identifying the overlapping and non-overlapping areas. There were 253 overlapping areas out of a total of 1,145 areas in the whole sample.

In order to identify the areas for the selection of 171 stores, we follow an approach based on the propensity score matching (PSM) methodology. PSM was developed as a technique to correct for sample selection bias that may affect the estimation of the treatment effect in non-randomized experiments. In randomized experiments, the results in the treated and control groups may often be directly compared because the two samples are likely to be similar (the assignment to the treated and control 'status' is indeed random). In non-randomized experiments, the direct comparison between the treated and control units may be misleading because units exposed to the treatment systematically differ from the units not exposed to the treatment. Propensity score matching allows to group treated and control units according to their probability of receiving the treatment based on observable characteristics. The propensity score is defined as the conditional probability of receiving the treatment given a set of pre-treatment variables:

$$
p(X)=\operatorname{Pr}(D=1 \mid X)
$$

The PSM technique allows for collapsing the multiple dimensions along which treated and control units might differ into one single dimension: the propensity score. In the case under examination, the probability of receiving the treatment may coincide with the probability of being 
an overlapping area. We computed a propensity score for each area and grouped overlapping and non-overlapping areas according to the similarity of their score. We estimate the probability of treatment running a logistic regression. The dependent variable is a discrete variable that takes value one if the area is overlapping and zero otherwise. The independent variables include demand and supply factors that may influence the decision of a supermarket insignia to locate its stores in a given area.

We then group treated and control cities according their estimated scores. Treated and control units with exactly the same propensity score are rarely found. Instead, each treated unit is usually matched with its closest control, as indicated by the propensity score value. We had to allow for multiple uses of the same control city in order to maximize the number of treated cities included in our final sample (i.e., to prevent some treated cities from falling 'off support'). ${ }^{32}$

Post matching, we then checked if treated and control areas are indeed similar in observable characteristics except for the treatment. We do that by testing the equality of means for the relevant explanatory variables and we conclude that the means across the treated and control areas are not statistically different (see Table 13).

\footnotetext{
${ }^{32}$ In some of the control matched cities, there were no merging stores. The empirical strategy underpinning the analysis across areas requires that at least one of the merging chains is present in the non-overlapping (control) cities. For this reason, we could not limit the match to the 'nearest neighbor', but had to extend the match to the third nearest neighbor.
} 
Table 13: Equality of the means between treated and control areas

\begin{tabular}{llllll}
\hline \hline & \multicolumn{2}{c}{ Means } & \multicolumn{3}{c}{ t-test } \\
& Treated & Control & \%bias & t-test & $\mathrm{p}>t$ \\
\hline Pscore & 0.3906 & 0.3712 & 10.8 & 1.18 & 0.237 \\
Average population density & 13,580 & 11,830 & 8.4 & 0.78 & 0.434 \\
Average store size & 922.67 & 927.57 & -1.6 & -0.18 & 0.855 \\
Average income & $2,407.7$ & $2,416.4$ & -2.8 & -0.31 & 0.757 \\
Number of stores (squared) & 37.226 & 31.381 & 8.0 & 0.74 & 0.459 \\
HHI & $4,731.1$ & $5,088.7$ & -11.7 & -1.27 & 0.204 \\
Average land price & 142.34 & 147.41 & -5.2 & -0.52 & 0.604 \\
HHI Discounters & $1,757.2$ & $1,776.9$ & -1.0 & -0.11 & 0.916 \\
\hline
\end{tabular}

Table 14 presents the list of areas obtained from the matching process and indicates those areas that, among the treated ones, were deemed problematic (i.e. where the merged entity had a combined market share above 50\%). Moreover, we highlight in which of the former areas a divestiture was required.

Table 14: List of matched areas

\begin{tabular}{|c|c|c|c|c|}
\hline City & Province & Treated & $\begin{array}{c}\text { Overlap } \\
\mathrm{MS}>50 \%\end{array}$ & $\begin{array}{c}\text { Overlap } \\
\mathrm{MS}<50 \%\end{array}$ \\
\hline 'S-HEERENBERG & Gelderland & Treated & 0 & 1 \\
\hline DEN BURG & Noord-Holland & Untreated & 0 & 0 \\
\hline DEN HAM OV & Overijssel & Treated & 1 & 0 \\
\hline TERSCHELLING FORMERUM & Friesland & Untreated & 0 & 0 \\
\hline BARNEVELD & Gelderland & Treated & 0 & 1 \\
\hline ASSENDELFT & Noord-Holland & Untreated & 0 & 0 \\
\hline BEMMEL & Gelderland & Treated & 0 & 1 \\
\hline BEST & Noord-Brabant & Untreated & 0 & 0 \\
\hline BODEGRAVEN & Zuid-Holland & Treated & 0 & 1 \\
\hline OOSTERBEEK & Gelderland & Untreated & 0 & 0 \\
\hline CAPELLE AAN DEN IJSSEL & Zuid-Holland & Treated & 0 & 1 \\
\hline LISSE & Zuid-Holland & Untreated & 0 & 0 \\
\hline DE MEERN & Utrecht & Treated & 0 & 1 \\
\hline DALFSEN & Overijssel & Untreated & 0 & 0 \\
\hline LICHTENVOORDE & Gelderland & Treated & 1 & 0 \\
\hline
\end{tabular}




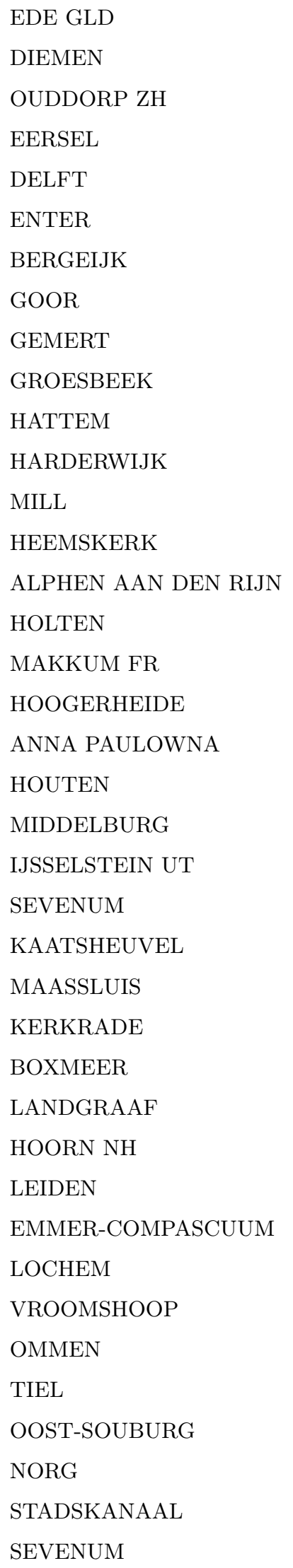

\begin{tabular}{|c|c|c|}
\hline Gelderland & Untreated & 0 \\
\hline Noord-Holland & Treated & 0 \\
\hline Zuid-Holland & Untreated & 0 \\
\hline Noord-Brabant & Treated & 0 \\
\hline Zuid-Holland & Untreated & 0 \\
\hline Overijssel & Treated & 0 \\
\hline Noord-Brabant & Untreated & 0 \\
\hline Overijssel & Treated & 0 \\
\hline Noord-Brabant & Untreated & 0 \\
\hline Gelderland & Treated & 0 \\
\hline Overijssel & Untreated & 0 \\
\hline Gelderland & Treated & 0 \\
\hline Noord-Brabant & Untreated & 0 \\
\hline Noord-Holland & Treated & 0 \\
\hline Zuid-Holland & Untreated & 0 \\
\hline Overijssel & Treated & 0 \\
\hline Friesland & Untreated & 0 \\
\hline Noord-Brabant & Treated & 0 \\
\hline Noord-Holland & Untreated & 0 \\
\hline Utrecht & Treated & 0 \\
\hline Zeeland & Untreated & 0 \\
\hline Utrecht & Treated & 1 \\
\hline Limburg & Untreated & 0 \\
\hline Noord-Brabant & Treated & 0 \\
\hline Zuid-Holland & Untreated & 0 \\
\hline Limburg & Treated & 0 \\
\hline Noord-Brabant & Untreated & 0 \\
\hline Limburg & Treated & 0 \\
\hline Noord-Holland & Untreated & 0 \\
\hline Zuid-Holland & Treated & 0 \\
\hline Drenthe & Untreated & 0 \\
\hline Gelderland & Treated & 0 \\
\hline Overijssel & Untreated & 0 \\
\hline Overijssel & Treated & 0 \\
\hline Gelderland & Untreated & 0 \\
\hline Zeeland & Treated & 0 \\
\hline Drenthe & Untreated & 0 \\
\hline Groningen & Treated & 1 \\
\hline Limburg & Untreated & 0 \\
\hline
\end{tabular}




CULEMBORG
ROOSENDAAL
ENKHUIZEN
SAPPEMEER
NIEUWE NIEDORP
SITTARD
HILLEGOM
SOEST
SMILDE
SOMEREN
ZETTEN
SON
LIENDEN
STEENBERGEN NB
EDE GLD
THOLEN
RENESSE
TWELLO
OOSTERWOLDE FR
URK
KROMMENIE
VELDHOVEN
OSS
VINKEVEEN
ZEVENHUIZEN ZH
WASSENAAR
KOLLUM
WESTERBORK
OPHEUSDEN
WIERDEN
SCHAGEN
WIJCHEN
GENNEP
WINSCHOTEN
EERBEEK
WOUDENBERG
ZEEWOLDE
ZELHEM

ZELHEM

AALSMEER

\begin{tabular}{|c|c|c|}
\hline Gelderland & Untreated & 0 \\
\hline Noord-Brabant & Treated & 0 \\
\hline Noord-Holland & Untreated & 0 \\
\hline Groningen & Treated & 0 \\
\hline Noord-Holland & Untreated & 0 \\
\hline Limburg & Treated & 0 \\
\hline Zuid-Holland & Untreated & 0 \\
\hline Utrecht & Treated & 0 \\
\hline Drenthe & Untreated & 0 \\
\hline Noord-Brabant & Treated & 0 \\
\hline Gelderland & Untreated & 0 \\
\hline Noord-Brabant & Treated & 0 \\
\hline Gelderland & Untreated & 0 \\
\hline Noord-Brabant & Treated & 0 \\
\hline Gelderland & Untreated & 0 \\
\hline Zeeland & Treated & 0 \\
\hline Zeeland & Untreated & 0 \\
\hline Gelderland & Treated & 0 \\
\hline Friesland & Untreated & 0 \\
\hline Overijssel & Treated & 0 \\
\hline Noord-Holland & Untreated & 0 \\
\hline Noord-Brabant & Treated & 0 \\
\hline Noord-Brabant & Untreated & 0 \\
\hline Utrecht & Treated & 0 \\
\hline Zuid-Holland & Untreated & 0 \\
\hline Zuid-Holland & Treated & 0 \\
\hline Friesland & Untreated & 0 \\
\hline Drenthe & Treated & 1 \\
\hline Gelderland & Untreated & 0 \\
\hline Overijssel & Treated & 0 \\
\hline Noord-Holland & Untreated & 0 \\
\hline Gelderland & Treated & 0 \\
\hline Limburg & Untreated & 0 \\
\hline Groningen & Treated & 0 \\
\hline Gelderland & Untreated & 0 \\
\hline Utrecht & Treated & 0 \\
\hline Flevoland & Untreated & 0 \\
\hline Gelderland & Treated & 0 \\
\hline Noord-Holland & Untreated & 0 \\
\hline
\end{tabular}




\begin{tabular}{lcccc} 
IJSSELSTEIN UT & Utrecht & Treated & 1 & 0 \\
CULEMBORG & Gelderland & Untreated & 0 & 0 \\
ZEVENBERGEN & Noord-Brabant & Treated & 0 & 1 \\
WOERDEN & Utrecht & Untreated & 0 & 0 \\
DEURNE & Noord-Brabant & Treated & Divestiture & 0 \\
LIENDEN & Gelderland & Untreated & 0 & 0 \\
GRAVE & Noord-Brabant & Treated & Divestiture & 0 \\
BERGEIJK & Noord-Brabant & Untreated & 0 & 0 \\
KAMPEN & Overijssel & Treated & Divestiture & 0 \\
EERBEEK & Gelderland & Untreated & 0 & 0 \\
OIRSCHOT & Noord-Brabant & Treated & Divestiture & 0 \\
DALFSEN & Overijssel & Untreated & 0 & 0 \\
RAALTE & Overijssel & Treated & Divestiture & 0 \\
VROOMSHOOP & Overijssel & Untreated & 0 & 0 \\
RAAMSDONKSVEER & Noord-Brabant & Treated & Divestiture & 0 \\
HILLEGOM & Zuid-Holland & Untreated & 0 & 0 \\
ZUIDLAREN & Drenthe & Treated & Divestiture & 0 \\
BOXMEER & Noord-Brabant & Untreated & 0 & 0 \\
IJSSELMUIDEN & Overijssel & Treated & 1 & 0 \\
BRUMMEN & Gelderland & Untreated & 0 & 0 \\
\hline
\end{tabular}

To conclude, the propensity score matching technique allows us to identify the areas from which we finally selected our sample of stores. In the next section, we describe this second selection exercise.

\section{A.0.1. The choice of stores}

Within areas of overlap and areas of non-overlap, we select a suitable number of stores from both the merging parties and the competing chains. ${ }^{33}$ However, we restrict the choice to two competitors' chains: Albert Heijn and COOP. This choice is based on a number of considerations.

First, available information on chains' strategy and the economic literature suggest that it might be appropriate to include in the analyses an explanatory variable attempting to capture "chain-specific effects." Consequently, we restrict the number of chains in order to ensure that a sufficient number of stores is available for each chain.

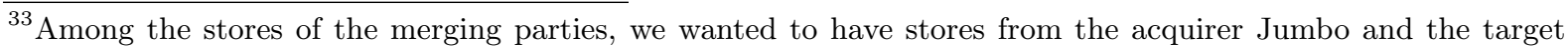
C1000. Moreover, we also tried to have stores that were re-brandend -i.e., adopted the Jumbo insigna - as well as stores that were not re-branded.
} 
Second, we want to include in our selection both a national competitor and a local competitor, to exploit any differences in their responses to a change in competition.

Third, we adjust our selection in order to take into account data availability issues. In particular, some supermarket chains - especially discounters like Aldi and Lidl - denied access to store level data. In addition, the data provider warned us about (i) missing data for some supermarket chains; and (ii) limited availability of data on private label goods in 2009 and 2010.

Our selection also attempts to ensure a widespread coverage of the Dutch territory as well as a balanced representation of merging parties and of the subset of competitors selected, across areas of overlap and areas of non-overlap. Moreover, we do not select stores from the largest cities. The main reason we excluded the largest cities from our selection is related to the difficulties of matching them with appropriate control regions. Data completeness proved to be an additional problem as supply level data are incomplete for most of the largest cities.

Concerning the kind of stores, the ACM defines a single 'product' market encompassing all supermarket formulas, including regular supermarkets, hypermarkets, and discounters. The difference between the various formulas is determined mainly by the shop size. ${ }^{34}$ The assortment size can be a further element of differentiation among stores. Hypermarkets typically have the broadest assortment (20,000 SKUs is a common figure for food products). Supermarkets typically sell between 5,000 and 10,000 different food SKUs. Finally, discounters have the narrowest assortment, typically between 1,000 and 2,000 SKUs. In our study, we follow a different approach. For each supermarket chain, we limit our selection to regular formula only, in order to focus on the stores that are the closest substitutes.

Our final selection includes over 171 different stores representing the merging parties' chains and two competitors (Albert Heijn and Coop). For this list of stores, we asked for data on turnover, volume, promotional turnover, promotional share, and variety for a selection of products, as described in the data section. Note that we have a slightly different sample for the price and variety specifications. Table 15 reports the sample of stores used in our regressions.

\footnotetext{
${ }^{34}$ In a recent study, the European Commission adopted the following definition: i) supermarkets: stores whose size is between 400 and 2,499 square meters; ii) hypermarkets: stores whose size is equal to or greater than 2500 square meters; iii) discounters: all stores size.
} 
Table 15: The sample of Stores

\begin{tabular}{llcccc}
\hline \hline & & \multicolumn{2}{c}{ Price } & \multicolumn{2}{c}{ Variety } \\
\cline { 3 - 6 } & & Overlap & Non-Overlap & Overlap & Non-Overlap \\
\hline \multirow{2}{*}{ C1000 } & Rebranded to Jumbo & 7 & 9 & 7 & 10 \\
& Not rebranded & 19 & 13 & 20 & 13 \\
\multirow{3}{*}{ Jumbo } & Jumbo & 21 & 14 & 23 & 14 \\
Competitors & Albert Heijn & 14 & 15 & 14 & 15 \\
& Coop & 3 & 3 & 5 & 3 \\
\hline
\end{tabular}




\section{B. List of SKUs}

The following table presents a list of the selected SKUs per products' category used in the price analysis. In the cells we report the number of stores for which we have information on that particular product.

Table 16: Selected SKUs per Product Category - Price Analysis

\begin{tabular}{|c|c|c|c|c|c|c|c|}
\hline \multirow[b]{2}{*}{ Category } & & \multirow[t]{2}{*}{ PRODUCTS } & \multicolumn{5}{|c|}{ CHAINS } \\
\hline & & & C1000 & Jumbo & $\mathrm{SdB}$ & Coop & $\mathrm{AH}$ \\
\hline \multirow[t]{10}{*}{ Cleaners } & A-brand & Ajax & 61 & 66 & 37 & 10 & 50 \\
\hline & & CITRONELLA & & & 37 & & \\
\hline & & WITTE REUS & 61 & 66 & & 10 & 50 \\
\hline & Private label & Albert heijn & & & & & 50 \\
\hline & & C1000 & 61 & & & & \\
\hline & & JUMBO & & 66 & & & \\
\hline & & MARKANT & & & & 10 & \\
\hline & & O'LACY & & 66 & & & \\
\hline & & PERFEKT & & & & & \\
\hline & & SUPER & & & 37 & & \\
\hline \multirow[t]{9}{*}{ Coffee } & A-brand & Douwe egberts & & & 37 & 10 & 50 \\
\hline & & KANIS \& GUNNINK & 61 & 66 & 37 & 10 & 50 \\
\hline & & VAN NELLE SUPRA & 61 & 66 & & & \\
\hline & Private label & C1000 & 61 & & & & \\
\hline & & HOOGVLIET & & & & & \\
\hline & & JUMBO & & 66 & & & \\
\hline & & MARKANT & & & & 10 & \\
\hline & & PERLA & & & & & 50 \\
\hline & & SUPER DE BOER & & & 37 & & \\
\hline \multirow[t]{9}{*}{ Cola } & A-brand & Coca cola & 61 & 66 & 37 & 10 & 50 \\
\hline & & PEPSI & 61 & 66 & 37 & 10 & 50 \\
\hline & Private label & Albert heijn & & & & & 50 \\
\hline & & C1000 & 61 & & & & \\
\hline & & JUMBO & & 66 & & & \\
\hline & & MARKANT & & & & 10 & \\
\hline & & O'LACY & & 66 & & & \\
\hline & & PERFEKT & & & & & \\
\hline & & SUPER & & & 37 & & \\
\hline Diapers & A-brand & Huggies super dry & & 66 & & & 50 \\
\hline
\end{tabular}




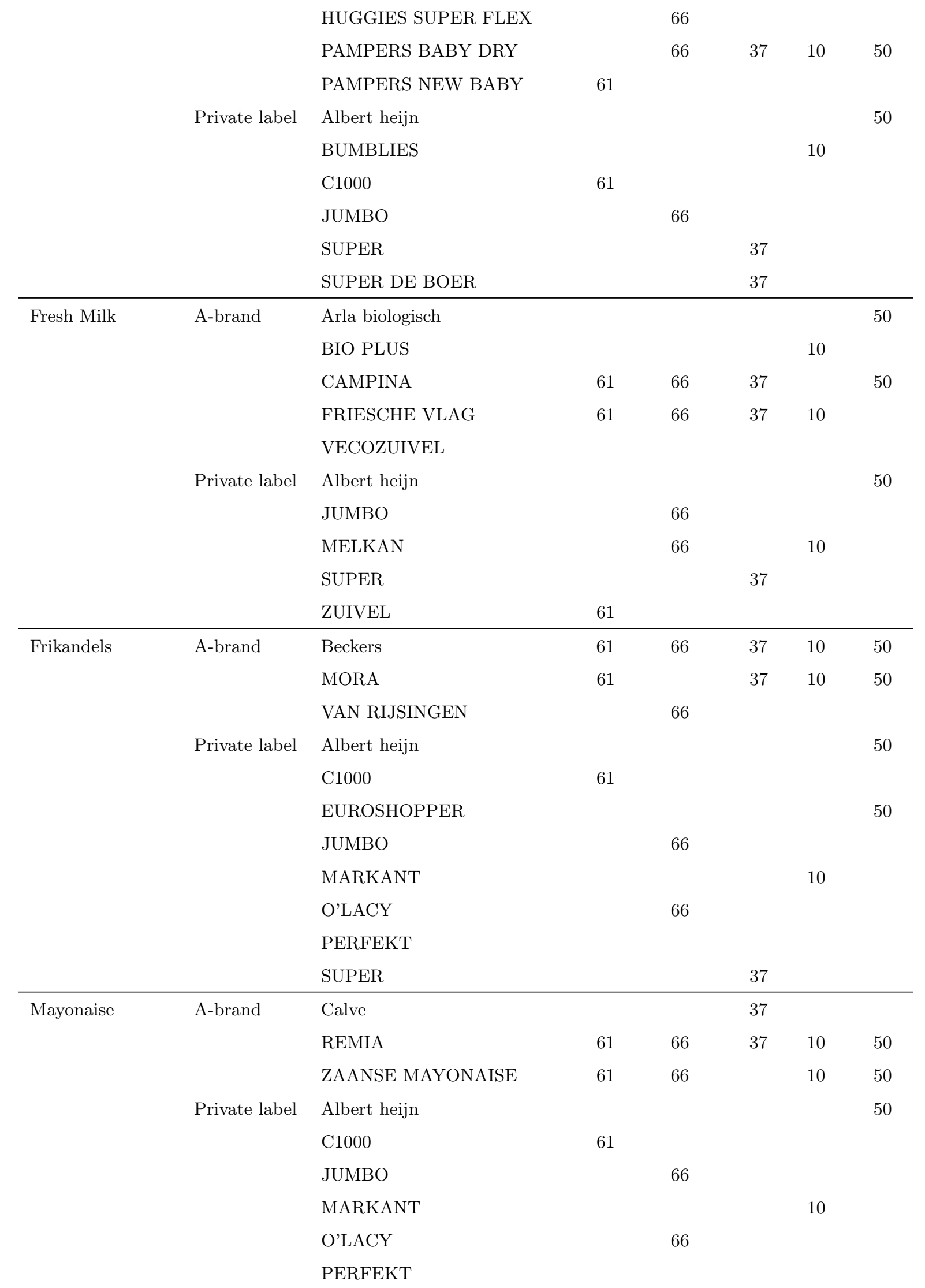




\begin{tabular}{|c|c|c|c|c|c|c|c|}
\hline & & SUPER DE BOER & & & 37 & & \\
\hline \multirow[t]{11}{*}{ Olive Oil } & A-brand & Bertolli & 61 & 66 & 37 & 10 & 50 \\
\hline & & BIO PLUS & & 66 & 37 & 10 & \\
\hline & & BIORGANIC & & & & & \\
\hline & & MONINI & 61 & & & & 50 \\
\hline & Private label & $\mathrm{C} 1000$ & 61 & & & & \\
\hline & & EUROSHOPPER & & & & & 50 \\
\hline & & JUMBO & & 66 & & & \\
\hline & & MARKANT & & & & 10 & \\
\hline & & O'LACY'S & & 66 & & & \\
\hline & & PERFEKT & & & & & \\
\hline & & SUPER DE BOER & & & 37 & & \\
\hline \multirow[t]{9}{*}{ Sanitary Napkins } & A-brand & Always ultra & 61 & & & 10 & \\
\hline & & ALWAYS ULTRA NORMAAL & 61 & & & 10 & \\
\hline & & KOTEX MAXI SUPER & & 66 & 37 & & 50 \\
\hline & & LIBRESSE INVISIBLE & 61 & 66 & 37 & 10 & 50 \\
\hline & Private label & Albert heijn & & & & & 50 \\
\hline & & $\mathrm{C} 1000$ & 61 & & & & \\
\hline & & JUMBO & & 66 & & & \\
\hline & & NEWWAY & & 66 & & 10 & \\
\hline & & SUPER & & & 37 & & \\
\hline \multirow[t]{3}{*}{ Shampoo } & A-brand & Guhl & 61 & 66 & 37 & & 50 \\
\hline & & NEUTRAL & & & & 10 & \\
\hline & & SYOSS SHINE BOOST & & & & & \\
\hline \multirow[t]{9}{*}{ Toiletpaper } & A-brand & Edet soft & 61 & 66 & 37 & 10 & 50 \\
\hline & & PAGE KUSSENZACHT & & 66 & 37 & 10 & 50 \\
\hline & & PAGE ZACHT EN STERK & 61 & & & & \\
\hline & Private label & Albert heijn & & & & & 50 \\
\hline & & $\mathrm{C} 1000$ & 61 & & & & \\
\hline & & JUMBO & & 66 & & & \\
\hline & & MARKANT & & & & 10 & \\
\hline & & PERFEKT & & & & & \\
\hline & & SUPER DE BOER & & & 37 & & \\
\hline
\end{tabular}




\section{Local Variation}

As explained in section, in this appendix we more carefully analyze the geographic extent of price and assortment variability. First, we graphically analyze the price and assortment distributions for different supermarket chains of each SKUs at different points in time by means of boxplots. Second, we compute a coefficient of variation for each SKU and each month. For prices, we first compute the standard deviation of price from SKU's average price of that month. We then divide the price standard deviation of each SKU by the average price of that SKU in order to obtain a measure of the price dispersion independent of the price level. In a similar way, we compute the coefficient of variation for variety. Below, we present a selection of the discussed graphs. Figures 5 to 9 show the geographic price variability of five SKUs, while figures 10 to 13 show geographic variability in stores' assortment for four selected categories.

For each SKU (category), the first graph (boxplot) shows the price (variety) dispersion in May 2010, May 2011, May 2012, and May 2013. These graphs allows comparing the price (variety) dispersion of Jumbo with:

- price (variety) dispersion of the same SKU (category) sold by two competitors: the market leader (Albert Heijn) and a smaller player (Coop). Both reportedly have adopted a national pricing strategy.

- price (variety) dispersion of the same SKU (category) sold by C1000. The data in the graph refer to those C1000 stores that did not change their insignia to the Jumbo's Insignia during the period under study, even after the merger.

The second graph shows the cumulative distribution function of the coefficient of variation for prices (figures 5 to 9 ) and variety (figures 10 to 13) respectively. The coefficient of variation for price (variety) of each SKU (category), for each point in time and for each chain, is computed as the ratio between the price (variety) standard deviation and the average price (variety), and then plotted in a single graph, irrespective of the moment of their measurement. The cumulative distribution function of the coefficient of variation shows the cumulative probability that the coefficient of variation is below a given threshold. If the distribution concentrates around zero, the coefficient of variation over the period of analysis for a given chain and SKU (category) is likely to be low; hence the conclusion is that the chain sets national prices (assortment), i.e. there is no variation across stores. A more evenly distribution, instead, shows that the coefficient of 
variation is higher than zero. In the latter case, we would expect local prices (variety). The inclusion of the cumulative distribution function of different chains in the same graph allows across-chains comparisons. Chains whose curve is close to the vertical axis, are expected to set national prices (have national assortment) with higher probability than the other chains: indeed, for that chain, the probability that the variation coefficient is around zero is higher. In the first panel, Jumbo is compared to its competitors Albert Heijn and Coop; in the second panel, Jumbo is compared to the target chain in the acquisition of C1000.

Figure 5: Box-plot (first panel) and cumulative distribution function of the coefficient of variation (second panel) for Ajax (cleaner brand)

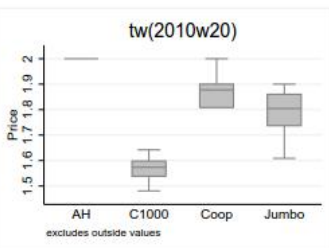

$\operatorname{tw}(2012 \mathrm{w} 20)$

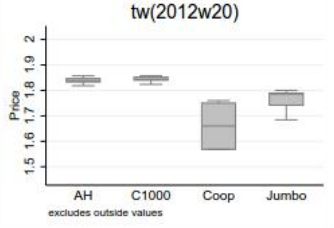

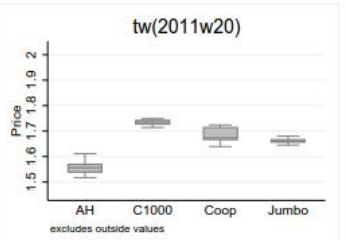

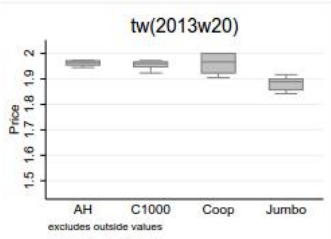

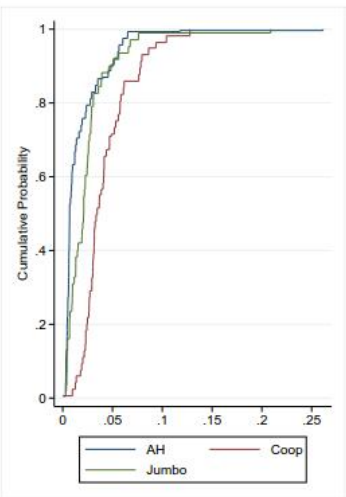

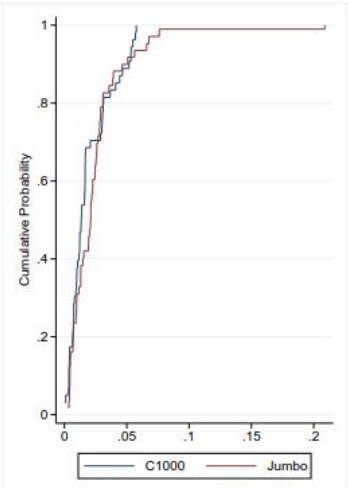

Source: our elaboration on IRI data.

Figure 6: Box-plot (first panel) and cumulative distribution function of the coefficient of variation (second panel) for REMIA (a mayonnaise brand)
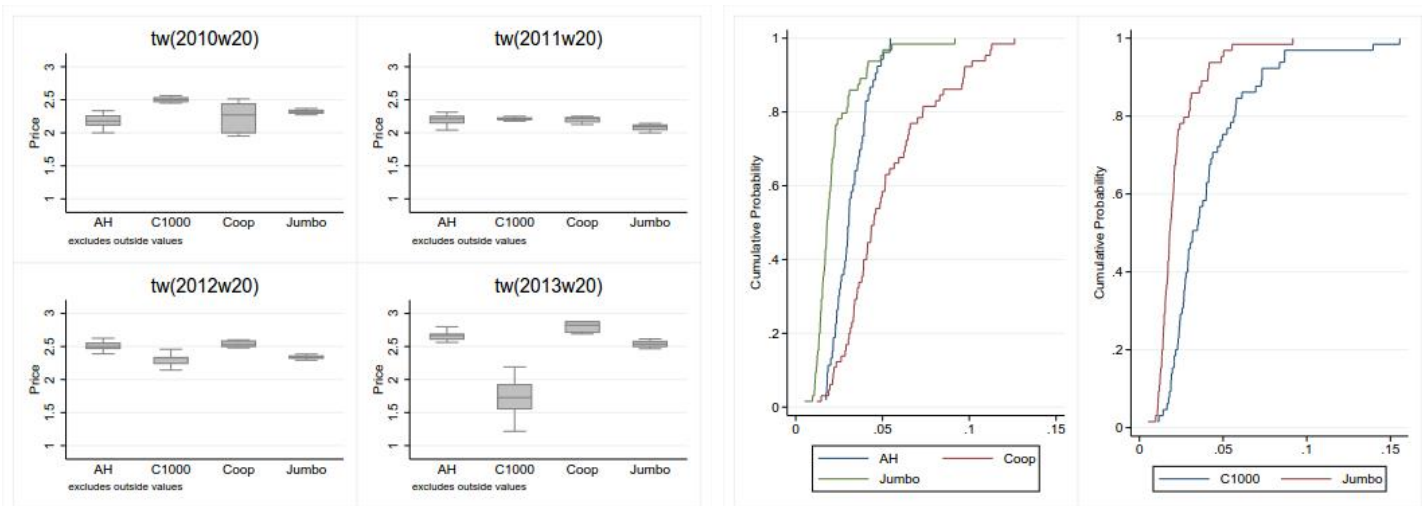

Source: Our elaboration on IRI data. 
Figure 7: Box-plot (first panel) and cumulative distribution function of the coefficient of variation (second panel) for Kanis \& Gunnink (coffee brand)

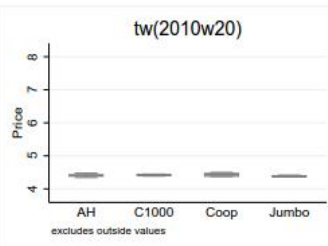

$\mathrm{tw}(2012 \mathrm{w} 20)$

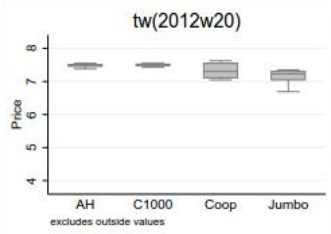

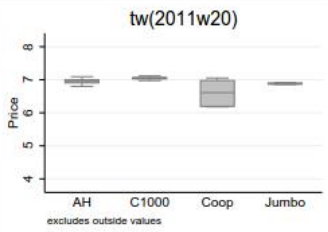

$\operatorname{tw}(2013 w 20)$

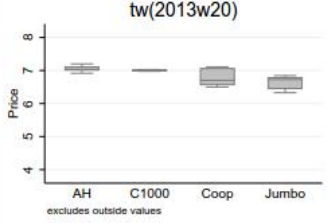

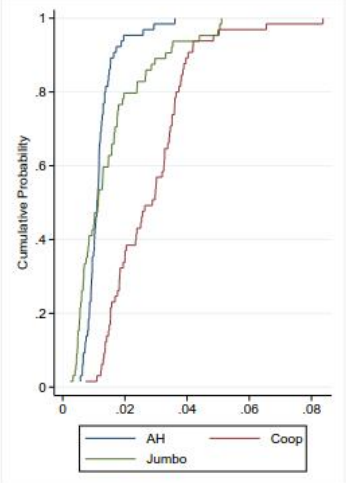

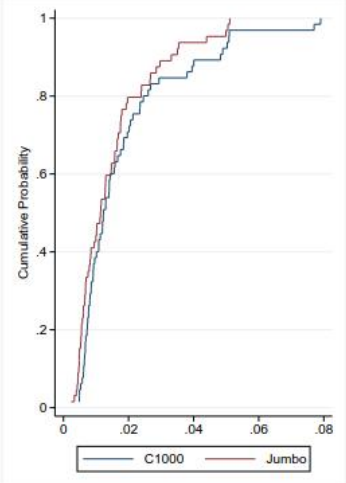

Source: Our elaboration on IRI data.

Figure 8: Box-plot (first panel) and cumulative distribution function of the coefficient of variation (second panel) for private label coffee brands
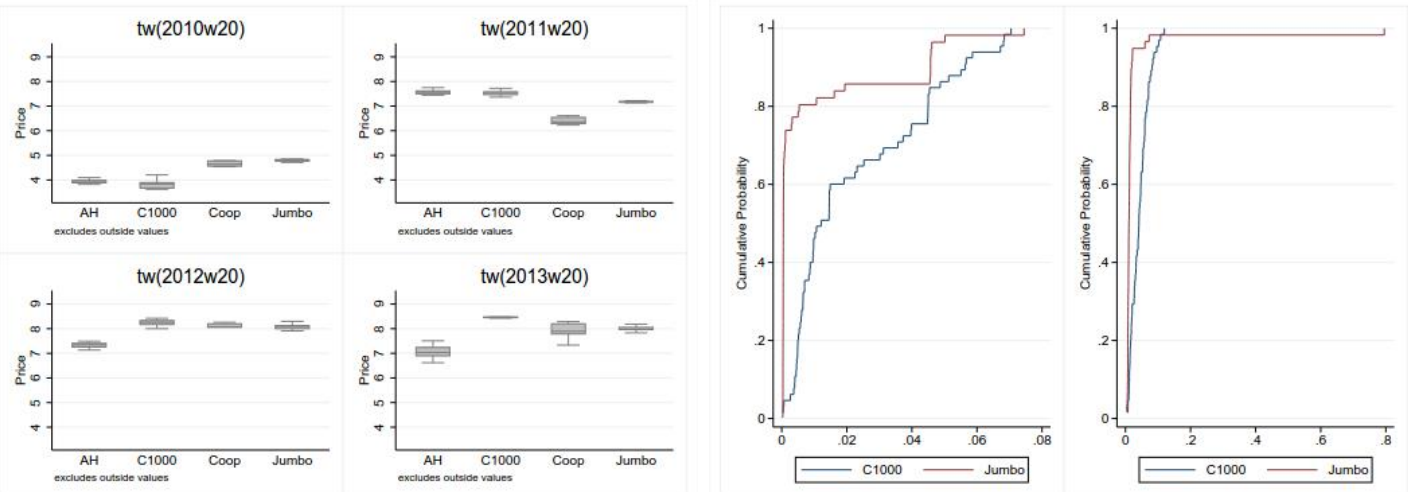

Source: Our elaboration on IRI data. 
Figure 9: Box-plot (first panel) and cumulative distribution function of the coefficient of variation (second panel) for Coca cola (brand)
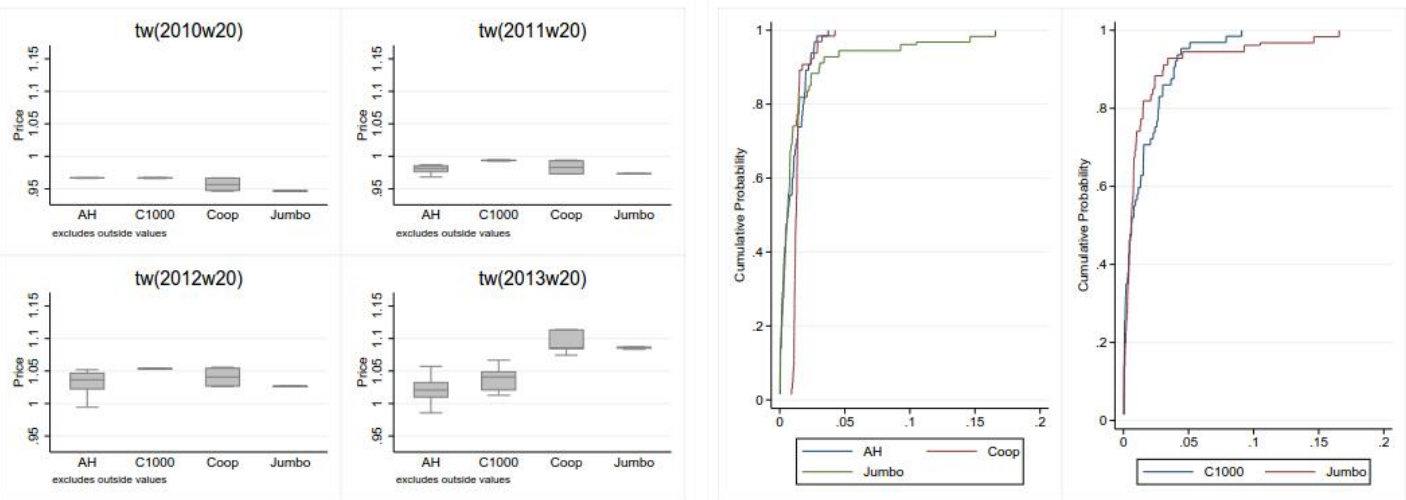

Source: Our elaboration on IRI data. 
Figure 10: Box-plot (first panel) and cumulative distribution function of the coefficient of variation (second panel) for the category cleaners)
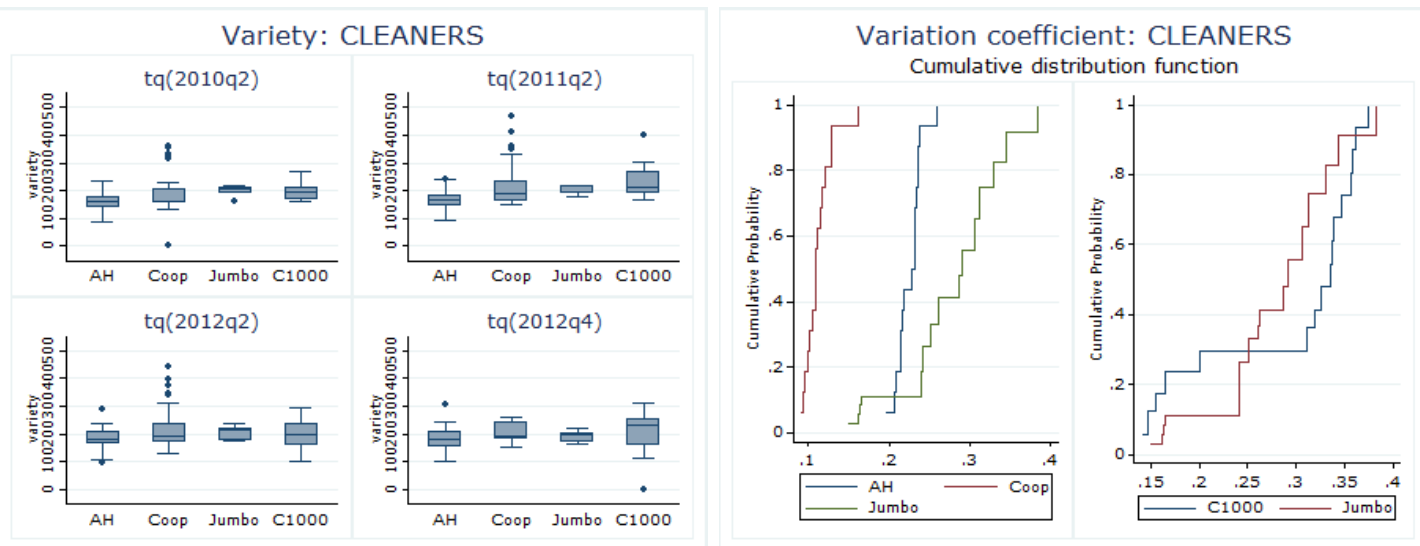

Source: our elaboration on IRI data.

Figure 11: Box-plot (first panel) and cumulative distribution function of the coefficient of variation (second panel) for the category coffee

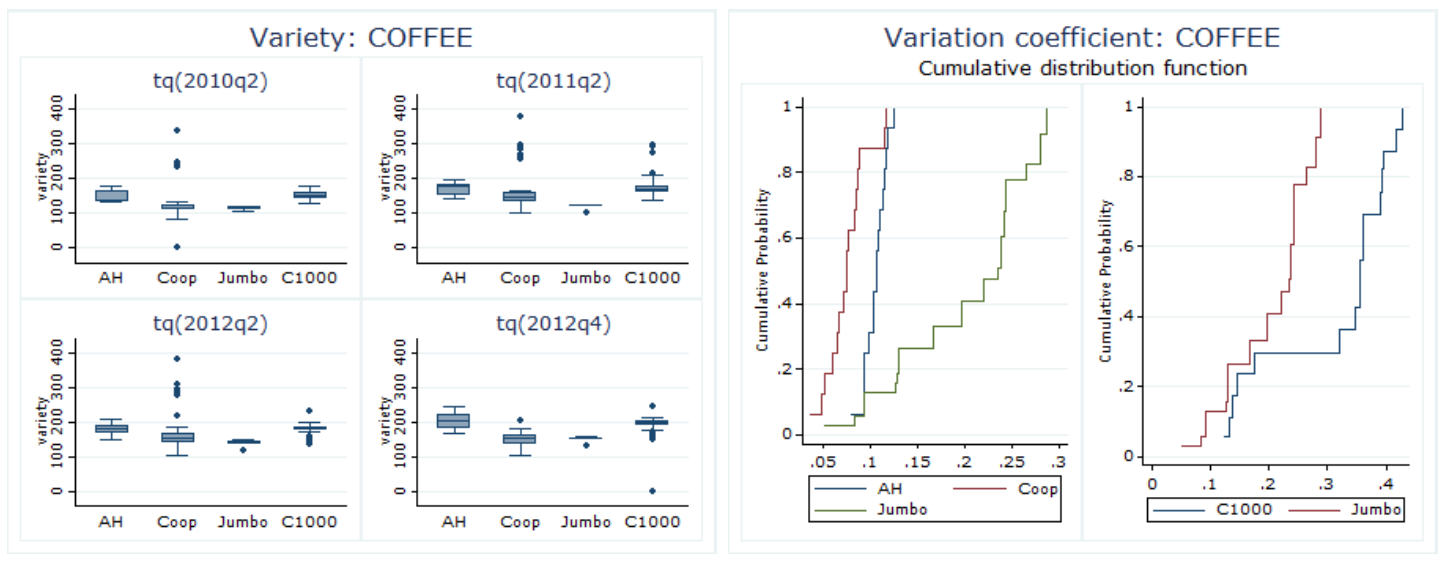

Source: Our elaboration on IRI data. 
Figure 12: Box-plot (first panel) and cumulative distribution function of the coefficient of variation (second panel) for the category cola

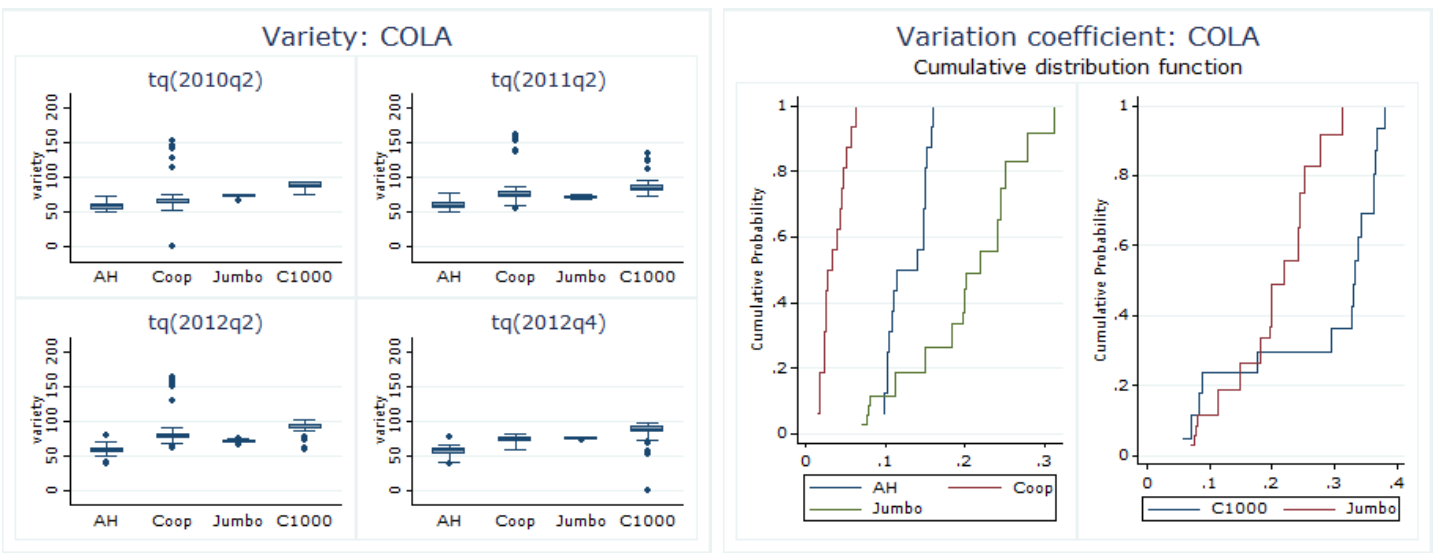

Source: Our elaboration on IRI data.

Figure 13: Box-plot (first panel) and cumulative distribution function of the coefficient of variation (second panel) for the category diapers

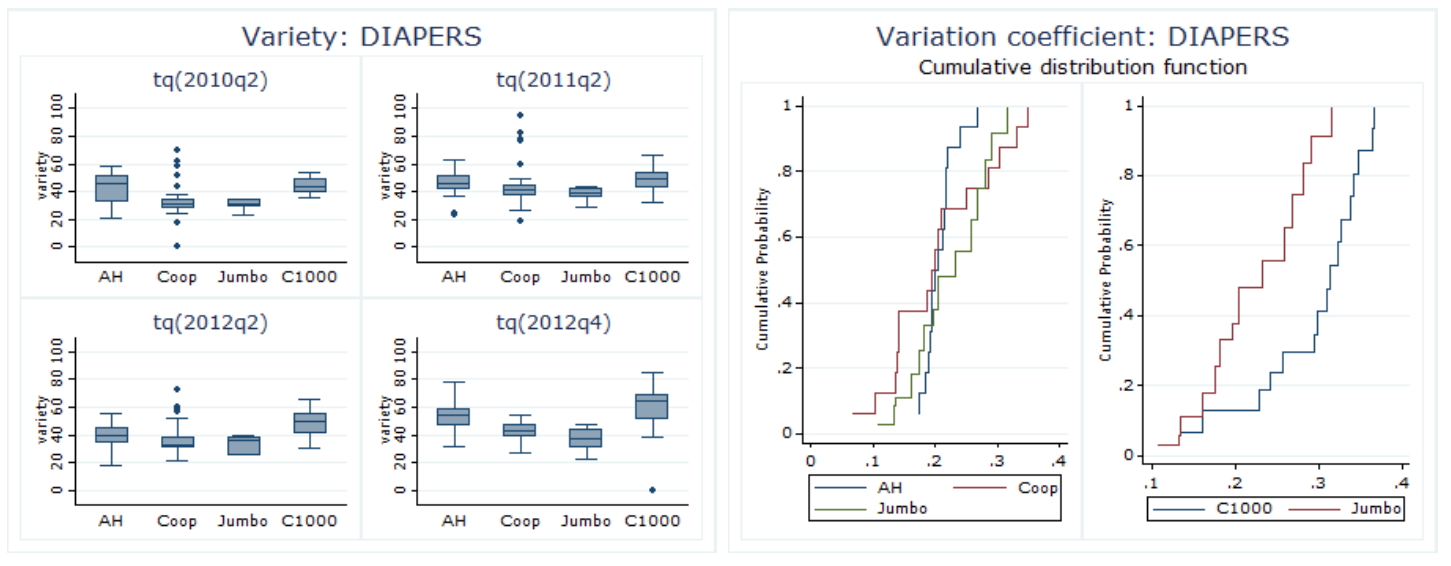

Source: Our elaboration on IRI data. 
D. Robustness Checks 


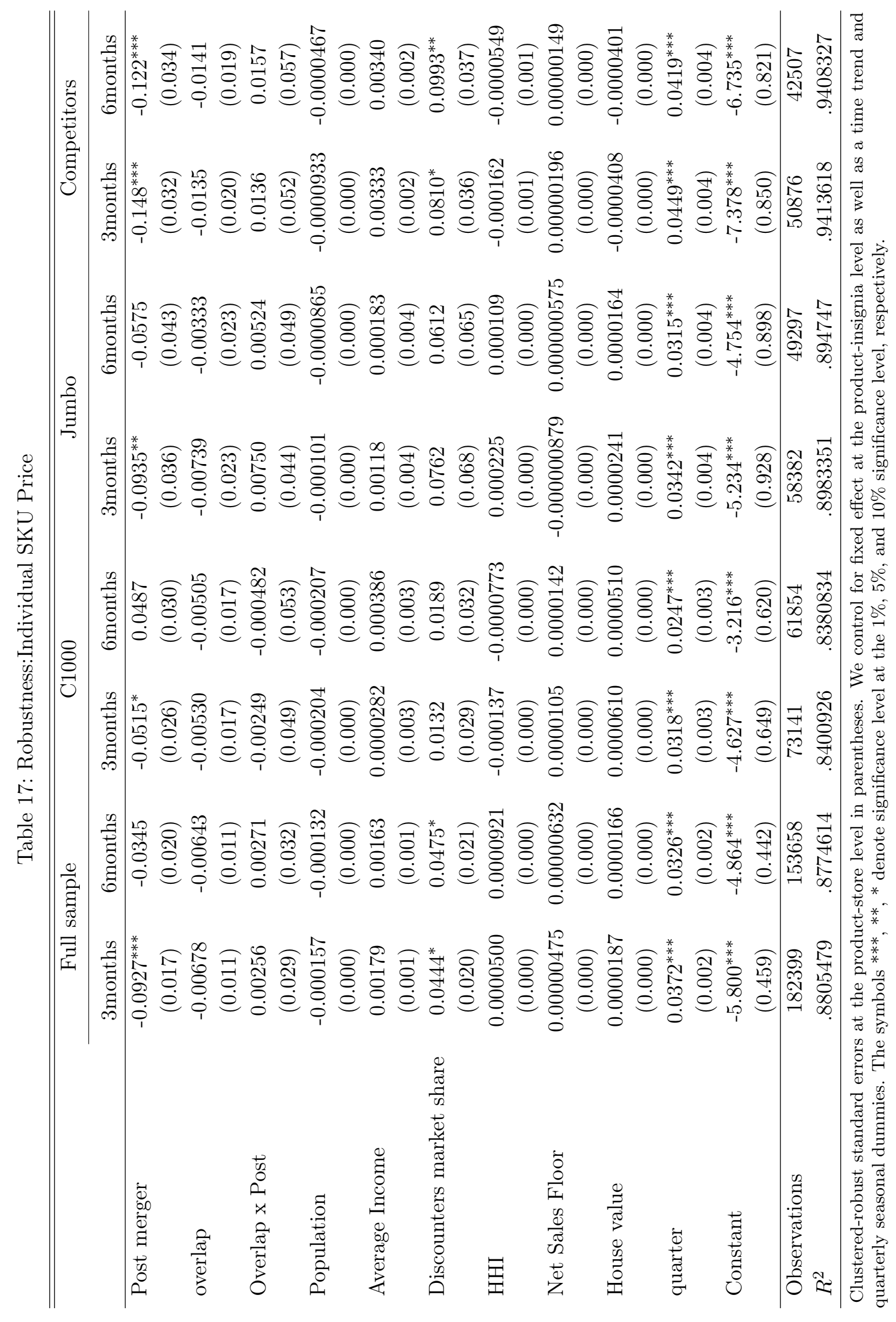




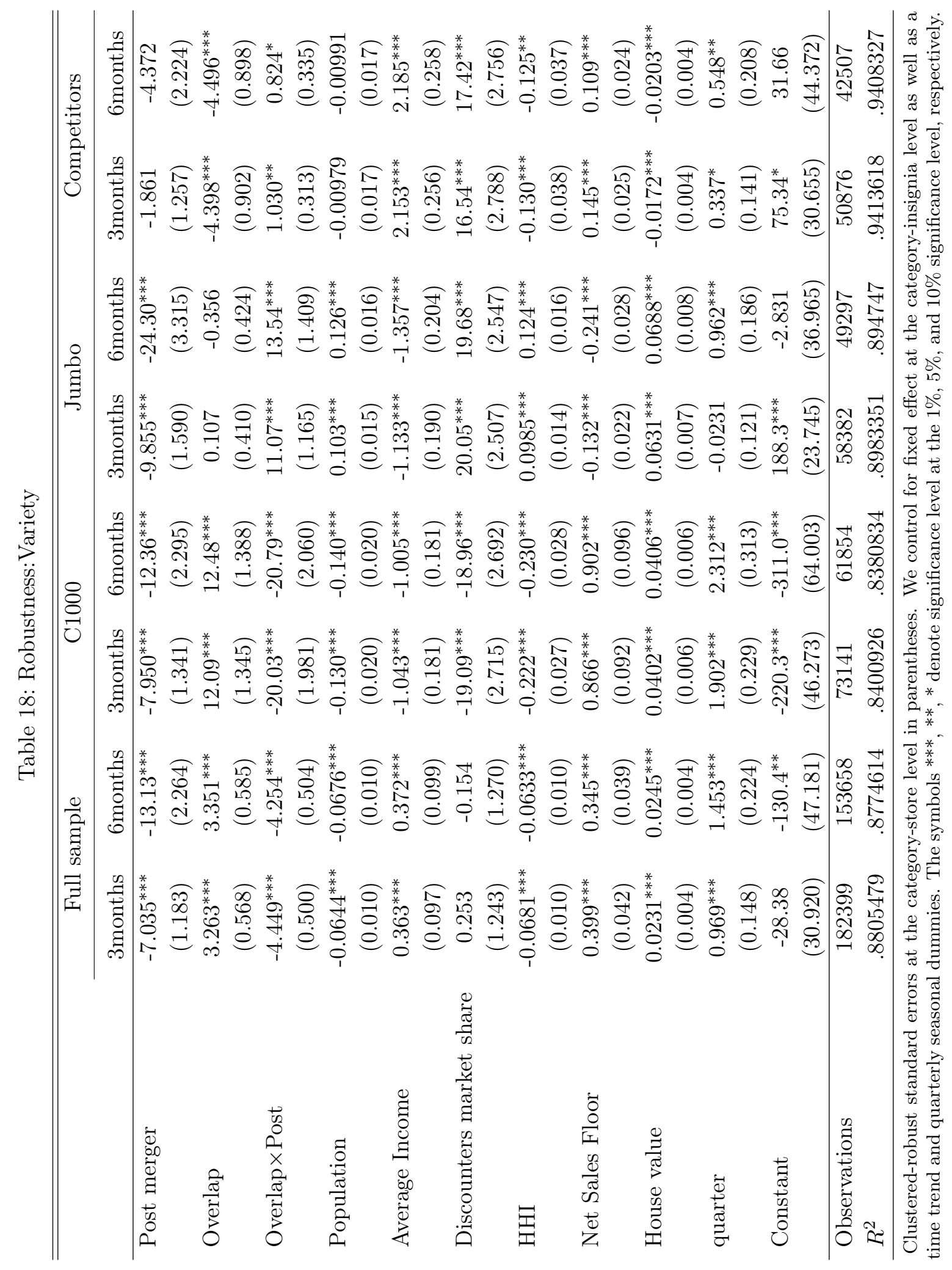




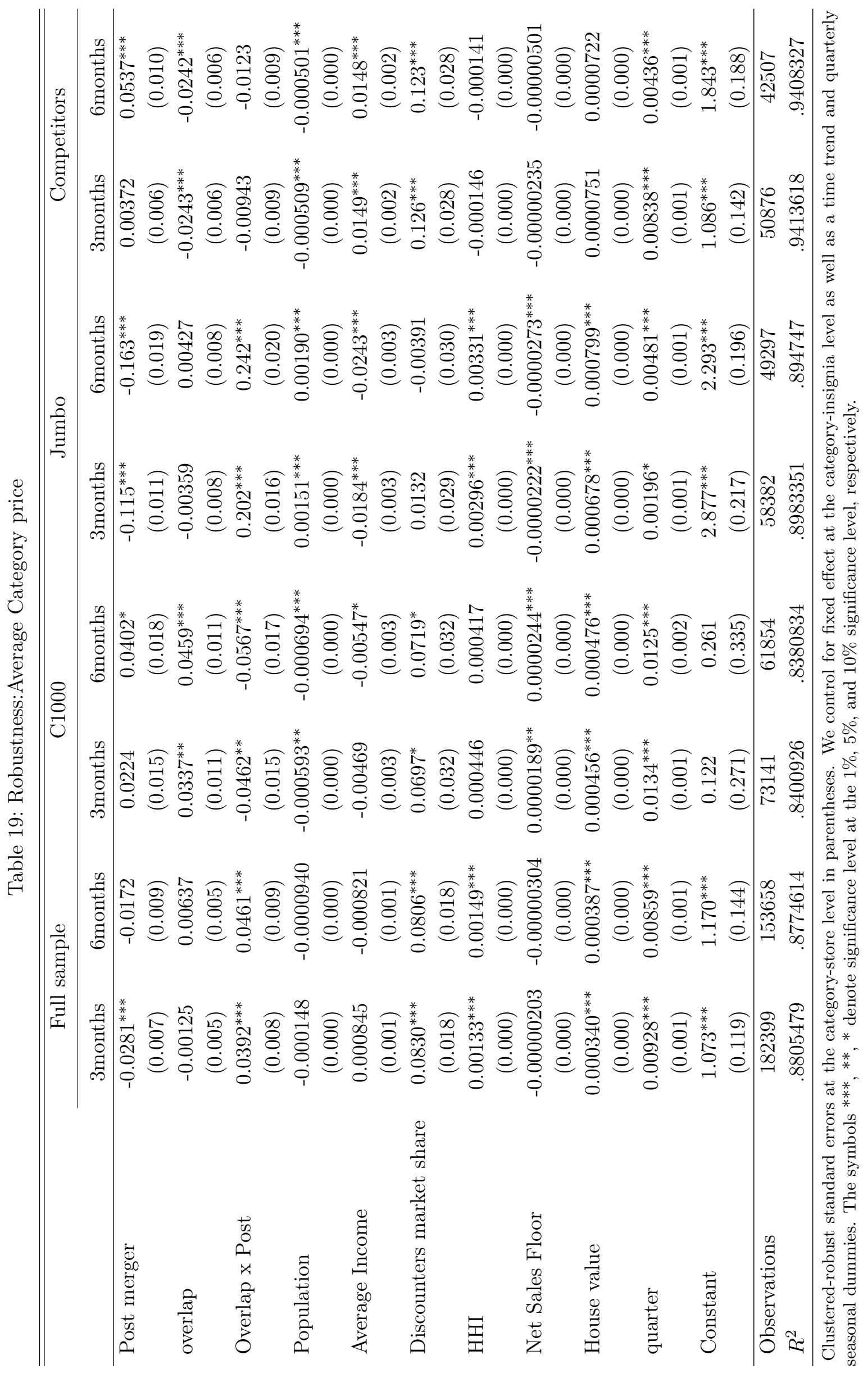




\section{E. Theoretical model: Additional results and Proofs}

Given the modeling assumptions described in Section 6, we can derive the stores' demand and profit functions. Let us start with the demand stemming from v-consumers. We can define $n+1$ indifference points, denoted by $w_{j}$, with $j=0, \ldots, n$, that partition the set $[0,1]$ in $n+2$ subsets such that the v-consumer with characteristic $w_{j}$ is indifferent between buying from store $j$ and store $j+1$. We interpret $w_{0}$ as the consumer who is indifferent between shopping at store 1 and not buying at all; similarly $w_{n}$ identifies the consumer who is indifferent between shopping at store $n$ and not buying. These indifference points are implicitly defined by the following conditions:

$$
u\left(v_{j+1}, w_{j}\right)-u\left(v_{j}, w_{j}\right)=\Delta_{j},
$$

where $\Delta_{j}=p_{j+1}-p_{j}, u\left(v_{0}, w_{0}\right)=0, \Delta_{0}=p_{1}, u\left(v_{n+1}, w_{n}\right)=0$ and $\Delta_{n}=-p_{n}$. The implicit solutions of equations (2) are denoted by $w_{j}\left(v_{j+1}, v_{j}\right)$. Their relevant characterization is given in the following Lemma.

Lemma E.1 For any $j=1, \ldots, n-1, w_{j}\left(v_{j+1}, v_{j}\right)$ is decreasing in $v_{j+1}$ and increasing in $v_{j}$.

proof 1 Lemma 1 is proved formally by the sign of the following derivatives:

$$
\frac{\partial w_{j}\left(v_{j+1}, v_{j}\right)}{\partial v_{j+1}}=-\frac{\frac{\partial u_{j}\left(v_{j+1}, w_{j}\right)}{\partial v_{j+1}}}{\frac{\partial u_{j}\left(v_{j+1}, w_{j}\right)}{\partial w_{j}}-\frac{\partial u_{j}\left(v_{j}, w_{j}\right)}{\partial w_{j}}}<0
$$

as $\frac{\partial u_{j}\left(v_{j+1}, w_{j}\right)}{\partial v_{j+1}}>0$ and $\frac{\partial u_{j}\left(v_{j}, w_{j}\right)}{\partial w_{j}}-\frac{\partial u_{j}\left(v_{j+1}, w_{j}\right)}{\partial w_{j}}<0$ by definition (see the meaning of $w_{i}$ ); similarly

$$
\frac{\partial w_{j}\left(v_{j+1}, v_{j}\right)}{\partial v_{j}}=-\frac{-\frac{\partial u_{j}\left(v_{j}, w_{j}\right)}{\partial v_{j+1}}}{\frac{\partial u_{j}\left(v_{j+1}, w_{j}\right)}{\partial w_{j}}-\frac{\partial u_{j}\left(v_{j}, w_{j}\right)}{\partial w_{j}}}>0
$$

The results can also be explained intuitively as follows. Let $w_{j}$ be the consumer indifferent between $j$ and $j+1$, suppose that store $j+1$ increases variety (i.e. $v_{j+1}$ increases), consumer $w_{j}$ is no longer indifferent between $j$ and $j+1$; he now prefers buying from $j+1$ as the monetary saving he obtains if he buys from $j$ (i.e. $\Delta_{j}$ ) does not suffice to offset the increased utility he gets by shopping at $j+1$. Hence, the new indifferent consumer is the one with a less intense preference for variety; this explains why $w_{j}\left(v_{j+1}, v_{j}\right)$ is decreasing in $v_{j+1}$. Now suppose that store $j$ increases variety (i.e. $v_{j}$ increases). Again consumer $w_{j}$ is no longer indifferent between $j$ and $j+1$; he prefers buying at $j$ because the higher utility he gets if he shops at $j+1$ is no longer sufficient 
to compensate for the extra-price he has to pay. The new indifferent consumer is the one with a more intense preference for variety; this explains why $w_{j}\left(v_{j+1}, v_{j}\right)$ is increasing in $v_{j}$.

All consumers with $w_{i}>w_{j}\left(v_{j+1}, v_{j}\right)$ prefer buying from store $j+1$, while all those with $w_{i}<w_{j}\left(v_{j+1}, v_{j}\right)$ prefer buying from store $j$. Hence, demand for store $j=1, \ldots, n$ stemming from v-consumers is:

$$
q_{v j}(v)=\alpha\left[G\left(w_{j}\right)-G\left(w_{j-1}\right)\right]
$$

We assume that all v-consumers are served and therefore that $G\left(w_{n}\right)=1$ and that $G\left(w_{0}\right)=0$.

Let us now turn to h-consumers. Again, we have to partition the set of h-consumers in $n+2$ sub-sets. To do so, we have to identify $n+1$ indifference points $h_{j}(j=0, \ldots, n)$ such that a consumer located at $h_{j} \in[0,1]$ is indifferent between shopping at $j$ and $j+1$. $h_{0}$ and $h_{n}$ have the same interpretation as the one given for v-consumers. These indifferent consumers are identified by the following conditions:

$$
b\left(h_{j}\right)-t\left(d\left(h_{j}, v_{j}\right)\right)-p_{j}=b\left(h_{j}\right)-t\left(d\left(h_{j}, v_{j+1}\right)\right)-p_{j+1}
$$

that can be written as:

$$
t\left(d\left(h_{j}, v_{j}\right)\right)-t\left(d\left(h_{j}, v_{j+1}\right)\right)=\Delta_{j}
$$

Equations (3) implicitly define the indifferent consumers, denoted as $h_{j}\left(v_{j}, v_{j+1}\right)$.

Lemma E.2 For any $j=1, \ldots, n-1, h_{j}\left(v_{j}, v_{j+1}\right)$ is increasing both in $v_{j}$ and in $v_{j+1}$.

proof 2 It is apparent that $h_{j}\left(v_{j}, v_{j+1}\right) \geq v_{j}$. Indeed, $\Delta_{j}$ is positive, as we assumed that $p_{j+1}>$ $p_{j}$, and the expression $t\left(d\left(h_{j}, v_{j}\right)\right)-t\left(d\left(h_{j}, v_{j+1}\right)\right)$ would be negative if $h_{j}\left(v_{j}, v_{j+1}\right)<v_{j}$, as $d\left(h_{j}, v_{j+1}\right)>d\left(h_{j}, v_{j}\right)$ and $t(\cdot)$ is an increasing function in $d(\cdot)$. Hence condition (3) cannot hold if $h_{j}\left(v_{j}, v_{j+1}\right)<v_{j}$. Given this and the assumption that $h_{j}\left(v_{j}, v_{j+1}\right)<v_{j+1}$, Lemma 2 is formally proved by the sign of the following derivatives:

$$
\frac{\partial h_{j}\left(v_{j+1}, v_{j}\right)}{\partial v_{j}}=-\frac{-\frac{\partial t}{\partial d} \frac{\partial d\left(h_{j}, v_{j}\right)}{\partial v_{j}}}{\frac{\partial t}{\partial d} \frac{\partial d\left(h_{j}, v_{j+1}\right)}{\partial h_{j}}-\frac{\partial t}{\partial d} \frac{\partial d\left(h_{j}, v_{j}\right)}{\partial h_{j}}}>0
$$

as $\frac{\partial t}{\partial d}>0, \frac{\partial d\left(h_{j}, v_{j}\right)}{\partial v_{j}}<0, \frac{\partial d\left(h_{j}, v_{j+1}\right)}{\partial h_{j}}<0$ and $\frac{\partial d\left(h_{j}, v_{j}\right)}{\partial h_{j}}>0$; similarly

$$
\frac{\partial h_{j}\left(v_{j+1}, v_{j}\right)}{\partial v_{j+1}}=-\frac{\frac{\partial t}{\partial d} \frac{\partial d\left(h_{j}, v_{j+1}\right)}{\partial v_{j+1}}}{\frac{\partial t}{\partial d} \frac{\partial d\left(h_{j}, v_{j+1}\right)}{\partial h_{j}}-\frac{\partial t}{\partial d} \frac{\partial d\left(h_{j}, v_{j}\right)}{\partial h_{j}}}>0
$$


as $\frac{\partial d\left(h_{j}, v_{j+1}\right)}{\partial v_{j+1}}>0$. Again Lemma 2 can be intuitively explained. Let $h_{j}$ be the consumer indifferent between $j$ and $j+1$, suppose that store $j+1$ increases variety (i.e. $v_{j+1}$ increases), consumer $h_{j}$ is now more distant from store $j+1$ and is no longer indifferent between $j$ and $j+1$; he now prefers buying from $j$. Hence, the new indifferent consumer is closer to the location of $j+1$ and, therefore, $h_{j}\left(v_{j+1}, v_{j}\right)$ increases. Suppose that store $j$ offers a higher level of variety (i.e. $v_{j}$ increases). Now consumer $h_{j}$ is closer to store $j$ and is no longer indifferent between $j$ and $j+1$; he prefers buying at $j$. In this case the new indifferent consumer is also closer to $j+1$; which explains why $h_{j}\left(v_{j+1}, v_{j}\right)$ is increasing in $v_{j}$.

All consumers with $v_{h}>h_{j}\left(v_{j+1}, v_{j}\right)$ prefer buying from store $j+1$, and all those with $v_{h}<h_{j}\left(v_{j+1}, v_{j}\right)$ prefer buying from store $j$. Hence, demand for store $j=1, \ldots, n$ stemming from h-consumers is:

$$
q_{h j}(v)=(1-\alpha)\left[H\left(h_{j}\right)-H\left(h_{j-1}\right)\right] .
$$

Again, we assume that all h-consumers are served and, therefore, that $H\left(h_{n}\right)=1$, and that $H\left(h_{0}\right)=0$.

The profit function of store $j=1, \ldots, n$ is:

$$
\pi_{j}(v)=p_{j}\left(q_{v j}(v)+q_{h j}(v)\right)-c\left(v_{j}\right) .
$$

Now suppose that stores $j(j=1, . ., n-k)$ and $j+k$ merge. Before proving the propositions stated in section 6 , we prove that a merger between "distant competitors" (i.e. when $k \geq 2$ ) does not affect variety.

Proposition E.1 A merger between two distant competitors does not affect the level of variety offered in the market.

proof 3 Post-merger the new entity maximizes the following profit function:

$$
\pi_{m}(v)=p_{j} q_{j}(v)+p_{j+k} q_{j+k}(v)-c\left(v_{j}\right)-c\left(v_{j+k}\right)
$$

The FOCs of this maximization problem are:

$$
\begin{gathered}
\frac{\partial \pi_{m}(v)}{\partial v_{j}}=p_{j} \frac{\partial q_{j}(v)}{\partial v_{j}}-\frac{\partial c\left(v_{j}\right)}{\partial v_{j}}+\frac{\partial q_{j+k}}{\partial v_{j}}=0 \\
\frac{\partial \pi_{m}(v)}{\partial v_{j+k}}=p_{j+k} \frac{\partial q_{j+k}(v)}{\partial v_{j+k}}-\frac{\partial c\left(v_{j+k}\right)}{\partial v_{j+k}}+\frac{\partial q_{j}}{\partial v_{j+k}}=0 .
\end{gathered}
$$


If $k \geq 2$, we have that

$$
\frac{\partial q_{j+k}}{\partial v_{j}}=0 \text { and } \frac{\partial q_{j}}{\partial v_{j+k}}=0 .
$$

Hence the $v_{j}$ and $v_{j+1}$ that solve the new entity's maximization problem are the same as the one that solve the maximization problem faced by the two stores pre-merger. Since the other store's maximization problem is not directly affected by the merger, it follows that the pre-merger equilibrium profile remains an equilibrium post-merger.

Intuitively, the consequence of the merger is to internalize the effect that the decision concerning variety has on the other merging party. Since the demand obtained by a store $j$ depends only on the level of variety set in the same store and in the two closest stores, $j+1$ and $j-1$, a merger between two distant competitors does not alter the merging parties' incentives as the effects of a change in variety remain external effects.

We can now prove the proposition in the text that is reported here for the sake of exposition.

Proposition E.2 After a merger between two close competitors, the new entity decreases variety in the low-variety store. The new entity decreases variety in the high-variety store only if there are "many" v-consumers.

proof 4 The new entity maximization problem and the FOCs are those described in the proof of Proposition E1. However, in this case $k=1$. The low-variety store, $j$, has an incentive to decrease variety if the FOC (4) is negative at the pre-merger equilibrium profile. We know that, by definition, at the pre-merger equilibrium

$$
p_{j} \frac{\partial q_{j}(v)}{\partial v_{j}}-\frac{\partial c\left(v_{j}\right)}{\partial v_{j}}=0
$$

Hence, the sign of the derivative depends on the sign of $\frac{\partial q_{j+1}}{\partial v_{j}}$, where we have replaced $k$ with 1 . Computing this derivative we get:

$$
\frac{\partial q_{j+1}}{\partial v_{j}}=-\alpha \frac{\partial G}{\partial w_{j}} \frac{\partial w_{j}}{\partial v_{j}}-(1-\alpha) \frac{\partial H}{\partial h_{j}} \frac{\partial h_{j}}{\partial v_{j}}
$$

Both $G$ and $H$ are increasing function by definition. Moreover from Lemmas 1 and 2 we know that $\frac{\partial w_{j}}{\partial v_{j}}>0$ and that $\frac{\partial h_{j}}{\partial v_{j}}>0$. This proves that $\frac{\partial q_{j+1}}{\partial v_{j}}<0$ and, therefore, that the low-variety store has an incentive to decrease variety post-merger. We can repeat the same reasoning for the high-variety store. In this case, the relevant FOC is (5) and the relevant sign is the sign of $\frac{\partial q_{j}}{\partial v_{j+1}}$. We have that:

$$
\frac{\partial q_{j}}{\partial v_{j+1}}=\alpha \frac{\partial G}{\partial w_{j}} \frac{\partial w_{j}}{\partial v_{j+1}}+(1-\alpha) \frac{\partial H}{\partial h_{j}} \frac{\partial h_{j}}{\partial v_{j+1}}
$$


Again we know that $G$ and $H$ are increasing functions; however from Lemmas 1 and 2 we know that $\frac{\partial w_{j}}{\partial v_{j+1}}<0$ and that $\frac{\partial h_{j}}{\partial v_{j+1}}>0$. Hence the sign of (6) is not unambiguously determined. The post-merger choice on variety of the high-variety store depends on the relative strength of the two effects just identified. In any case, we can define a threshold value of $\alpha$, denoted with $\alpha^{*}$, such that:

$$
\frac{\alpha^{*}}{1-\alpha^{*}}=\frac{\partial H}{\partial h_{j}} \frac{\partial h_{j}}{\partial v_{j+1}} / \frac{\partial G}{\partial w_{j}} \frac{\partial w_{j}}{\partial v_{j+1}}
$$

and we say that there are "many" v-consumers if $\alpha>\alpha^{*}$. From all of the above it stems that if there are many v-consumers the sign of (6) is negative and the high-variety store will decrease variety after the merger. If $\alpha=\alpha^{*}$ the merger will have no impact on the variety offered in the high-variety store. Finally if there are few v-consumers (i.e. $\left.\alpha<\alpha^{*}\right)$ the high-variety store increases variety post-merger. 